University of Louisville

ThinkIR: The University of Louisville's Institutional Repository

Electronic Theses and Dissertations

$12-2003$

\title{
Factors that predict student performance in dual credit courses in Kentucky community and technical colleges.
}

Nicholas L. Brake

University of Louisville

Follow this and additional works at: https://ir.library.louisville.edu/etd

\section{Recommended Citation}

Brake, Nicholas L., "Factors that predict student performance in dual credit courses in Kentucky community and technical colleges." (2003). Electronic Theses and Dissertations. Paper 139. https://doi.org/10.18297/etd/139

This Doctoral Dissertation is brought to you for free and open access by ThinkIR: The University of Louisville's Institutional Repository. It has been accepted for inclusion in Electronic Theses and Dissertations by an authorized administrator of ThinkIR: The University of Louisville's Institutional Repository. This title appears here courtesy of the author, who has retained all other copyrights. For more information, please contact thinkir@louisville.edu. 


\title{
FACTORS THAT PREDICT STUDENT PERFORMANCE IN DUAL CREDIT COURSES IN KENTUCKY COMMUNITY AND TECHNICAL COLLEGES
}

\author{
By \\ Nicholas L. Brake \\ B.A. Northern Kentucky University \\ M.A. Western Kentucky University \\ A Dissertation \\ Submitted to the Faculty of the \\ Graduate School of the University of Louisville \\ in Partial Fulfillment of the Requirements \\ for the Degree of
}

\begin{abstract}
Doctor of Philosophy
Department of Leadership, Foundations, and Human Resource Education University of Louisville

Louisville, KY
\end{abstract}

December 2003 
Copyright 2003 by Nicholas L. Brake

All rights reserved 
FACTORS THAT PREDICT STUDENT PERFORMANCE IN DUAL CREDIT COURSES IN KENTUCKY COMMUNITY AND TECHNICAL COLLEGES

\author{
By \\ Nicholas L. Brake \\ B.A. Northern Kentucky University \\ M.A. Western Kentucky University \\ A Dissertation Approved on
}

August 26, 2003

By the following Dissertation Committee:

Dr. John Welsh, Dissertation Director

Dr. John Keedy

Dr. Paul Winter

Dr. Jeff Guan

Dr. Namok Choi 


\section{DEDICATION}

This dissertation is dedicate to my wife

\section{Candance Castlen Brake}

and

my children Anna Caroline and Nicholas Castlen, who have supported me throughout my educational pursuits. 


\section{AKNOWLEDGEMENTS}

Every student completing a dissertation owes an enormous gratitude to the committee of dedicated university faculty as they guide the student through the journey of creating a dissertation from a mere idea. I have been blessed with an exceptional committee of faculty members from the University of Louisville. Dr. John Welsh, my chair, always seemed to find the time to provide advise, support, and remove road blocks despite his ever increasing responsibilities as an administrator. I owe to him many thanks for helping me take a simple idea and turn it into a significant piece of scholarship. I am also grateful for his work in helping me accomplish this work in the span of shortly over one year. Dr. Namok Choi spent countless hours working as a methodologist. Dr. John Keedy's support began the moment I walked in the door in his introductory doctoral seminar five years ago. I also wish to thank Dr. Paul Winter and Dr. Jeff Guan for their work as committee members.

I am also professionally indebted to many colleagues of mine in the Kentucky Community and Technical College System and the Owensboro Community and Technical College, particularly Dr. Keith Bird, KCTCS Chancellor, and Dr. Jon Hesseldenz in Institutional Research for their approval and support on this project at the system level. 
Numerous colleagues at the Owensboro Community and Technical College showed a keen interest and strong support of this project. Dr. Jacqueline Addington, President of OCTC, supported my work from the very beginning of my tenure as an administrator at the college. Her vision in opening the doors of postsecondary education to thousands of high school students in Greater Owensboro for dual credit and dual enrollment courses at the college provided my inspiration for this research. I wish to thank Kevin Beardmore, OCTC Director Institutional Research, for his help to access the data through the RDM database; Dr. Greg Labyak for his continued encouragement; and Rene Durand for taking care of me in every way possible throughout my work on this dissertation.

Lastly, and most importantly I would like to thank my family. Without their support, love, and encouragement this degree would have never been possible. I thank my mother, father, and brother for raising me to value the importance of education and modeling its importance in your accomplishments. To Joe and Nancy Castlen, Chris and Stacy Castlen and their daughters Emily and Paige, thank you for putting up with my nose in a book on Sunday afternoons. Finally to my two children, Anna Caroline and Nicholas Castlen and my wife Candance, I cannot begin to thank the three of you enough for supporting me on what seemed like and endless journey of classes on week nights and Saturdays, travel back and fourth between Owensboro, Louisville, and Bowling Green, and hour upon hour of studying and working on this degree. I love you all very much. I owe this degree to all of you, but especially to Candance, without her love, encouragement, and constant support 
and belief in my abilities I would never have accomplished the honor of this degree.

This degree truly belongs to her as much as it belongs to me. 


\begin{abstract}
FACTORS THAT PREDICT STUDENT PERFORMANCE IN DUAL CREDIT COURSES IN KENTUCKY COMMUNITY AND TECHNICAL COLLEGES

Nicholas Brake
\end{abstract}

August 26, 2003

This research addresses the problem of productivity in the P-16 system of education, emphasizing the repetition of the senior year of high school with the first year of postsecondary education. This study analyzes this integration through dual credit courses in the context of both P-12 and higher education reform in Kentucky. An analysis of these factors is critical in light of the deregulation of dual credit and dual enrollment in Kentucky since 2000 and the increased enrollment of high school students in college courses both nationally and in Kentucky.

Dual credit courses in Kentucky community and technical colleges are evaluated based on the learning productivity in transition from secondary to postsecondary education for students according to their gender, race, residence, socio-economic status, high school performance, and a student preparation for college. The design incorporates methods prevalent from the literature in research conducted on dual credit programs. Student performance in dual credit courses is the criterion variable, while high school performance and preparation for college are the 
primary predictor variables. Gender, race, residence, and socio-economic status are examined as demographic variables.

The population for this research includes high school students taking dual credit courses in Kentucky community colleges and technical colleges. The sample extracted from the Kentucky Community and Technical College System database consists of high school students admitted with ACT placement scores in English and mathematics to Kentucky community and technical colleges in the Fall 2000, spring 2001, Fall 2001, and Spring 2002 semesters $(N=3,822)$. Chi-square was used to evaluate the change in student participation in dual credit courses by demographic variable. Multivariate multiple regression was used to predict the factors that influence performance in dual credit programs.

The results indicated no significant changes in the proportion of students from each demographic variable taking dual credit courses, despite a significant increase in the overall numbers of students taking these courses from Fall 2000 to Fall 2001. The results of the regression analysis indicated that demographic variables such as gender, race, residence, and socio-economic status significantly predict, both at the multivariate and univariate level, student achievement in dual credit courses. The demographic variables of gender and residence were the most consistent predictors of the criterion variables, however, high school preparation, as measured by the ACT English subtest was the strongest predictor of student performance in dual credit courses. 


\section{TABLE OF CONTENTS}

\section{PAGE}

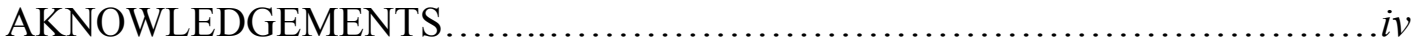

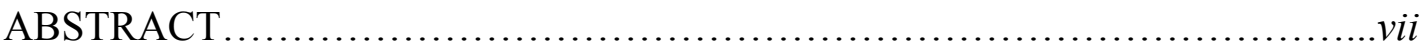

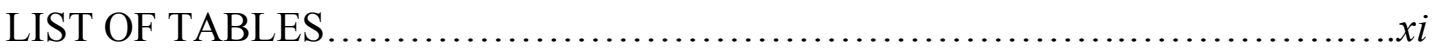

\section{CHAPTER I:}

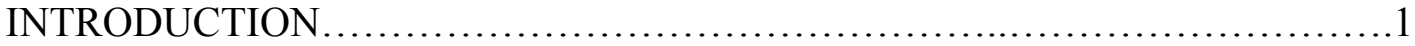

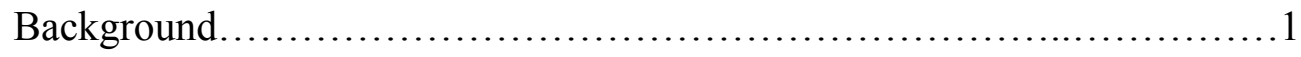

Research Problem.....................................................15

Research Purpose................................................16

Research Questions................................................ 17

Definitions...........................................................

Significance of the Study.......................................... 19

\section{CHAPTER II:}

REVIEW OF LITERATURE............................................... 22

Organization of the Literature Review...............................23

More Productive and Efficient Learning Organizations....................24

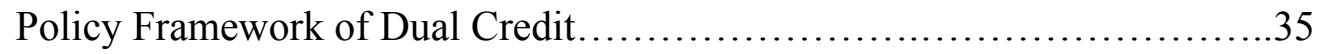

Learning Productivity from a P-16 Perspective.........................61

Dual Credit Models and Outcomes...................................93

Factors of Dual Credit Student Success................................. 130 
Summary

CHAPTER III:

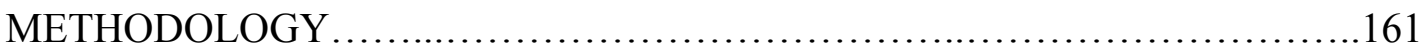

Research Design..................................................... 161

Participants.........................................................

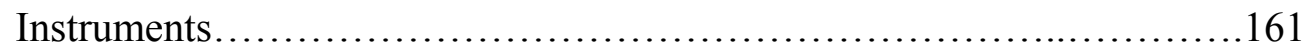

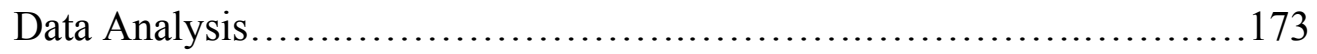

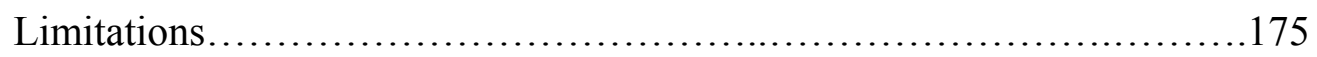

CHAPTER IV:

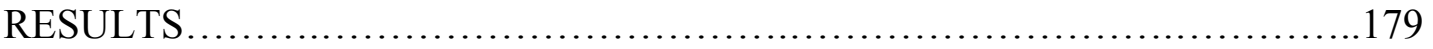

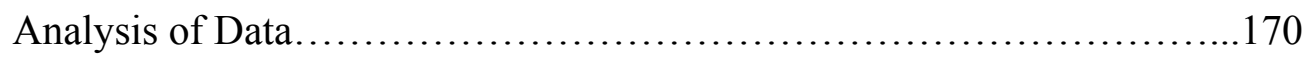

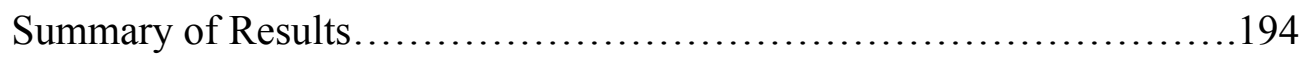

CHAPTER V:

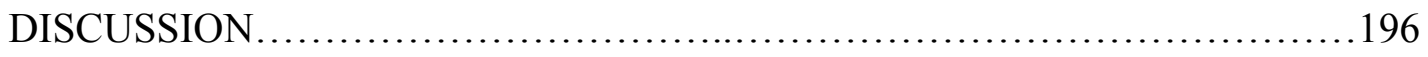

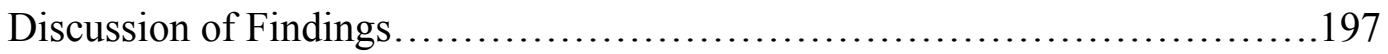

Implications for Practice ............................................... 200

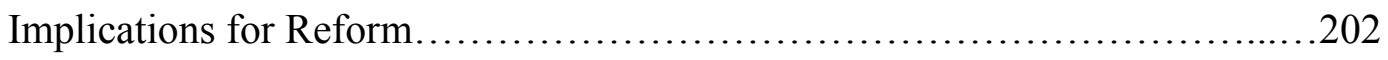

Implications for Future Research.......................................205

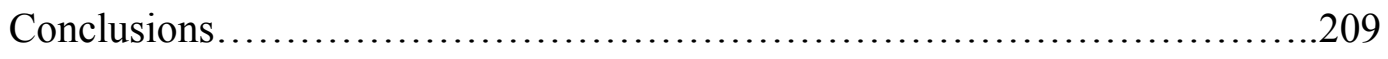

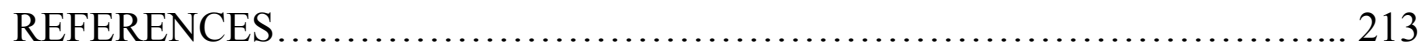

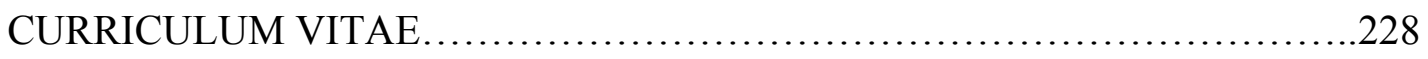




\section{LIST OF TABLES}

\section{TABLE}

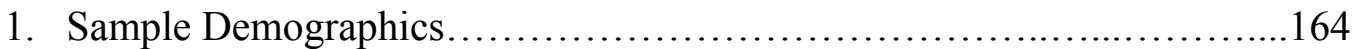

2. Kentucky Urban Areas Classified according to U.S. Census Guidelines for Urban Population Area............................................... 168

3. Mean, Standard Deviation, and Range of Achievement Predictor Variables.

4. Frequency and Proportion according to Demographic Group for Fall 2000 and Fall 2001 Enrollment Terms. ...

5. Descriptive Statistics and ANOVA Results for Fall 2000 and Fall 2001 Enrollment Terms................................................... 182

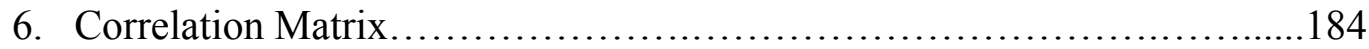

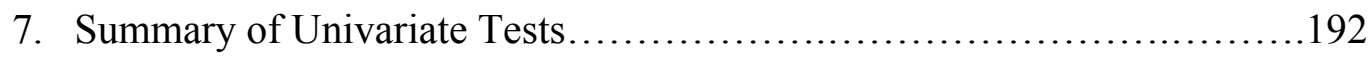

8. Summary of Standardized Regression Coefficients for Predictor Set........193 


\section{CHAPTER I INTRODUCTION}

Dual credit programs are a strategy by which high school students may acquire college credit while enrolled in secondary school. It is one of the fastest growing programs during the past ten years in U.S. education. Dual credit programs are a product of both economic and school reform agendas, attempting to blend the end of high school with the early part of college (Hoffman, 2003). This research addresses the factors that are the strongest predictors of student performance in dual credit courses in Kentucky community and technical colleges, evaluating the importance of high school performance and preparation for college on student participation and performance in dual credit programs

\section{Background}

Reform movements in secondary and postsecondary education during the last two decades have called into question many accepted tenets of the U.S. system of education. During the past five years there has been an increasing push for choice in American P-12 schools, in the form of vouchers, charter schools, and other patterns designed to give parents and students options free from government controlled schools. Osborne and Gaebler (1992) emphasize the productivity and efficiency by which the public sector spends taxpayers' money and the lack of accountability for 
outcomes. They point to choice in public education and a significant trend in the way in which government will be "reinvented" using entrepreneurial principles.

Many P-12 reforms have targeted the inadequacies of the secondary school model as lacking rigor and relevance in failing to prepare the large masses of students for success in postsecondary education and the workforce. Standardized tests such as the American College Test (ACT), the Scholastic Aptitude Test (SAT), and the National Assessment of Educational Progress (NAEP) suggest that student achievement, especially in the $12^{\text {th }}$ grade has been stagnant or decline while U.S. high schools continue to turn out larger and larger graduating classes (National Center for Education Statistics, 2000a).

Haycock and Huang (2001) identify data that demonstrate that overall student achievement in high school has not changed much since $A$ Nation At Risk was released in 1983. Key indicators cited by Haycock and Huang (2001) include the following:

(a) High school completion rates have remained the same for nearly 30 years. After decades of leading the world in high school completion, the U.S. currently ranks $17^{\text {th }}$. (b) Despite some improvements in the reading skills students bring with them to high school, today's high school students are reading no better when they leave then did their peers a decade ago. (c) While students are taking and completing more college preparatory courses, the effect on student learning has not been great, raising serious questions about the rigor of those courses. (d) In the 1990s achievement gaps widened between Blacks, Hispanics and Whites in reading and mathematics. (Haycock \& Huang, pp. 3-4) 
These trends are true in Kentucky. The 1990s were a period of extensive and nationally recognized reform in the Commonwealth. In 1990, the state legislature, in response to a court decision that declared the system of elementary and secondary education unconstitutional, totally revamped P-12 education with the Kentucky Education Reform Act (KERA). The sweeping reform established changes in the pedagogy, accountability, and the structure of schools. Reforms at the high school level have come at a much slower pace than those impacting elementary and middle grades. It is evident in state assessment results. Kentucky high schools still lag behind in overall achievement compared to elementary and middle grades on the Commonwealth Accountability Testing System. The state scores on the ACT and Advanced Placement Tests are also below the national average (Kentucky Department of Education, 2002).

Recent reforms in higher education demonstrate the need to increase the productivity and efficiency of the system. House (1994) contends that U.S. higher education must find a way to provide more services while receiving fewer resources to improve its productivity and efficiency if it is to continue to educate large numbers of students from modest backgrounds. Johnstone (1998) advocates for increasing the "productivity of learning" in U.S. higher education highlighting the curricular redundancy of the first and second year of college and the last two years of high school.

Higher education in Kentucky also underwent reform in the late 1990s. The Kentucky Postsecondary Improvement Act of 1997 emphasized the importance of making state higher education more efficient, productive, and accountable. The 
reform was prompted by Kentucky's inability to compete regionally or nationally with states in measures such as college attendance, literacy, high school graduation rate, and per capita research and development. The most sweeping aspect of the reform stripped all community colleges from the governance of the University of Kentucky, except Lexington Community College. The reform also stripped the technical schools away from the state workforce cabinet the reform creating the Kentucky Community and Technical College (KCTCS) (Kentucky General Assembly, 1998). The creation of KCTCS as comprehensive community college system brings Kentucky into step with the evolution of this type of institution across the U.S. Wattenbarger and Witt (1995) define a comprehensive community college as an institution that provides services for a diverse clientele. These services provide degrees, certificates or other credentials in transfer, technical, and occupational subjects in hopes of increasing access to postsecondary education to the masses.

The development of a comprehensive community college system in the midst of scrutiny over mediocre student achievement in high schools gives leverage to the issue of creating learning productivity and efficiency using dual credit for high school students. Much of the rhetoric focuses on collapsing the high school and college systems by blending the last two years of high school with the initial two years of postsecondary education, thereby creating a more productive learning organization than the four-year model currently employed. The fastest growing programs in the last two years of high school are dual credit programs that allow high school students to earn college credit. Conversely, the fastest growing programs of the first two years of higher education are remediation programs for 
academically unprepared students. The senior year of high school, subject of much attention since the work of the National Commission on the Senior Year of High School (2001), stands in the center of this transition. The question is not so much how to fix the senior year, rather it is the need for a senior year at all and whether dual credit or dual enrollment programs can add greater value to what is traditionally happening during the last two years of high school.

This commission levied much criticism on the last two years of high school as unproductive, inefficient, and a replication of the first two years of college. Many recent reform strategies have focused on a P-16 approach to education by addressing the grades 11 through 14-problem in numerous ways. Botstein (2001), for example, advocates the need for high schools to replace junior high schools to focus on 13 to 16 year olds. He advocates that those aged 16 sould take their high school diploma and choose to attend a community college, four-year college, start work, internships, or perhaps some form of national service. Orrill (1998) discusses additional proposals for fundamental structural change have been advanced by a long list of prominent and influential educators such as Butler, Dewey, Hutchins, and Conant to name a few. The dual credit movement represents a more moderate attempt to create a more integrated grade 11 through 14-program. Policy makers have utilized dual credit as a vehicle intended to prod education reforms by raising academic standards, making the existing educational institutions more efficient while requiring no additional tax dollars.

Recent research supports a P-16 approach focusing on the transition from secondary to postsecondary education. Johnstone (1993) in evaluating the lack of 
productivity of secondary and higher education argues that students entering college, or coming of college age, are not sufficiently prepared for college work or for productive work in the workforce. He also identifies the traditional high school curriculum during the last years of high school as not rigorous enough for collegelevel standards.

The need for reform in secondary education has been a prevalent theme in educational research for the past two decades. Many tenets of the high school curriculum came under scrutiny in A Nation at Risk (1983), issued by the National Commission on Excellence in Education. An important recommendation was to increase the number of courses required for graduation from high school by introducing a "New Basics" curriculum, which included four years of English, three years of mathematics, three years of science, three years of social studies, and onehalf of computer science. While "New Basics" lead to increased requirements for graduation in many states, the rigor of such courses quickly became a central issue. Powell, Farrar and Cohen (1985) argued that the "New Basics" created a new American High School, organized much like a shopping mall where students could pick and choose from courses like retail goods in a clothing store. The courses ranged in challenge and quality much like the goods on store shelves. Everything a student/ customer could wish for was available at every price and quality range to meet the needs of a very diverse clientele. Despite the introduction of the "New Basics," increased graduation requirements, and phenomena like block scheduling, little has changed with the level of academic achievement in American high schools since the reforms of the 1980s and 1990s. 
Over the past 10 years there has been a significant increase in the options available to secondary students to earn college hours through dual credit programs. The options created for high school students to earn college credit while in high school are the fastest growing programs and most significant strand of reform in high schools today. In many ways, these programs are the greatest hope for substantial reform in American secondary schools.

Johnstone and Del Genio (2000) classify these programs in the following three ways: (a) credit by examination through programs such as Advanced Placement, (b) school-based programs where instruction is delivered by a high school or college instructor, and (c) college-based programs where the students are dually enrolled and attend the class on the college campus. Other forms of dual credit collaboration include articulation between secondary and postsecondary institutions through Tech Prep dual credit articulation. Middle college is another growing trend that merges the structure of the high school and college together and often targets at-risk populations.

While national data on the number of high school students participating in dual credit programs are not routinely collected, there is some evidence that these numbers are on the rise. The National Center for Education Statistics $(1997,1999, \&$ $2000 \mathrm{~b}$ ) reports that the number of students under the age of eighteen who enroll in public two-year colleges on a part-time basis either in school-based or college-based programs increased from 96,913 in the fall of 1993 to 123,039 in the fall of 1995. That number rose to 225,783 by 1997 . The most prominent examination-based dual credit program, Advanced Placement also saw sharp increases. Between 1984 and 
1997, the number of students who took the AP examination increased from 50 to 130 students per $1,00012^{\text {th }}$ graders (Who takes Advanced Placement, 1999).

The increased interest in dual credit has lead to a careful examination by legislators and policymakers in several states. Boswell (2001) reports that only two states report no policy or known practice to govern dual credit programs. Thirtyeight states have policies to encourage students to take advantage of dual credit programs, while 10 have agreements at the institutional level promoting dual credit. These policies are complicated by entanglements related to funding, the transferability of dual credits, control of the curriculum, turf issues regarding the traditional role of the secondary school, and the type of students that should qualify or benefit by dual credit courses.

The funding issue illustrates the extent of the complexity. There is a concern that publicly financing dual credit programs constitutes a form of double dipping whereby the taxpayers are paying twice for students enrolled simultaneously in the secondary and postsecondary systems (Kummerer, 2000). Others view financing dual credit programs as a way to increase the efficiency of the current educational system. Dual credit provides many parents with a more cost effective way to finance a college education in the face of rising tuition costs (Jones, 2000). Boswell (2001) adds that many states are embracing dual credit policies as a way to meet the projected demands for college access by the "baby boom echo"-children of the baby boomers approaching college age. Many states see dual credit as an opportunity to increase the aspirations of students to attend college. Much research documents the success of dual credit courses encouraging students to attend college 
(Simmons, 1994; Swiney, 1999; Urahn, 1993; Windham, 2001). However, very little research effectively addresses the success of dual credit programs in serving populations other than the academic elite (Kirst, 2001b).

For the purpose of this study, dual credit refers to any college level learning in high school that involves a student being enrolled in both high school and college. In some instances the students will receive dual credit, credit at both the high school and college. In other instances the students will receive only credit at the college. It is important to point out that many states, including Kentucky, differentiate between dual credit and dual or concurrent enrollment as to whether the student receives high school and/ or college credit for the course. Dual credit results when the student receives credit for the course at the high school and college concurrently. Dual or concurrent enrollment results when the students receive college credit only while enrolled as both a high school and college student. Many states, such as Minnesota and Washington, broadly refer to any arrangement of dual credit or dual enrollment as part of a postsecondary options program. A few researchers, such as Johnstone and Del Genio (2000) lump all varieties of dual credit together with other programs that result in college credit while in high school, such as Advanced Placement, and call it college-level learning in high school. Clark (2001) refers to any form of college credit earned while in high school as dual credit. For the sake of simplicity, this study will adopt the nomenclature used by Clark (2001). Rather than using the confusing dual classification of dual credit and dual enrollment as used in Kentucky, this research will classify-- unless a more specific distinction is necessary-- all high 
school students enrolled in courses in the Kentucky Community and Technical College System as dual credit students.

Middle college is yet another variety of college-level learning in high school. It refers to blending the last two or three years of high school with the first year or two of postsecondary education. Middle college programs are typically located on college campus and utilize curriculum and instruction that is a combination of high school and college work. Several middle college programs target students classified as academically at-risk. Early college is a program that focuses more on students classified as academically gifted and talented. Instead of blending the end of high school with the beginning of college, students in early college programs typically skip high school (or part of high school) and attend college through an early college program.

Perhaps the largest body of research on dual credit programs focuses on the transferability of dual credits earned by students in school-based programs and in community college-based programs. The school-based programs such as the Syracuse University Project Advance (SUPA) and the Florida dual credit programs provide an abundance of research documenting the integrity of courses taught by high school teachers as a viable delivery model for dual credit promoting student success in subsequent postsecondary coursework (Lambert \& Mercurio, 1986; Mercurio, 1983; Herbert, 2001; Windham, 1998). Despite this, many dual credit programs are plagued by questions regarding the successful transfer of courses earned by high school students. 
The dual credit movement does present U.S. education with a unique opportunity to change the foundation of secondary and postsecondary education. Any major revolution or paradigm shift quickly leads to a backlash of those trying to protect the existing order (Kuhn, 1996). This is manifest at the postsecondary level with those fearful that bringing a college curriculum, especially in the liberal arts, to high school students will lead to a change in the lotus of control of the coveted general education by faculty members in postsecondary institutions. At the secondary level, the fear runs to the core of the secondary school as the principal player in the rite of passage from adolescence to adulthood. Many reformers view dual credit as a way to strengthen the high school curriculum and enrich the experience of students, especially during the "wasteland" of the senior year (Kirst, 2001a). The research strongly supports a rigorous curriculum, especially during the last year of high school (Adelman, 1999; Horn, Kojaku, \& Carroll, 2001; Alexander \& Pallas, 1984).

Under the current system of P-12 and higher education, the years between high school and postsecondary education are characterized by sorting between the traditional college-bound and those destined for work or "trade school." The courses students take are sorted into during the last two years of high school often determine a student's fate after graduation (Adler, 1982; Powell, Farrar, \& Cohen, 1985). This "gate keeping" is typically influenced by a student's socio-economic background, gender, race, and high school performance. Changes in the workforce and economy have made the current model of secondary-to-postsecondary transition obsolete. The two-year college can play a large role in facilitating the transition of students 
between secondary and postsecondary education due to the comprehensive nature of its mission and it emerging role as an open access institution of higher education.

For nearly 30 years reforms in higher education have focused on increasing postsecondary education for individuals and groups by providing students with financial aid to offset costs of attendance. Although financial resources are important, it is not the only predictor of college enrollment. Recent research indicates significant gaps in college attendance based on race, socio-economic status, and residence. Haycock and Huang (2001) cite the rate of college attendance for Blacks and Hispanics at $71 \%$, while Whites and Asians attend college at a rate of $76 \%$ and $86 \%$ respectively. Perna (2000) cites an even greater gap of students by race and ethnicity considered qualified for college (47\% Black, 53\% Hispanic, and $68 \%$ White). Access to postsecondary education is also an issue for students in rural areas. For many students in economically distressed rural areas, postsecondary education has been an alien idea and college a forbidding institution (Eller, Martinez, Pace, Pavel, Garza, \& Barnett, 1998). Community colleges are playing a major role in narrowing the college attendance gap among these traditionally underrepresented groups.

The mission of the two-year college as an open access institution designed to meet the needs of the community has evolved in the last decade to meet an increasing demand for mass higher education. Wattenbarger and Witt (1995) cite the movement toward mass higher education as a driving force making the community college more comprehensive by meeting the needs of students through services such as adult education, technical/ occupational programs, and courses that transfer for a 
baccalaureate degree. Boesel (2001) emphasizes the value that postsecondary education adds to the potential earning power of students that even attend without graduating. The economic effects of postsecondary education will continue to expand as the economy changes.

Carnevale \& Desrochers (1999) estimate that by 2020 there will be a deficit of at least 12 million workers with some postsecondary education that will be required to fill jobs in the knowledge-based economy. Bird (2002) predicts that most jobs of the future will require a college degree. In 2002 there are an estimated 50 million jobs that require a two- or four-year degree, by 2012 there will be an estimated 70 million jobs requiring these degrees. Under the existing system of secondary and postsecondary education there will be a shortage of six million college graduates by 2012. Winter (2002) indicates that the increase in two-year college enrollment is leading more students to transfer to four-year colleges and universities for degrees.

The Kentucky Community and Technical College System is responding to these needs. Enrollment at KCTCS colleges has increased by 21\% from Fall 2000 $(52,201)$ to Fall $2001(63,120)$. The number of graduates earning certificate, diploma, or degree credentials increased by $15 \%$ between Spring 2001 and Spring 2002 (Armstrong, 2002).

The knowledge-based economy demands that all students seek some form of postsecondary education regardless of a student's socio-economic background, gender, race, and high school performance. Dual credit programs can play multiple roles in creating a more productive and efficient system of P-16 education. Dual 
credit programs and course offerings can accelerate the start of college for those that are ready (Andrews \& Marshall, 1991; Janos, Robinson, \& Lunneborg, 1989). They can provide general education offerings that are universal in U.S. community colleges and universities. Dual credit can add rigor and relevance to the curriculum experience in the last two years of high school while encouraging cooperation and integration of secondary and postsecondary education improving student transition and success in postsecondary education (Windham, 1998; Delicath, 1999; Crossland, 1999; Hanson, 2001; Urahn, 1993). Dual credit programs can also play a role in providing access to college for minority students that are typically underrepresented in U.S. higher education (Opp, 2001; Brigham, 1989; Hugo, 2001; Hoffman, 2003). Dual credit can motivate underachievers and at-risk students disengaged with high school to find the way toward achievement (Lieberman, 1986; Broughton, 1987; Chen, Konantz, Rosenfeld, and Frost, 2000). Finally, dual credit can play a role in helping students unprepared for college to graduate from high school ready for postsecondary education without the need for remedial courses (Brigham, 1989; Lieberman, 1975).

Dual credit programs, therefore, can provide U.S. educators with a unique opportunity to create a more seamless $\mathrm{P}-16$ experience critical to the future of our workforce and prosperity (Clark, 2001). The dual credit experience can translate to greater learning productivity, increased student participation in postsecondary education, while raising the level of education and expectations for an increasingly diverse population (Johnstone \& Del Genio, 2000). 


\section{Research Problem}

The Kentucky Council on Postsecondary Education deregulated its policy on dual credit in 2000, eliminating the state guidelines restricting dual credit access to only the top students in each high school. Since the deregulation, the Kentucky Community and Technical College System has relaxed admission guidelines to encourage more students and more colleges to opt for dual credit as a alternative to traditional high school.

This opens access to dual credit courses to students that traditionally were unable to participate in dual credit previously, including many underrepresented students from minority populations, academic ability-levels, and places of residence. Kirst (2001b) called for the extension of dual credit to a larger segment of the high school population to include underrepresented students and students other than the academic elite. Research has shown that dual credit programs can have a very positive effect on the postsecondary performance of underachievers, minority, and at-risk students (Opp, 2001; Brigham, 1989; Hugo, 2001; Lieberman, 1986; Broughton, 1987).

Johnstone and Maloney (1998) found that increased access and successful student performance in dual credit courses positively influenced the transition between high school and postsecondary education and thereby the improving the overall productivity and efficiency of student learning. The creation of a P-16 educational framework in reform measures such as the Kentucky Postsecondary Education Improvement Act of 1997 elevates the significance of dual credit programs in the overall lotus of education reform in Kentucky. It also questions the 
accepted structure of the secondary to postsecondary transition and, along with the increased demand for universal access to postsecondary education and the decreased relevance of the high school diploma, makes the comprehensive community college a significant player in a potentially new educational structure that includes an articulated grade 11-14 educational program.

This research addresses the problem of productivity in the P-16 system of education, emphasizing the repetition of the senior year of high school with the first year of postsecondary education. Osborne and Gaebler (1992), Orill (1998), and Johnstone and Del Genio (2000) emphasize the integration of the secondary and postsecondary systems of education creating a new overall theoretical framework of $\mathrm{P}$ through grade 16. Increased productivity of learning through dual credit courses is a way to eliminate the duplication and lack of articulation in the P-16 educational system. This research examines the use of dual credit as a possible alternative to this duplication in making the P-16 system more optimally productive.

\section{Research Purpose}

This study is an investigation into the factors that are the most significant predictors of student performance in dual credit courses in Kentucky community and technical colleges to determine the value of such courses for students from different demographic representations, and academic ability levels.

The study evaluated the success of students in dual credit courses since 2000 in the 28 colleges of the Kentucky Community and Technical College System (KCTCS) to determine if such courses had a positive effect as an initial 
postsecondary access point for low achieving, minority, and at-risk students.

Gender, ethnicity, student residence, and socio-economic status were analyzed as demographic variables.

\section{Research Questions}

This research addressed the following research questions:

1. Is there a significant difference in the number of students enrolled in dual credit courses between Fall 2000 and Fall 2001 by gender, residence, ethnicity, and socio-economic status?

2. Is there a multivariate level of significance in predicting the criterion variables (credits earned, deficient credits, and cumulative GPA) from the predictor variables (high school performance, gender, residence, ethnicity, and socio-economic status)?

3. Is there a univariate level of significance in predicting credits earned from the predictor variables (high school performance, gender, residence, ethnicity, and socio-economic status)?

4. Is there a univariate level of significance in predicting deficient credits from the predictor variables (high school performance, gender, residence, ethnicity, and socio-economic status)?

5. Is there a univariate level of significance in predicting credits earned from the predictor variables (high school performance, gender, residence, ethnicity, and socio-economic status)? 
6. What is the relative contribution of each predictor variable (ACT English test score, ACT mathematics test score, student gender, student residence, student ethnicity, and student socio-economic status) as a predictor of the criterion variables (credits earned, deficient credits, college GPA)?

\section{Definitions}

Hage (1972) suggests techniques in searching for general variables in sociological and social science research. The following is an overview of the operational and conceptual definitions of terms used in the study.

Dual credit: This refers to any college level learning in high school that involves a student being enrolled in both high school and college. In some instances the students will receive dual credit, credit at both the high school and college. In other instances the students will receive only credit at the college. It is important to point out that many states, including Kentucky, differentiate between dual credit and dual or concurrent enrollment as to whether the student receives high school and/ or college credit for the course. Dual credit results when the student receives credit for the course at the high school and college concurrently. Dual or concurrent enrollment results when the students receive college credit only while enrolled in high school.

Test Performance: This is defined in the study as student performance on the American College Test (ACT) assessment used for placement or entrance into postsecondary education. The score on the English and mathematics ACT 
assessment is intended to provide an indication of a student's performance in high school.

Ethnicity: This is defined based on a student's race or ethnic group. Since the study focuses on dual credit in Kentucky, a state comprised of an overwhelming majority of White Caucasians, other ethnic groups will be coded as “African American" and "other minorities" since the database contains an insignificant number of minorities other than African Americans to identify minority groups in dual credit programs.

Socio-economic status: This is defined in this study is based on the median house-hold income in the students' home postal zip code based on the 2000 U.S. Census. Studies previously reviewed have shown that socio-economic status plays a significant role in access and degree completion.

Residence: This is defined dichotomously in this study based on a student's residence in an urban or rural community. The U.S. Census Bureau classifies as "urban" all territory, population, and housing units which consist of core census block groups or blocks that have a population density of at least 1,000 people per square mile and surrounding census blocks that have a population density of at least 500 people per square mile. The Census Bureau's classification of "rural" consists of all territory, population, and housing units outside of urban areas.

\section{Significance of the Study}

An examination of the factors that predict student performance in dual credit courses in Kentucky community and technical colleges is a timely contribution 
linking the era of $\mathrm{P}-12$ reform to the reforms in higher education in Kentucky. This evaluation of student performance in dual credit courses parallels the issue of access, efficiency, and learning productivity in higher education that are characteristic of the mandates of the Postsecondary Improvement Act of 1997. The identification of the type of students taking dual credit in Kentucky community and technical colleges will provide state policy makers with the first opportunity to determine if deregulating and relaxing dual credit policies has had an impact on the type of students taking dual credit and how well these students perform.

The examination of student performance in dual credit programs links with many P-12 reforms under KERA. In light of deficiencies in student performance among high school students nationally and in Kentucky, research has shown dual credit courses to provide a rigorous curricular alternative to the traditional high school curriculum (Windham, 1998; Delicath, 1999; Mercurio, Lambert, \& Oesterle, 1983; Crossland, 1999; Hanson, 2001; Urahn, 1993, Chatman, \& Smith, 1998). The research examined in this study clearly demonstrates the value of a strong academic curriculum on student success in postsecondary education school (Adelman, 1999; Horn, Kojaku, \& Carroll, 2001; Alexander \& Pallas, 1984). While this study will not provide a direct examination of the curriculum students in dual credit courses are exposed to, it will evaluate the merits of using dual credit courses regardless of the student's level of performance in high school. An examination highlighting the access of students other than the academic elite to dual credit courses coupled with their performance in these courses is a resounding need for future studies cited by 
numerous researchers of dual credit programs (Kirst, 2001b; Clark, 2001; Johnstone and Del Genio, 2000).

Finally, this study contributes to the overall theoretical framework of P-16 integration of the educational system. Increased access and successful student performance in dual credit courses positively influences the transition between high school and college and the overall productivity of learning of the P-16 educational system (Johnstone, \& Maloney, 1998). This P-16 theoretical construct created by dual credit calls into question the accepted structure of the secondary to postsecondary transition. It questions the institutional effectiveness of the traditional American high school (Clark, 2001; Johnstone, \& Del Genio, 2000). The demand for mass higher education makes the community college a key player in a new structure that includes an exit point at grade 14 much the like the high school diploma is the exit point at grade 12 (Carnevale \& Desrochers, 1999).

To summarize, dual credit courses are a growing force in the P-16 landscape of educational reform. The levels of participation and performance of students in dual credit courses provides a pivotal measuring stick for the use of dual credit as a leveraging point for increased learning productivity and efficiency—and ultimately structural change of the existing transition between secondary and postsecondary education. 


\section{CHAPTER II LITERATURE REVIEW}

In the past decade record numbers of American students enrolled in postsecondary education after high school. As the economy demands increasingly higher levels of education and technical training the coming decades, the ability of American higher education to productively and efficiently respond to this demand will be a major thrust of policies. House (1994) points to the next decade as one of transformation and reform for higher education. While the American higher education model has been enormously successful in educating large numbers of students from modest backgrounds, providing scholarly support to society, and leading international scholarship, it is extremely expensive to maintain. He warns that the American system of higher education without reforms in its overall efficiency may face a period of decline in quality. With the increased demand for mass higher education, providing open access to postsecondary education, particularly to underrepresented student populations will a challenge for many colleges in the coming years.

The call for increased productivity without compromising quality occurs as American high schools produce record numbers of graduates. Standardized tests and the National Assessment of Educational Progress (NAEP), demonstrate that student achievement, especially at the $12^{\text {th }}$ grade level, has declined since the $1970 \mathrm{~s}$ 
(National Center for Education Statistics, 2000a). Much of the debate reforming secondary and postsecondary education focuses on downsizing each institution by blending the last two years of high school with the initial two years of postsecondary education, thereby creating a more productive learning organization than the fouryear model currently employed. The fastest growing program in the last two years of high school are dual credit programs that allow high school students to earn college credit, while the fastest growing segment of the first two years of higher education are remediation programs for academically unprepared students (Clark, 2001). The senior year of high school, subject of much attention since the work of the National Commission on the Senior Year of High School (2001), stands in the center of this transition. The work of the National Commission on the Senior Year directed much criticism at the last two years of high school as unproductive, inefficient, and a replication of the first two years of college. The creation of a P-16 framework of educational integration emphasizing increased access and achievement in the learning productivity of grades 11 through 14 . Dual credit courses will play a key role in this evolution.

\section{Organization of the Literature Review}

The literature review contains five sections. The first section discusses the theories on learning productivity in the context of Kentucky's reform movement in higher education under House Bill 1. This subsection frames the Kentucky reform with learning productivity and identifies policy deregulation in dual credit as a facet of this reform. The second section discusses a review of policy issues associated 
with dual credit programs, the history of dual credit, an overview of various state policies on dual credit, and the financial implications of such polices. The third section discusses these policies in the context of the P-16 movement, which emphasizes the need to merge existing systems of P-12 education with postsecondary education. This section includes subsections on the curricular duplication in high school and college, and high school and college integration through career and technical education. These subsections examine research on the inefficiencies of the current secondary-to- postsecondary model, and ways the systems could be blended to improve learning productivity, including dual credit programs.

The fourth section examines the research on dual credit models and outcomes with subsections addressing various delivery models, student and faculty perceptions of such programs, and student outcomes of dual credit programs. The fifth section identifies the demographic factors of student participation and performance in dual credit courses with subsections addressing the major variables in this study. The last section is a summary of the literature review and implications of recent policy changes in Kentucky on the productivity of the system.

\section{More Productive and Efficient Learning Environments} Johnstone's (1993) work on learning productivity has strong implications for the use of dual credit as a way to streamline the higher education system while improving student achievement in high school. Significant and sustainable productivity advances in higher education must be achieved through greater 
attention to the learner. Learning productivity cannot be achieved through the traditional approach of reducing inputs such as faculty or staff while holding outputs_-enrollment—constant or forcing it to increase. According to Johnstone, learning productivity is defined through four major problems in American higher education: (a) the financial strains on colleges and universities with revenue unable to keep pace with expenditures; (b) financial strains on parents and students; (c) students entering college, or coming of college age, unprepared for college or the workforce; and (d) inadequate learning in college.

Johnstone presents higher education with the challenge of being more productive, less costly and more efficient. He suggests learner-based reforms such individually-paced mastery learning, utilization of technology, discouraging the lack of focus common in undergraduate education as they "drift" through unneeded courses. Year-round study, and starting undergraduate and graduate education at an earlier age through programs such as dual credit are two solutions proposed by Johnstone to this problem.

In a study focused on curricular implications of learning productivity, Johnstone (1998) highlights the curricular redundancy of the first and second year of college and the last two years of high school. He cites three basic models of collegelevel learning taking place in the high school: examination-based, college or university-based, and school-based. Examination-based occurs mainly through the matriculation of credit from examinations administered through the College Board Advanced Placement program or the International Baccalaureate program. College or university-based consists of dual credit or dual credit programs taught either at a 
college or by a college instructor in the high school. The school-based model occurs through articulation agreements or by colleges or universities certifying courses taught in high schools by high school teachers for college credit. The most successful example here is the Syracuse University program Project Advance. Johnstone (1996) cites three benefits utilizing these models to improve the learning productivity of colleges. Successful dual credit performance can lessen the number of courses needed for the baccalaureate programs thus reducing the time and cost to the degree. Second, dual credit courses can reduce much of the lowerdivision redundancy taken in college. Finally, dual credit programs strengthen the high school curriculum and raise the stakes for good performance during the senior year of high school, regardless of the credits that count toward a future degree.

One of the earliest examples of attempts to increase the productivity of learning between secondary education and postsecondary education through dual credit and middle college high school concept emerged in the 1940s at the University of Chicago under the leadership of Robert Maynard Hutchins. Hutchins introduced a movement to end the duplication that existed between traditional high school and college. Hutchins advanced an innovative plan to create a coherent program from high school to junior college to the four-year university. The result was a fully functioning high school centered on the liberal studies at the University of Chicago in the 1940s (McNeill, 1991).

The European model of the secondary school and university influenced Hutchins, Chicago Dean Chauncey Boucher, and professor and long-time Hutchins confidant Mortimer Adler. The European model advocated a cohesive high school 
and junior college experience that included the awarding of the BA degree at grade 14 after students completed a prescribed curriculum in "general" education (Adler, 1980). The plan attempted to address many of the skill deficits of high school graduates under-prepared for college. It also allowed large research universities such as the University of Chicago to delineate clearly between the general education of the junior college and the specialized and highly technical studies of senior college and graduate school. The plan never got off the ground because high schools were unsure of surrendering their students to colleges at age 16 or 17 . Faculty at the University never embraced the plan due to disagreements over the appropriate course of study for general education (McNeill, 1991).

Adler (1980) made a similar attempt to streamline the educational process through the Paideia movement with a proposed consolidation of high school and the first two years of college and awarding a bachelor of arts grounded in general education at the $12^{\text {th }}$ year of education followed by a year of work, military service, or travel before a student continues their formal and more specialized education.

Van Gelder (1972) reviewed literature on the theory of a three-year bachelor of arts degree dating back to 1640 when such degrees were awarded at Harvard. The main issue in this literature is agreement on the curriculum that would be part of such a program since financial savings are only realized when degree requirements are reduced. Much of the research emphasized cutbacks in the general education. The role of the community college in offering three-year degrees was also not widely supported, calling into question the potential merits of the three-year degree approach. 
A learning productivity model centered on connecting the end of high school with college emerged in California under the leadership of William Proctor of Stanford University calling for a 6-4-4 system through an associate degree, again connecting the traditional high school to the university via the junior college with a grades 11-14 arrangement. This program, called by some the first "middle college" lasted only a few years through the 1950s (Broughton, 1987).

Focusing on the 16- to 20-year age group, a study completed by the College Entrance Examination Board (1970) suggested that the idea of the "middle college," could provide the last two years of high school and the first two years of college and concluding with the bachelor of arts degree. The College Board suggested that liberal education could be an integral part of the curriculum from grades 11 through 14. Medical and psychiatric experts interviewed by the College Board for the study supported this configuration. In many respects, they cited a stronger developmental reason to group 16 to 20 year-olds compared to the current grouping arrangement of 14 to 18 year-olds.

In two publications, the Carnegie Commission on Higher Education, Less Time, More Options (1971) and Continuity and Discontinuity (1973) suggested that resurrecting the University of Chicago proposal would provide an excellent answer to the overlap and discontinuity between school and college. Adding that:

This [proposal] should be seriously explored by large numbers of private liberal arts colleges. It might well provide them with a new market of students, and, at the same time, give liberal education a new lease on life. The middle college concept would put all liberal or general education into 
one institution. Universities might then feel free to concentrate upon what they can do best, which is advancing knowledge through research and providing professional training. (p. 80)

Despite the recommendations made in both studies supporting proposals such as the University of Chicago's few attempt were made to establish programs suggested by the Carnegie studies. Smart and Evans (1977) studied state policymakers attitudes toward time-shortened degree programs as a result of legislation growing out of these Carnegie reports of the 1970s. In reviewing state actions, the researchers found little attention paid to the concept of time-shortened degree programs and increased higher education productivity. The most significant state-mandated program was found in Florida, which required local school districts to articulate and offer dual credits with postsecondary institutions. Their review also revealed legislative actions in Hawaii and California that strongly encouraged dual credit and articulation between grades $11,12,13$, and 14 .

The researchers hypothesized that the concept of time-shortened degrees did not attract significant attention of state legislatures or governors. To try and gauge the attitudes of legislators on these ideas, the researchers developed a short questionnaire that was mailed to selected legislators in five states and to all directors of statewide coordinating boards of higher education. The states selected included California, Illinois, New York, and Ohio. The Carnegie Corporation funded timeshortened degree programs in these states, in whole or in part, in 1971 and 1972. Replies were received from a total of 58 legislators (30\% response rate) and an 82 $\%$ response rate from state coordinating boards. Respondents were asked to rate 
their responses in terms of "good," "satisfactory," or "poor." Data were analyzed using descriptive data of respondent's survey responses using percentages. Smart and Evans did not provide any information on the reliability of the instrument used in this study.

The findings indicate a general approval from both legislators and state higher education staff of the concept of time-shortened degree programs (93\%). The highest marks went to challenging high school courses and college requirements by examination and independent study, which were rated as "good" or "satisfactory" by $96 \%$ of the combined groups. Encouraging high school students to begin college-level work while in high school was next (57\% "good" and $31 \%$ "satisfactory"). Sixteen percent of legislators, however, found this to be a "poor" approach. Despite this, several legislators noted that the most positive area for change in this area was with the elimination of duplication between the senior year of high school and the freshman year of college. One legislator commented, "'I don't care whether the twelfth grade is dropped or the freshman year is skipped just so the competent student can move on"” (p. 209).

The two approaches that were clearly not favored by respondents included reducing high school graduation requirements to permit early enrollment in college (rated as "poor" by $63 \%$ of respondents), and the reduction of the general or liberal education requirements from the usual two years to approximately one (rated "poor" by $71 \%$ of respondents).

Smart and Evans (1977) provide an interesting perspective for the policymaker to various approaches of the time-shortened degree approach to 
learning productivity in higher education. While the response rate and relatively simplistic methods of data analysis are limitations, it does identify dual credit/ enrollment, high school-college collaboration and the blending of the last year of high school and the first year of college as a potential for reform. Since the late 1970s, interest among state policymakers to increasing learning productivity and the efficiency of educational systems has increased considerably.

Recent researchers in public sector agencies such as government and education place great emphasis on increasing the productivity by which the public sector spends taxpayer money. Osborne and Gaebler (1992) call for the transformation of the public sector through entrepreneurialism. They advocate a fundamental restructuring of government based around ten principals which entrepreneurial organizations are built. A key principle for management includes the idea of "steering more than rowing." Steering requires people to see the larger issues and possibilities and can balance competing demands for resources, while rowing focuses more on the operational tasks and service delivery. "Steering organizations need to find the best methods to achieve their goals. Rowing organizations tend to 'defend' their methods and their costs" (p. 35). Missions instead of rules drive entrepreneurial governments; they fund outcomes, rather than inputs, best meet the needs of the customer rather than the bureaucracy.

They cite Minnesota as a test case in education. The Minnesota Early Options program allows high school juniors and seniors to attend college in lieu of attending high school through dual credit at the taxpayers' expense. It is an example of the downsizing and choice created through public policies creating a more 
productive system. Data available through Minnesota surveys underscore that dual credit participants are far from stereotypical elite: $60 \%$ were B, C, and D students in high school, yet more that half of those participating received a grade of A or B in their college courses (Osborne \& Gaebler, 1992). These results provide evidence that dual credit programs can be an effective way to make higher education more accessible to a broad array of students while challenging students not currently being challenged in the present system. Programs such as the Postsecondary Enrollment Student Options (PESO) could significantly improve the productivity of students from a broad section of the population rather than just the traditional gifted and talented student as they transition from secondary to postsecondary education.

\section{Kentucky Higher Education Reform}

The ideas advanced by Osborne and Gaebler are consistent with many strands of educational reform in Kentucky and around the nation. The first reform in Kentucky education occurred in 1988 when the Kentucky Supreme Court declared the entire system of K-12 education in the Commonwealth to be unconstitutional. The result was the 1990 Kentucky Education Reform Act (KERA), which refocused K-12 education in Kentucky around such entrepreneurial practices as accountability, site-based control, and a funding formula based on outcomes rather than inputs. The KERA reform received much national attention and lead to similar reforms in other states.

The Kentucky Education Reform Act also greatly influenced the 1997 measure passed by the legislature as House Bill 1 intended to reform Kentucky higher education. The Kentucky Postsecondary Education Improvement Act 
promoted an even greater entrepreneurial spirit than KERA. The legislation emphasized the importance of making state higher education more efficient, productive, and accountable. The reform was prompted by Kentucky's inability to compete regionally or nationally with states in measures such as the college attendance, the literacy, the high school graduation rate, and per capita research and development, and prevalence of high-tech jobs. The most sweeping aspect of the reform, in response to industry and economic demands, dealt with adult and technical education.

The bill stripped the community colleges from the governance of the University of Kentucky by also breaking technical schools away from the state workforce cabinet it created the Kentucky Community and Technical College (KCTCS) (Kentucky General Assembly, 1998). The KCTCS structure will lead to the eventual consolidation of the state's 28 community and technical colleges into 16 comprehensive community college districts with a single accreditation by 2005 (Kentucky Community and Technical College System, 2002a).

In adult education, the Council on Postsecondary Education (CPE) was given a significant policy-making role in serving adults that lack the basic literacy and skills needed to be successful, which accounts for nearly half of the state's population. State higher education also became linked to the transformation of the "new" economy through the Kentucky Innovation Act, which links universities and businesses in a unique entrepreneurial relationship. The measure also tackled key productivity issues in the higher education system by intensively reviewing some 150 programs that produce few graduates. Since these programs outnumbered new 
programs nearly two to one, many under-productive programs were either altered or closed (Council on Postsecondary Education, 2001).

Accountability, a hallmark of the KERA reform, was manifest in the higher education version through five key indicators in what CPE billed as the "2020 Vision" for the Commonwealth. The five key indictors were as follows: (a) Are more Kentuckians ready for postsecondary education? (b) Are more students enrolling? (c) Are more students advancing through the system? (d) Are we preparing Kentuckians for life and work, and (e) Are Kentucky's communities and economy benefiting? The indicators have become the driving force of the reform and to accomplish them the CPE soon recognized that any reform in higher education must also involve linkages with the P-12 system.

In hopes of enhancing the learning productivity of the entire system, the CPE created a statewide P-16 Council, focusing on remedial education, identifying disadvantaged students in middle school and targeting them for postsecondary education, and working with local communities to find more efficient ways of partnering to create better students and better transitions for students. The statewide P-16 Council consists of membership from the CPE, Kentucky Department of Education, Cabinet for Workforce Development, Department of Adult Education and Literacy, and the Education Professional Standards Board. The P-16 has placed a great emphasis on linking the systems together with programs such as dual credit.

The Kentucky Postsecondary Education Improvement Act provides a framework of the climate in the Commonwealth for "reinventing" higher education in the Osborne and Gaebler style while creating a more productive system of higher 
education. The P-16 emphasis that is part of the reform highlights the importance that dual credit will ultimately play in the scope of this overall transformation. Increasing the number of Kentuckians not traditionally inclined to attending college into postsecondary education is a critical aspect of the Commonwealth's reform agenda. This study will evaluate in the context of the Kentucky policy framework for dual credit the performance of these non-traditional students in dual credit courses. The next section examines the policy framework of dual credit both nationally and in Kentucky.

Policy Framework of Dual credit

The Education Commission of the States (2001) lists dual credit programs as the fastest growing program for the last two years of secondary education based on the inquiries they receive and the policy interest in programs among the 50 states. They list 25 states with policies governing dual credit programs. Of these 25,12 states have policies through their state higher education board while 13 states have institutional policies (Education Commission of the States, 2001). This section reviews the background of high school and college integration with an examination of the Advanced Placement program, a review of state dual credit policies; the financial implications of dual credit, college and university policies, and an analysis of the current state of enrollment in Kentucky. This section will provide a context for the importance of state and local policies toward dual credit and how the policy framework impacts dual credit enrollment and student performance. 


\section{Background}

Neither the concept nor the practice of a dual credit delivery system is new. Examples of contrasting age group students studying together can be found over 200 years ago at Phillips Academy in Andover, Massachusetts. Other examples dated back to the $16^{\text {th }}$ and $17^{\text {th }}$ centuries at Oxford in England (Boughton, 1987). Flexibility based on individual abilities was the practice of the day. Cotton Mather graduated from Harvard at 16, as did Jonathon Edwards from Yale. One of the first actions of the Board of Regents of the State of New York, after its founding in 1784, "was to specify that students entering college did not necessarily have to start out as freshman, and would be admitted into such classes in the said colleges as shall be qualified to enter" (Whitlock, 1978).

In 1888, President Eliot of Harvard criticized the evolution of our educational structure into primary, grammar, and high school based solely on age grouping as artificial (Boughton, 1987). Several events emerged in the early $20^{\text {th }}$ century that solidified the lock step educational system, the most significant of which was the Carnegie Foundation for the Advancement of Teaching in 1906. This group set up the structure and methodology of high school to college articulation by defining college in terms of academic units and the bookkeeping system known as Carnegie units took over the role of defining an official moment at which a student finished high school and was elevated to college (Cremin, 1961).

The progressive movement of the early part of the $20^{\text {th }}$ century, which focused on social and educational reforms leading to progress, led to the expansion of non-academic goals to schools through the 1918 list of Cardinal Principles of the 
Commission on the Reorganization of Secondary Education. The Cardinal Principles drastically changed the nature and function of the high school and moved the high school purposefully away from curricular and organizations links to colleges. The intellectual purpose of schools diminished in favor of a greater custodial function. Schools were now expected to solve societal problems rather than transmit knowledge and even prepare students for college (Hofstadter, 1963; Agnus \& Mirel, 1999; Ravitch, 2000). The traditional pre-college curriculum grounded in the liberal arts and classics was soon replaced with courses in vocations, citizenship, and practical arts. The result was a comprehensive high school based on the various social and economic groups that populate the nation. Schools became more concerned with providing something different for every student, that direct linkages to colleges envisioned by Elliot soon disappeared.

Despite the barriers erected in the early part of last century, efforts toward high school and college integration through dual credit and middle college high schools developed. The Hutchins and Proctor models at the University of Chicago and Stanford University, discussed previously, attempted to break this lockstep with innovative plans to create a coherent program from high school to junior college inventing the "middle college" design. Various forms of school-based and collegebased dual credit programs began to rise in popularity in the early 1970s in response to many of the Carnegie Commission reports and the successful implementation of the middle college model at LaGuardia Community College in New York. The rise in popularity of the Advanced Placement program, allowing students to earn college credit, also accelerated the growth of dual credit. 


\section{Advanced Placement Program}

The most enduring attempt to blur the lines in the curriculum of secondary and postsecondary schools emerged with the development of the Advanced Placement (AP) program by the College Board. Valentine (1987) traced the impact of the College Board on high school curriculum and American education. The College Entrance Examination Board played a significant role in setting the standards in secondary education. The first college entrance examinations, which became known as College Boards, were first administered in 1901. The rationale was that a set of common entrance examinations would be better than separate examinations by colleges.

The College Board Advanced Placement (AP) program began in 1951 when the Ford Foundation funded a study designed to determine if high school juniors and seniors would be better prepared for college if they were taught with a more challenging high school curriculum. At the same time a group called the School and College Admissions with Advanced Standing selected 11 subjects and appointed committees to write course descriptions while the Educational Testing Service (ETS) began developing assessments to gage student performance.

Currently, the College Board offers preparatory courses and exams in 33 subjects. Postsecondary institutions award credit by recognizing student performance on examinations administered by the College Board. Exam scores range from one to five, with a one signaling no recommendation of credit, two indicating a candidate possibly being qualified for credit, a three score indicates a candidate being qualified, a four is well qualified and a five is considered an 
extremely well qualified candidate for college credit. Advanced Placement has been lauded over the years as a model of collaboration among high schools and postsecondary institutions. Making a strong case to states and policy makers to increase access and volume of students and high schools involved with AP, especially in traditionally low achieving areas, Adelman (1999) identified AP courses as strong predictors of bachelor's degree completion.

Considerable discussion accumulated over the years about the reliability of the exam scores and the program's target population. Willingham and Morris (1986) conducted a longitudinal study of AP students in college four years after taking AP courses. The study was based on extensive information on 4,814 students who participated in the Personal Qualities Project, a longitudinal study in nine colleges and universities. The project included information on AP $(n=1,115)$ and non-AP $(n=3,699)$ students. The researchers compared these two groups on measures of background characteristics, special achievements in secondary school, goals and interests, transition to college, and different measures of success using analysis of variance (ANOVA). Areas of study included: (a) How AP and non-AP students compare at the time of college entry? (b) Whether AP or non-AP students take a similar academic program on a similar schedule? (c) How AP and non-AP students perform academically through four years, and (d) Whether there are differences between AP and non-AP students generally comparable for major groups of students; whether AP in particular subjects reduces the likelihood of students taking college coursework in those areas; and whether the AP grade is a useful predictor of college performance? 
The findings revealed that AP students (a) were superior, at the time of entry to college, on all pre-admission measures of ability and achievement $(p<.05)$; (b) specialized in majors with more demanding grading standards; and graduated with a double major $(p<.05)$; (c) performed better academically through four years $(p<$ $.05)$; (d) did as well academically as would be expected given their superior ability $(p<.05)$; (e) were superior in terms of broad criteria of college success $(p<.05)$.

The results of studies such as Willingham and Morris prompted a significant increase in the number of students taking AP exams, the number of high schools offering the courses, and interest among state policy-makers. Between 1984 and 1997, the number of students who took AP examinations nationally increased dramatically, rising from 50 to 130 students per $1,00012^{\text {th }}$-graders. The number of examinees increased for both sexes and all racial/ ethnic groups (Students who took Advanced Placement exams, 1999). In 2000, 11,830 students took AP examinations in Kentucky. During 2001 the Kentucky General Assembly began to pay closer attention to the progress of students in the state through the AP program. A legislative committee reviewed the current status of advanced placement in the state. The result is a measure passed in 2002 as Senate Bill 74 to standardize the acceptance of AP scores by state higher education institutions to encourage more schools and students to take AP courses, and set standards of teacher quality for all programs, including dual credit that offer students advanced placement in college (Kentucky General Assembly, 2002). In addition to standardizing the acceptance of the AP courses, the legislature's interest in the program is motivated, in part, to increase access to the program of students rather than just the traditional gifted and 
talented student. Many high schools create a strong gatekeeper function in determining which students have access to the AP curriculum and which do not. Increasing access to AP is the subject of great debate.

Lichten (2000) in a policy analysis makes a strong argument against increasing access of more students and high schools to AP. He reviewed the AP Program and cited data collected from various participating colleges demonstrating a while the quantity of students taking AP courses and AP exams has increased; the overall quality as measured by exam results has declined.

Lichten first took issue with the College Board's exam score scale that recommended students with a three as qualified for college credit. He cited data from the Princeton Review, College Board, and the Educational Testing Service (ETS) that indicated the many of the most selective colleges do not accept an exam score of three for college credit in many disciplines. About $50 \%$ of selective admissions schools accepted a score of three for college credit. He proposeed a new scale labeling students with scores of four and five as being qualified and well qualified respectively, students with three should be considered possibly qualified, while scores of one and two should receive no recommendation. Under such a scale, Lichten argued that about half of the students taking AP exams would qualify compared to the around $76 \%$ that qualify using the current scale.

To support this recommendation, he cited data from ETS showing math placement in college for students that took the AP Calculus $\mathrm{AB}$ course in high school. Around a fourth of the students taking the course did not take math in postsecondary education ( $24 \%$ of those that made a three on the exam and $29 \%$ of 
those that took the course, but not the exam). Nearly half of the students that took the course, but not the exam started with remedial math compared to $17 \%$ of exam takers that earned a three. Twenty-one percent of those taking the course, but not the exam and $37 \%$ of those taking the exam and scoring a three re-took the first level of calculus in college. Only $22 \%$ of those scoring a three placed in the second level of calculus in college.

The main focus of Lichten's policy analysis, in addition to calling the scale into question, focused on the diminishing returns of the current rate of expansion in of the AP Program for the next decade. He uses College Board data to indicate that expansion will cause a decline in the marginal yield of pupils qualifying for college credit as a result of their AP experience. Increasing the volume of test takers, according to Lichten, results in lowering the criterion and therefore the quality of the program.

Camara, Dorans, Morgan, and Myford (2000) in a stern rebuttal to Lichten questioned the accuracy and context of many of the data he presented in his policy analysis. They speculated that increased scores in AP would be a natural consequence of reducing the availability of AP courses to students. They claimed Lichten's thesis confounds quality with scarcity. The researchers, affiliated with either the College Board or ETS, advocated that the AP context of quality is multifaceted, based on subject matter, quality teachers, students, and a welldeveloped exam. Increasing access, they argued, does not guarantee a reduction in quality. The increased access, they contended, exposes students to college-level curriculum, encourages teachers to expand their content domain, and serves as a 
mechanism for increasing curriculum rigor, and provides students with the opportunity to experience the challenges associated with college while still in high school.

Considerable debate has raged about the value of Advanced Placement compared to dual credit as the most viable option for students in providing a rigorous curriculum in blending the last years of high school with the first couple of years of college. Advocates of dual credit say dual credit programs provide a challenging environment to students, increases access of college-level courses to a wider spectrum of students, and the outcomes show students participating in such programs are much more prepared and more likely to succeed in college (Jones, 2000). Critics of dual credit contend that AP programs provide a more viable alternative to dual credit because of its research base, higher standard and level of challenge. They also contend that dual credit programs lack the same type of high standard tied to a nationally accepted test, and dual credit programs are difficult to administer because of the difficulty in combing resources and overlapping policies between K-12 and postsecondary institutions (Kummerer, 2000). The support of dual credit programs via a policy framework at the state level is a critical aspect of program success. The next section of the review examines the impact of state policies on dual credit programs.

\section{State Policies for Dual Credit}

The dual-credit movement has exploded during the last two decades of the $20^{\text {th }}$ century. A number of universities and four-year colleges across the nation have 
developed dual-credit or concurrent enrollment programs. The most significant growth recently, however, has been in the community college systems.

State education agencies, community colleges, and universities have worked closely with their state legislators to develop supportive legislation, funding, standards for delivery, and guarantees for transferability of these dual-credit programs to universities and colleges. Legislation and procedures that support dual credit have added greatly to the legitimacy of this program's thrust.

A policy analysis commissioned by Oregon's Joint Boards of Education (1999), found a total of 31 states as having some type of dual-credit program. Fourteen states reported having specific laws or policies addressing early options programs such as dual-credit. They were Arizona, Colorado, Florida, Georgia, Idaho, Indiana, Iowa, Michigan, Minnesota, North Dakota, Ohio, Oklahoma, Virginia, and Washington. State Higher Education Executive Officers (1998) reported that 44 states have some type of postsecondary options available for high school students. Reisberg (1998) reported 38 states identified as having formal dualcredit programs. Andrews (2001a) reported 48 states having some active dual-credit or concurrent enrollment coursework for secondary students.

Strong evidence of potential growth is apparent in the many state initiatives encouraging dual credit. Minnesota lawmakers, for example, enacted legislation in 1985 that enabled high-achieving secondary students to take courses at the community colleges, state universities, and the University of Minnesota. The number of participating high school students rose from 3,528 (3\% of eligible juniors and seniors) in 1985-86 to 6,671 (6\% of all eligible juniors and seniors) in 1994-95 
(Minnesota Office of the Legislative Auditor, 1996). Almost half of all students participating in 1994-95 took community college courses, and an additional $18 \%$ enrolled in classes that technical colleges offered (Minnesota Office of the Legislative Auditor, 1996).

Washington and Florida also provide statewide examples. Washington's Running Start program began in 1990 as a pilot project stemming from the "Learning by Choice" law. It expanded to statewide operation in 1992-93, enrolling approximately 3,350 high school students in community college classes. Crossland (1999) reports the number of enrollees in Running Start increased to 12,355 students in 1998-99. In Florida, state statute (Florida Statutes, section 240.116[1]) requires school superintendents and community college presidents to implement an articulation agreement that specifies the following: courses and programs for dual credits, eligibility requirements for student participation in dual credit opportunities, “institutional responsibilities regarding student screening prior to enrollment and monitoring student performance," criteria for judging the quality of dual credit and monitoring student performance. Windham (1997) reports that the number of high school students taking community college classes under these dual credit provisions rose from 19,375 in 1992 to 46,541 in 1996.

Several other states have similar laws. Missouri legislation, first passed in 1990 and amended in 1999, stipulates "public high schools may, in cooperation with Missouri public community colleges and public or private four-year colleges and universities, offer postsecondary course options to high school students" (Missouri Revised Statues, section 167.223). For purposes of state aid, students are counted 
both within average daily attendance reports of the school districts and as resident students at the community colleges. New Mexico passed similar legislation in 1990, allowing dual reimbursement to both schools and the community colleges, as did Illinois in 1997 (New Mexico Association of Community Colleges, 1990; Illinois Community College Board, 1999). These dual-payment options contributed to the explosion in secondary school enrollments in postsecondary education.

Administrators and governing boards in these states no longer have to be concerned about how much income high school enrollments are taking away from secondary schools or about how the enrollments impact postsecondary funding.

Other states seek efficiencies by eliminating overlap between curricula at high schools and colleges. Massachusetts specified that dual credit courses should be those that the high schools themselves do not offer; eligible students were those who have grade point average of 3.0 or above and demonstrate ability to benefit from college-level work (Massachusetts Department of Education, 1999). Similarly, Michigan's Postsecondary Enrollment Options Act authorized high school students to enroll in college courses only if these courses are not offered by the school district or if they are not available to students because of scheduling conflicts (Michigan Department of Education, 1999). The school districts themselves were responsible for tuition and fees with state school aid funds; cash payment to both the school districts and the colleges were not part of Michigan's policy.

Financial Implications of Dual Credit Programs

The dual credit programs of Illinois, Michigan, and New Mexico illustrated the importance of the financial implications for K-12 school districts, colleges, 
students, and, ultimately, the taxpayers. Most state dual credit policies required the burden of tuition and book costs to be assumed by the students. Four states paid tuition costs, however, while five states required that local school districts assume such expenses. No states required the colleges to assume these costs (Education Commission of the States, 2001). Many of the key issues with funding has implications for the issue of higher education productivity as well as overall educational productivity. Of the 25 states that the Education Commission of the States (2001) reported to have policies on dual credit, 20 required students to assume the costs of the program. These costs were assumed while the K-12 school district and higher education institution counts the student in their average daily attendance and headcount for state funding. In many of these cases, the students involved and their parents paid tuition costs in addition to supporting the K-12 and higher education institutions as taxpayers.

The Washington case provided a good example of the complexity of the funding issues and the implications of state or school district funding policies on the taxpayers. Two studies conducted by the Washington State Board for Community and Technical Colleges (Crossland, 1999; Hanson, 2001) indicate that the Running Start program, which allows juniors and seniors to take free college courses at community and technical colleges and universities, has saved taxpayers millions of dollars. The Crossland (1999) study lists the savings to both the student and the taxpayer one of the most significant impacts of the program. The state used K-12 basic education funds that follow the student to the college they attend. The program saved students $\$ 12.5$ million and taxpayers $\$ 24.6$ million in 1998-99 
because of the "two-for-one" aspect of Running Start that translates to the taxpayers paying only once for the last two years of high school and the first two years of college. The Hanson (2001) study listed savings to students as \$14.6 million and \$28.8 million to taxpayers. Both studies listed the loss of revenue by K-12 districts as a major concern expressed by school district officials. These concerns, however, are secondary to the satisfaction expressed by parents and students on the overall impact of the program.

Similar financial implications emerged from studies conducted in Minnesota. Urahn (1993) in a study of Minnesota's Postsecondary Enrollment Student Options Program (PESO) evaluated the financial benefit of the program to students, and the quality of the investment by the state. The Minnesota program is one of the most progressively funded dual credit programs in the country, as a result of changes made in the level of funding from 1985 to 1993.

From 1985 to 1991 the state funded the program by deducting the cost of PESO student tuition, fees, and books from the school district's general education state aid and paid it to postsecondary institutions. The postsecondary institutions also received average cost funding for each PESO student on the postsecondary side of the budget. In 1992, the funding was changed so that school districts received only a portion of general education revenue for each student. Postsecondary institutions received the cost of tuition, books, and fees for PESO courses from the K-12 budget they had before, however, funding for PESO students from the postsecondary budget was reduced from average cost funding (67\% of the average 
cost of instruction) to marginal cost funding (32\% of the average cost of instruction).

Beginning in 1993, school districts again saw a decrease in the amount of general education revenue for each PESO student while postsecondary institutions received a flat reimbursement per credit plus marginal cost funding. These changes in the fiscal aspect of the PESO program led to greater financial efficiency in the resources allocated to K-12 and postsecondary education. Prior to the changes in the program the total state budget allocation for a typical student attending PESO for a half day and high school for a half day was $\$ 5,367$ and $\$ 6,489$ for students to attend college for a full day while still enrolled in high school. After the changes in funding it cost the state $\$ 4,373$ for a half-day student and $\$ 5,272$ for a full-day student.

While the program cost the state about $\$ 2.2$ million a year in fiscal year 1992, Urahn added that the program would save the state money in the long run because the postsecondary funding for PESO students cost about \$4 million in 1992. Had PESO students taken the same number of college credits as college students, it would have const the state over $\$ 8$ million in addition to fully funding the students at the general K-12 cost level.

The best case illustrating the impact of state money being used to absorb the cost of dual credit was found in Florida. Florida provided school districts funding to support advanced placement, international baccalaureate, and dual credit. The state Postsecondary Education Planning Commission (1988) studied the funding of these learning productivity options. After thorough cost analysis, comparisons to 
other states, and telephone and interviews with community colleges and public schools the commission concluded that the support of such acceleration mechanisms, including dual credit, was an efficient and productive use of state funds.

The state of Utah provided another example. To provide a strong incentive to take dual credit courses, the state created a New Century scholarship, which was given to high school graduates who have completed all of the requirements for an associate degree prior to September 1 of the same year they qualify to graduate from high school. The scholarship paid $75 \%$ of a student's tuition for a baccalaureate degree at a state institution (Education Commission of the States. 2001).

Kruger (2000) analyzed the costs and savings of the dual credit program at Salt Lake Community College (SLCC) in Utah. Students in Utah are counted in the funding formula for public K-12 schools as well as in the full-time equivalent (FTE) funding formula used to fund postsecondary education. The study included SLCC graduates from 1998, 1999, and 2000 who completed at least one dual credit course.

Results indicated that at least $60 \%$ of students completed about one quarter of college-level courses and saved up to $\$ 600$ in tuition per student. A small percentage completed one year of college prior to graduation and saved over $\$ 2,200$. The results indicated that the state of Utah receives fiscal benefits if the dual credit courses counted toward college graduation. More than $80 \%$ of the courses in the study counted toward graduation, saving the state over $\$ 138,000$. While the results for just one community college are difficult to generalize at the dollar figure, the 
study illustrated the potential overall savings for the state if students fulfilled general education courses at community colleges while in high school.

In an evaluation of the Arizona dual credit program, Kummerer (2000) questioned the double funding of dual credit courses offered at the high school using high school teachers. Since in most cases secondary schools are incurring the expense of these programs, state funding provided to the secondary school for these students is not unreasonable. It is counting these student credit hours toward the community college full-time equivalent and receiving state aid for the same students the high schools are receiving state funds for "amounts to double dipping - the taxpayers paying twice for the same students. Kummerer cited the Joint Legislative Budget Committee report that dual credit in Arizona accounted for a total of 40,393 student credits, 31,283 of which have some element of double funding.

As previously cited several states, including Kentucky, more commonly experience the double dipping the other way around. Students typically took courses on the community college or university campus while the postsecondary institution received tuition and state funding in addition to the K-12 school district. In this case the K-12 school district was not providing any services to the student and the double funding was to the benefit of local school district.

The financial aspects of dual credit are controversial and complex. Many states allow both secondary and postsecondary institutions to receive funds for students in dual credit programs and hold students responsible for paying tuition. More and more states are offering such classes at no expense to the student and maintaining the level of funding for schools districts and colleges, such as Illinois 
(Andrews, 2001b). Few states like Minnesota and Utah have innovative funding formulas that have mechanisms to encourage the productivity of learning and fiscal productivity at the same time. The growth of dual credit in the last decade has prompted many states to re-examine their approach to dual credit. It has also prompted many colleges and universities to do the same.

\section{College and University Policies toward Dual Credit}

Johnstone and Del Ginio (2001) provided the best information about college and university policies toward dual credit in a comprehensive study of college-level learning in high school. The study addressed the following research questions: (a) To what extent did college-level learning experiences from high school take place in colleges or universities? (b) To what extent did the college or university itself participate in or actively sponsor college-level learning in high schools, either through a program of welcoming into its classes exceptional students from local high schools, or through accepting classes taught by high school teachers for college credit? (c) What are the general attitudes toward college-level learning in high school (welcoming, moderately accepting, discouraging), what type of differences exit among the types of institutions by Carnegie classification? (d) What policies were applied to college-level learning in high school that are accepted toward a baccalaureate degree, and (e) What is the general view of the purpose and/or benefits of college-level learning in high school?

Johnstone and Del Ginio used a survey design administered in the 1998-99 academic year to a national sample of colleges and universities. The questionnaire was sent to approximately $50 \%$ of two- and four-year colleges and universities 
categorized by the 1998 Carnegie classification (Carnegie Foundation for the Advancement of Teaching, 1994). For the purpose of analysis the institutions were further collapsed into the following six categories: selective $(n=57)$, other universities $(n=52)$, masters/ comprehensive $(n=103)$, baccalaureate I $(n=18)$, baccalaureate II $(n=74)$, and two-year $(n=147)$. The states of California, New York, Florida, Virginia, Minnesota, and Utah, where state policies support dual credit programs, were over sampled. The questionnaires were addressed to the chief academic officers. A 33\% response rate brought 451 usable completed questionnaires.

The questionnaire was constructed as a five-point Likert scale $(5=$ strongly agree, $1=$ strongly disagree). Data were analyzed using descriptive statistics and ANOVA was used to evaluate the mean differences of the surveys.

The findings illustrate a significant difference in the type of colleges sponsoring college-level learning programs. As far as dual credit is concerned, 72\% of two-year institutions report sponsoring a college-based program and 60\% report sponsoring a school-based program. That compares with $40 \%$ of selective institutions sponsoring college-based and 11\% school-based. The lowest percentage was found among more selective baccalaureate I colleges with $28 \%$ offering collegebased and $11 \%$ school-based.

A statistically significant difference was found between two-year colleges and all other varieties regarding the amount of encouragement and accommodation of college-level learning in high school. All varieties of colleges except the twoyear colleges were neutral, agreed, or strongly agreed that they were worried about 
the trend of college-level learning in high school $(F=22.1, p \leq .05)$. Two-year colleges differ significantly from all other institutions in their encouragement of high school students to enroll in dual credit $(F=17.9, p \leq .05)$. Two-year colleges also agreed that college-level learning in high school is important to lower the cost for parents and taxpayers, while masters and selective institutions disagreed $(F=24.3, p$ $\leq .05)$.

Significant differences also exist in the perception of school-based dual credit programs. Selective institutions indicate that they are "suspicious" of such programs that use high school teachers in an adjunct status, while two-year institutions disagree $(F=18.4, p \leq .05)$.

This study strongly illustrated the complications of dual credit programs based on the varying levels of support depending on the type of institution and the type of dual credit program offered. It provided evidence that successful dual credit programs hinge on the amount of support provided by the college or university offering the courses. These differences also hinted at the importance of carefully constructed state policies to govern the most complicated issues, such as funding, transferability, and faculty credentials. The major limitation of the Johnstone and Del Genio study was the lack of disaggregated data from states that have wellconstructed policies covering dual credit and the amount of acceptance of programs in various colleges in those states.

Cambra (2000) surveyed admissions officers from all 50 states about enrollment guidelines for dual credit. The inquiry addressed the following questions: (a) What evidence do admissions officers have regarding the extent to 
which entering students have had courses carrying dual credit and are these policies different when the student transfers? (b) What evidence do admissions officers have regarding the success of students who enrolled in one or more courses for which they received dual credit, and (c) What is the relative frequency with which students who gain dual credit use that credit for different types of institutions?

Cambra presented the survey in two steps. He sent the first draft to admissions and records office and the student academic advising office for comment. As a result of the comments received, he redesigned the survey. The reconstructed survey was pre-tested in a 10-campus university system that included several four-year campuses and eight community colleges. After the pre-test was completed successfully, it was distributed to a national sample. The 1999-2000 Member Guide of the American Association of College Registrars and Admissions Officers was used to generate a list of 262 names from all 50 states. A deliberate effort was made to identify a range of higher education institutions, including large public state universities and community colleges. Each institution was categorized using the Carnegie Classification system.

The surveys were mailed in August 2000 to deans or directors of admissions, and records officers. Returned surveys yielded a response rate of 53\% $(N=139)$ from 44 states. The final design of the survey was a list of 10 "yes" or "no" questions. Institutions had the opportunity to add open-ended information as well. Data were analyzed from the closed-ended questions using summary descriptive statistics in the form of percentages. 
The findings indicate that community colleges are the most accepting of credits earned in dual credit programs $(100 \%=$ "yes," $n=44)$. The largest institution-type indicating an increase in the number of dual credit students came from Research I and II universities $(91 \%=$ "yes," $n=29)$, while a sizable number of Doctoral I and II ( $86 \%=$ "yes," $n=12)$ and Community Colleges $(82 \%=$ "yes," $n=$ 27) also saw an increase as well. As an indication that additional study is needed, few respondents regardless of the type of institution indicate that they are assessing the success of dual credit students using either retention or academic success data $(15 \%=$ "yes," $n=20)$.

This study provides additional evidence to support the need for further research on student performance in dual credit programs. The study limitations of a rather crude survey scale of "yes" and "no" answers do not allow for much detailed information, however, it shows the need for states to address dual credit issues as a significant area of potential growth in higher education. Kentucky provides an interesting test case in that dual credit is rapidly growing and catching the attention of state higher education leaders and policymakers.

Dual Credit Policy in Kentucky

Since the advent of the Kentucky Postsecondary Education Improvement Act policymakers in the state developed a keen interest in dual credit. The state Council on Postsecondary Education (CPE) deregulated its policy on dual credit in 2000 to be much less cumbersome, allowing local colleges and universities more autonomy in developing dual credit programs (Legislative Subcommittee on Advanced Placement, 2001). The new policy also provides provisions insuring the successful 
transfer of dual credit courses to other state institutions (Council on Postsecondary Education, 2000). Prior to deregulation, the old policy made only the highest achieving high school students eligible for dual credit courses. The program was opened to high school seniors meeting one of the following two qualifications. Students with a 3.25 grade point average on a four-point scale and a 60 percentile score standardized tests such as the ACT or SAT, or students with a 3.0 grade point average and a 70 percentile score on the ACT or SAT (Council of Higher Education, 1990).

In 2001 the state General Assembly created the Legislative Subcommittee on Advanced Placement to review the status of advanced placement programs in the Commonwealth. According to the minutes of the proceedings of the Legislative Subcommittee on Advanced Placement (2001), serious concerns were expressed about the availability of advanced placement courses for all students in Kentucky. In many cases, the subcommittee found serious equity issues in the availability of AP courses in nearly half of the school districts around the state. While efforts to place many courses on-line through the Kentucky Virtual High School, dual credit has been mentioned as a viable option in creating a more level playing field to a rigorous high school curriculum in places where AP courses are not available. Many individuals interviewed by the subcommittee believed that AP courses are intended for only a limited number of students who plan to attend selective liberal arts colleges or research universities. They viewed dual credit courses as a way to increase the number of Kentucky students pursing postsecondary education, a major goal of the higher education reform. Dual credit, according to those interviewed, 
provides students with the credit automatically upon successful completion of the course and can provide a meaningful option for B and C average students.

The unexpected testimony regarding the value of dual credit influenced the legislature to include dual credit in the legislation that resulted from the work of the subcommittee-- Senate Bill 74. The legislation requires the CPE to work with the Kentucky Board of Education and the Education Professional Standards Board to encourage teacher training and parameters for dual credit programs in the state.

Despite the interest from a policy perspective, there is little evidence of an increased interest at the institution level. Since deregulation, each college, university and community college had the option of establishing through the faculty senate process guidelines for dual credit. According to minutes from the Legislative Subcommittee on Advanced Placement (2001) most state institutions are aware of the changes made in the policy. The University of Louisville is the only public institution that offers dual credit. In the fall 2000, there were 204 dual credit students.

As with most dual credit programs nationally, there is significant interest among the two-year colleges. The Kentucky Community and Technical College System (KCTCS) reports the largest number of dual credit students among the 28 colleges in its system. In the fall 2000, KCTCS reported 2,809 students being enrolled in dual credit courses by 2001 the number increased to 4,842. Most of these are students in technical programs. The system has an umbrella policy to guide the state's community and technical colleges in the development of dual credit 
programs. Each community and technical college can establish additional dual credit policies (KCTCS Community College Senate Rules, 2001).

Administrative Policies and Procedures from KCTCS (2002b) provide all colleges with the expectation of creating partnerships with high schools to provide postsecondary educational opportunities to high school students. The policy identifies three mechanisms for awarding credit to high school students. The first, articulated credit is awarded after graduation by virtue of an agreement between the high school and the college. The second, dual credit, involves concurrent enrollment in high school and college and credit is awarded for the same course simultaneously by the high school and the college. The third, dual credit consists of concurrent enrollment with credit being awarded only by the college for the course, rather than by both the high school and the college (Kentucky Community and Technical College System, 2002b).

In 2002 KCTCS partnered with the state Department for Technical Education and the Cabinet for Workforce Development to create a blanket dual credit agreement for all KCTCS colleges and the high school area technology centers for dual credit in career and technical courses (Kentucky Community and Technical College System, 2002c).

\section{Summary}

In a review of state policies on postsecondary enrollment options and dual credit, Boswell (2001) summarizes the benefits policymakers name for increasing interest in creating postsecondary enrollment options include: (a) reducing college tuition costs for students and their families, (b) accelerating student progress toward 
a degree to meet additional demands for college access in the coming years, (c) provide greater academic challenges to high school students, (d) encouraging greater collaboration between high school and college faculties, (e) increasing student aspirations to go to college, (f) providing greater academic opportunities for students at small rural schools, and (g) building closer ties between colleges and their communities.

Boswell identifies several critical questions that policymakers are asking regarding dual credit programs due to the wide variety of policies that exist from state to state. Policymakers have identified the following critical questions: (a) Should there be a statewide policy ensuring access to postsecondary options, or it is best to allow communities and institutions to adopt as local needs dictate? (b) Is statewide funding required in order to ensure equity across the state? (c) What financial incentives should be provided to encourage participation among secondary schools and colleges? Does providing per diem support to both colleges and universities represent "double dipping" at the expense of the taxpayers, and (d) How do we ensure that dual credit programs are indeed providing high-quality college-level education to high school students?

These questions illustrate the complexity of the issues surrounding dual credit programs from the state perspective. Before massive state policy changes additional research on dual credit programs dealing with issues such as access of underrepresented students, student performance, funding, and rigor.

Despite the increased interest in the two-year college system, little evidence exists as to the impact of dual credit courses on students, especially students that are 
typically underrepresented in college. As dual credit grows as a mechanism for learning productivity and fiscal productivity throughout the 50 states, policy makers will not only be paying attention to the immediate student outcomes related to such policy decisions, the impact dual credit will play in the overall scheme of educational productivity from preschool through grade 16 will play an even larger role on the success programs. In highlighting the curricular redundancy of the first and second year of college with the last two years of high school, Johnstone (1998) emphasizes dual credit as a way to strengthen the high school curriculum and raise the stakes for good performance during the senior year. Changes in Kentucky policy toward dual credit and dual enrollment favor more integration between the secondary and postsecondary systems, especially during the senior year of high school. The next section explores the current movement in education toward P-16 learning productivity with special emphasis on the transition from secondary to postsecondary education.

\section{Learning Productivity from a P-16 Perspective}

The concept of weaving high school and college curriculum together has come to the forefront in research conducted by Kirst and others involved with the Stanford Bridge Project. As part of the research conducted through the Stanford University Bridge Project, Kirst (1998) studied the policies, practices, and perceptions relating to the transition of students from secondary to postsecondary education. 
Recommendations from the study were based on case studies from six states and review of relevant literature. To understand current higher education preparation practices in secondary schools and disjuncture between college admissions-related policies and P-12 reforms, this research provides a comparative analysis of P-16 policies and practices in California, Georgia, Illinois, Maryland, Oregon, and Texas. Kirst addressed the following research questions: (a) What are the formal and informal state and higher education institutional P-16 policies and practices in each of the six states? (b) How compatible are the P-16 standards and assessments in terms of their content, objectives, and specifications? In seeking to answer these questions, the case study completed an analysis of existing P-16 policies as well as an analytical matching of state and institutional standards for content, performance, and assessment. This includes research with community colleges, focusing on issues related to matriculation, placement, articulation, transfer, P-16 policy development and implementation, and data collection. The findings identified three factors that call for greater integration of secondary and postsecondary curriculum. First, more than half of the students enrolling in postsecondary education need remediation in core areas such as mathematics before they are able to do college work. The price tag of this remediation leads to an opportunity cost of potential programming at both the secondary and postsecondary level. Second, the research points to the "babble" of assessments and expectations students face. The high stakes testing movement, along with pre-college admissions tests such as ACT, AP exams, and diagnostic exams used to identify remediation needs confuse students, parents and teachers 
trying to prepare students to succeed in many tests that are not aligned with the curriculum. The third issue concern problems associated with the senior year of high school. Many students experience a "senior slump" by not engaging in a rigorous or relevant curriculum during their last year of high school many times as a result of college admissions on the basis of records going only through the junior year.

In addition to the above recommendations, Kirst (2001a) and the Education Trust (1999), a national non-profit focused on P-16 reform advocate a rigorous college preparatory curriculum for all students including rewards for high performing students by allowing them to begin college work early, and expand existing dual credit or concurrent enrollment programs to include all students. Most noteworthy, Kirst (2001b) considers the expansion of existing dual credit programs to include all students, not just traditionally the college-bound as a key element to improve the productivity of the transition from high school to college.

The P-16 movement was a significant part of the higher education reform in Kentucky. The state P-16 Council, which includes members from the State Board of Education, the Council on Postsecondary Education, Cabinet for Workforce Development, Department of Adult Education and Literacy, and the Education Professional Standards Board. The P-16 Council has pursued an agenda consistent with the results of the Kirst research, including issues related with the transition from secondary to postsecondary education, a common core academic curriculum for all students, and dual credit (Council on Postsecondary Education, 2001). 
The P-16 movement and the work of state P-16 Council's, like that of Kentucky's are focusing on many issues concerning problems in U.S. high schools. This part of the literature review includes subsections on the unproductive high school, followed by an analysis of research supporting a rigorous high school curriculum, the significance of the senior year of high school, college remediation issues, career and technical curricula for high school students, and college- high school collaboration through Tech Prep.

\section{The Unproductive High School}

Recent research supports a P-16 approach focusing on the transition from secondary to postsecondary education. Johnstone (1993) in evaluating the lack of productivity of secondary and higher education argues that students entering college, or coming of college age, are not sufficiently prepared for college work or for productive work in the workforce. He also identifies the traditional high school curriculum during the last years of high school as not rigorous enough for collegelevel standards. The current 9-12 configuration allows most students to get just what they want out of high school. Students motivated to perform at high levels do so with Advanced Placement classes, programs such as the International Baccalaureate Diploma, or dual credit courses. The current 9-12 configuration allows students motivated to avoid a challenging curriculum to do so by offering a vast array of elective courses, work-study programs, a watered down general track, and vocational classes not connected to academic content and intended to train the student for a specific job. The need for reform in secondary education has been a prevalent theme for the past two decades. 
The National Commission on Excellence in Education issued A Nation at Risk (1983), a report that set out a blueprint for reforming elementary and secondary education. Many tenets of the high school curriculum came under scrutiny in the report. An important recommendation was to increase the number of courses required for graduation from high school by introducing a "New Basics" curriculum, which included four years of English, three years of mathematics, three years of science, three years of social studies, and one-half of computer science.

The response to this report was immediate and widespread. After A Nation at Risk, several landmark books in the 1980s focused on issues of high school restructuring by diminishing the comprehensive nature of the American high school in favor of a strong core curriculum for all students. The lack of a strong core curriculum in high school came under direct attack by Powell, Farrar and Cohen (1985). They argued that the typical American High School was organized much like a shopping mall where students could pick and choose from courses like retail goods in a clothing store. The courses ranged in challenge and quality much like the goods on store shelves. Everything a student/ customer could wish for was available at every price and quality range to meet the needs of a very diverse clientele. Adler (1982) advocated the same level of education for all students based on the assumption that all students could learn at very high levels. Research clearly supports a rigorous academic curriculum as a predictor for student success after high school. Johnstone (1993) calls resisting rigorous standards as "elitist" or "discriminatory," a version of educational neglect. 


\section{Rigorous Curriculum}

Various studies evaluate the impact of rigorous academic curriculum and increased academic requirements such as the "New Basics" that were the subject of the reform movement in the 1980s. Clune and White (1992) studied the increased academic course taking via increased state policies for graduation requirements. The study addresses two primary research questions focusing on the expected gains for increased graduation requirements. First, to what extent did the gains occur in basic and remedial courses, thus diluting the impact of the courses on achievement? Second, was there an adverse substitution of basic courses in math and science? The study employs a document analysis design based on transcript data of changes in course taking among graduates of high schools enrolling mostly in lower achieving students in states with increased graduation requirements.

The researchers selected four states (California, Florida, Missouri, and Pennsylvania) that are representative of states with high graduation requirements. Four high schools were sampled in each state, including large urban high schools and rural, suburban medium-sized high schools. Each school selected was a grade 9-12 non-magnet or comprehensive high school in the bottom quartile of the state on standardized achievement data. A non-randomized sample was utilized to provide some degree of representativeness with access to student transcripts. Once selected, a random sample of approximately 25 transcripts of graduated seniors was collected from each high school at three points in time, two before and one after the implementation of new state graduation requirements. Typical cohorts graduated in 
1982, 1985, 1987, and 1988. All students were selected from a pool of students that maintained attendance in the same school throughout their high school career.

Courses were coded according to level of difficulty using the Secondary Schools Taxonomy (SST) developed by Brown, Gifford, Hoachlander, Meyer, and Tuma (1989), as cited in Clune and White (1992). The SST codes courses in academic subjects by level of difficulty using a hierarchical format of basic or remedial, middle, and advanced. Data were presented showing the percentage of enrollment in each academic area. The mean credits and mean credit change for each comparison group with p-values were presented, indicating the level of significance of the mean credit change in each academic and nonacademic area. Data were analyzed using multiple analysis of variance; no $F$ statistics were given. Data was presented using $p$-values only.

The findings from the study are presented in the form of nine conclusions from the data indicating moderate success in enrolling lower achieving students in academic courses. Average credits per student increased in all academic subjects (10\% increase in academic course load), as did the level of difficulty of these courses. Biggest gains were seen in science with beginning academic courses $(51 \%$ change, $p=.95$ ). In math, basic or remedial courses such as general math lost credits while gains occurred in middle and advanced level courses (13\% change, $p=$ .37). Major gains in English were seen at the advanced level (5\% change, $p=.20$ ). While graduates of lower achieving urban high schools did not reach the state average in college preparatory enrollment, the amount of additional course taking in such schools was meaningful — almost a half year of additional academic credits in 
foreign language, and a third of a year in math. The level of difficulty in these courses also increased, in most cases from the basic level to the middle or advanced level.

A major limitation of this study is the unrepresentative sample due to the difficulties in collecting data via transcripts. It does serve, however, as a useful aide to policy makers faced with decisions about increasing graduation requirements for students in schools that are traditionally low achieving.

Additional evidence of the power of the academic curriculum as a predictor of student success after high school, despite barriers such as race, gender, and poverty, are presented in a series of studies from the reform era of the 1980s. Alexander, Riordian, Fennessey, and Pallas (1982) studied the completion of baccalaureate degrees according to two categories of individual characteristics: social background factors, and academic factors. The authors addresses two primary objectives: (a) to describe how bachelor's degree prospects are limited by race, gender, and family socio-economic status; and (b) to consider whether differences in academic qualifications might account for differences in college completion rates for student groups defined by these traits.

The sample $(N=3,120)$ included the National Longitudinal Study (NLS) Class of 1972 employing a two-stage probability sample, with schools at the first stage of sampling and students at the second stage. The base-year questionnaire and test battery were administered in 1972 to over 16,000 seniors at over 1,000 public and private high schools. To obtain an adequate minority student rate, schools 
located in low income areas or those with high proportions of minority enrollment were sampled at approximately twice the normal rate.

Data were analyzed using logistic regression with probabilities presented using a $G^{*}$-values and DeMouchel's $R^{2}$ analog (1976) as cited in Alexander et al (1982). The $G^{*}$ - statistic's absolute value is not of great interest and will not be presented here, but for alternative sets of predictors the $G^{*}$ indicates a goodness of fit. Smaller $G^{*}$ 's imply better and more efficient prediction. DeMouchel's $R^{2}$, which is presented in this review, is constructed so that a value of zero implies perfect prediction. All measures were obtained from student questionnaires, school records, or the test battery. The major independent variables measured included: socio-economic status based on family income, the father's education-level, occupation, race, sex, track placement of college prep or non-college prep, and class rank. Bachelor's degree attainment served as the dependent variable.

Results indicate essentially no difference in rates of degree completion because of gender, modest differentials between Blacks and Whites (with Blacks generally having higher completion rates), and substantial differences based on socio-economic status (SES). The academic characteristics are by far the strongest predictors of degree completion $\left(R^{2}=.072\right)$. Moreover, when academic characteristics are included in the analysis, the effect of SES is somewhat reduced. In fact, when the academic variables were included into the logistic regression model the $G^{*}$ statistic shrank to almost a fourth variance associated with these variables more than tripled $\left(R^{2}=.075 ; R^{2}=.235\right)$. The probability of completing college improves substantially as one advances up the academic scale — - holding true 
for everyone: Blacks and Whites, males and females, and students from all SES levels.

The Alexander, Riordian, Fennessey, and Pallas (1982) study focused on the complex interplay between academic and nonacademic factors as predictors for student success in college, it illuminates the importance of the academic factors as relevant to college completion compared to their social background characteristics.

Studying attendance in higher education is far different than degree attainment. Adelman (1999) studied the variables that contribute to bachelor's degree attainment using National Center for Education Statistics (NCES) High School and Beyond longitudinal data that followed students from the time they were in $10^{\text {th }}$ grade until the age of $30(N=10,470)$. All available data of students who attained a bachelor's degree from the NCES data base were analyzed. He explored the question of what variable contributes most to bachelor's degree attainment. Adelman uses a series of linear Ordinary Least Squares regressions to explain how much variance in bachelor's degree attainment can be attributed to different background characteristics, achievement, and experiences when all other variables are held constant. A five-step logistic regression underscored the principal findings from 11 independent variables with bachelor's degree attainment as the dependent variable.

The findings indicated that high school curriculum reflected $41 \%$ of the academic resources students bring to higher education. The correlation of curriculum with bachelor's degree attainment is also higher $\left(R^{2}=.54\right)$ than test scores $\left(R^{2}=.48\right)$ or class rank/GPA $\left(R^{2}=.44\right)$. The impact of a high school 
curriculum of high academic intensity and quality on degree attainment is far more pronounced for African American and Latino students than any other pre-college indicator. This impact also produces a much steeper curve toward degree attainment than does socioeconomic status. Students from the lowest two SES quintiles who also were in the highest curricular intensity levels earned bachelor's degrees at a higher rate than a majority of students from the top SES quintile. Of all pre-college curricula, the highest level of mathematics studied in secondary school had the strongest continuing influence on bachelor's degree attainment. Last, college level courses such as Advanced Placement are more strongly correlated with bachelor's degree attainment than it is with college access.

In a similar study, Horn, Kojaku, and Carroll (2001) examined the relationship between high school academic curricula and student persistence path through college, approximately three years after enrolling. The high school academic curriculum measure identifies three levels of course-taking: below, midlevel, and rigorous based on the core "New Basics." The highest threshold (rigorous curriculum) included the core and three years of foreign language, four years of math (including pre-calculus or higher), three years of science (including biology, chemistry, and physics) and at least one Advanced Placement class. The mid-level covers curricula between the core and the highest level, including a minimum of algebra I, geometry, and one year of foreign language, and two courses from either biology, chemistry, and physics.

The study examined these patterns for a cohort of students $(N=10,300)$ who first enrolled in a four-year college in 1995-96 and who followed up three years later 
in 1998 and participated in the beginning postsecondary students longitudinal study (BPS). The researchers used covariance adjustments based on simple linear regression models analyzing two dependent variables (a) continuous enrollment at the initial institution, and (b) staying on track to a bachelor's degree. Independent variables reflect student academic experiences in high school, demographic characteristics, socioeconomic characteristics, and the economic status of their high schools.

The findings indicate a consistent advantage experienced by students who completed a rigorous high school curricula $\left(R^{2}=.792, p<.05\right)$, and to a lesser extent by those completing mid-level curricula over their peers completing core curricula or lower $\left(R^{2}=.621, p<.05\right)$. The level of high school curricula was also related to family background characteristics and indicators of socioeconomic status, including family income $\left(R^{2}=.518, p<.05\right)$, parents' education level $\left(R^{2}=.512, p<.05\right)$, race/ethnicity $\left(R^{2}=.502, p<.05\right.$, Blacks), and the economic status of their high school's student body $\left(R^{2}=.582, p<.05\right)$. All of these factors relate to whether or not students have the opportunities to participate in and complete a rigorous curriculum. Moreover, a students' success in staying in college was also related to where they first enrolled and how well they did in their first year $\left(R^{2}=.698, p<.05\right.$, public institutions; $R^{2}=.717, p<.05$, private institutions). Yet, even when all of these factors were taken into consideration, the advantage of completing a rigorous high school curriculum remained. Perhaps most notable in the study, is the apparent benefit of a strong high school academic curriculum for transfer students. For these 
students, as their level of academic curriculum increased, so did their likelihood of staying on track to a bachelor's degree.

The results from various studies suggest that completing a rigorous academic curriculum in high school may help students over come socio-economic disadvantages such as low family income and parents with no college experience, as well as helping those who get a poor start in college and decide to transfer. These findings have implications for the need for substantial change in the curriculum most students are exposed to during the last two years of high school and the role colleges can play in creating both rigor and efficiency.

Senior Year of High School

Many issues of rigor and efficiency rest squarely with the senior year of high school. Alexander and Pallas (1984) studied the effects of the "New Basics" curriculum proposed by the National Commission on Excellence in Education in $A$ Nation at Risk (1983), especially as related to the senior year of high school. Their study addressed two main issues: to determine the popularity of the "New Basics" curriculum among the students in the sample, and to determine the benefit that might be realized through this curriculum for student outcomes as measured by the SAT.

The quasi-experimental design used data from the Educational Testing Service's Study of Academic Prediction and Growth from 1961 to 1969, which tested students from 17 communities in the United States. Communities selected were dispersed geographically, including small and large school systems, and differed greatly in the proportion of high school graduates continuing into college. The study entailed semi-annual administrations of a survey and test in grades 5, 7, 9, 
11 , and 12 creating a set of longitudinal data that also subsequently included their SAT scores. The Educational Testing Service (ETS) also obtained high school transcripts for the 1969 senior class in most of the communities. These data enabled the researchers to examine the "New Basics" curriculum "after the fact." The analysis was drawn from a convenience sample $(N=6,000)$ limited to students for whom transcript data were available from 15 of the 17 communities. In attempting to approximate the "New Basics" curriculum, the authors relied heavily on Adelman's (1983 \& 1999) analysis of over 1,000 course titles distinguished in the Growth Study transcript data and collapsed into 131 mutually exclusive course categories.

The primary independent variable was the course taking of the students. The researchers, however, controlled for such variables as gender, race, SES, and high school GPA. Data were analyzed using various logistic regression and stepwise regression models. Most models used test scores such as SAT, PSAT, the School College Ability Test (SCAT), and other tests administered as part of the Growth Study research as dependent variables. To promote the reliability of the sample used in the study, Alexander and Pallas compared student course taking in the sample to the results of the more recently collected HSB data from 1980 graduates. The sample using Growth Study data compared favorably with those from the HSB sample. While no correlation statistic was given, $19.5 \%$ of the Growth Study data took the equivalent of the "New Basics" compared to $13.5 \%$ from the HSB sample. Additionally, they call attention to a trend in SAT score decline from the 1970s to 
1980. Despite this, the authors cite the sample used from the mid-to-late sixties as a limitation of the study.

In general terms, the findings indicate that completion of the core curriculum had sizable effects on senior year test performance, even when prior levels of test performance were controlled. More specifically, regression coefficients indicate that students who complete the foreign language requirement average about 14 points better on the SAT-Verbal than those who do not. The "New Basics" overall create an advantage on the verbal subtest of about 14 points $\left(R^{2}=.688\right.$ vs. .690$)$, a significant part of the 37-point SAT-V decline from 1967 to $1977 . \quad$ The SATMathematics subtest results indicate a 40-point gain for students that took at least three years of math, and three years of science contributes another 22 points $\left(R^{2}=\right.$ .625 vs. .654). These gains would recoup the difference lost in the SAT-M score decline the previous decade. Results also indicate that the core curriculum is most effective for students that perform at relatively high levels in their courses. In controlling for GPA through interaction effects, the researchers found that at relatively low GPA levels, it mattered little whether a student completed core requirements. The core is most useful for students that actually master the core curriculum compared to those that are merely "getting by" in the "New Basic" curriculum.

Perhaps the most noteworthy result from the Alexander and Pallas study as it pertains to the senior year of high school is the analysis of the value added by completing the core curriculum during the last year of high school. The results are quite clear in that the last year matters a great deal. In fact, in several instances most 
of the value of the "New Basics" appears to come from completing the sequence's final year. Results from the SAT-M are the most telling. Students who have completed math and science programs through the $11^{\text {th }}$ grade score about 23-points better than students that fall short of the standard (two credits). Completing the final year of the math contributes about 40 points to the SAT-M while the final year of science contributes another 29 points. While not as dramatic, the results on the SAT-V display a similar pattern.

In addition to the value of the curriculum in the "New Basics," a major implication of this study is the importance of the curriculum in the senior year. Just under half of students complete all of the academic study required of them during by the end of the junior year; thus, most are eligible to complete this curriculum during the senior year of high school. The striking statistic is that less than $20 \%$ complete the curriculum after grade 12. The evidence supports the value of the "New Basic" curriculum; therefore, the senior year becomes the prime target for reform. This research indicates that partial completion of the core is not almost as good as full completion of the core. There is evidence to address the time-honored "senior slump."

The overall body of Alexander's and Adelman's research gained prominence more recently in addressing the "senior slump" through the work of the National Commission on the Senior Year of High School, a group assembled by Secretary of Education Richard Riley in 2000 and chaired by Kentucky Governor Paul Patton. The concept of weaving the secondary and postsecondary curriculum together and the advocacy of programs such as dual credit/ enrollment and middle colleges 
received great attention in the two reports released by the commission in 2001. The commissions' first report, The Lost Opportunity of the Senior Year (2001) was prepared in conjunction with the Education Trust and almost served as a report card on the progress of high schools since A Nation at Risk (1983) and the Carnegie studies of high schools and higher education in the 1980s. High schools did not receive high marks for their progress, according to the report. Many students face severe limitations on their opportunities after graduation due to the prevalence of the general track in most comprehensive high schools. High schools also suffer from the same tyranny of low expectations that plagued them decades earlier. The report emphasized various factors that were critical to the success of students in high schools, such as the level of curriculum, size of the school, quality of the teacher, and the expectations placed on the student by the school (Conley, 2001).

The second report, No Senior Left Behind (2001), called for a series of recommendations to remedy the senior year problem. The triple "A" program of articulation, achievement, and alternatives calls for many reforms found in the blending of secondary and postsecondary curriculum and middle college concept. Dual credit programs can offer a double incentive of providing a powerful academic curriculum while making the senior year more substantial.

England (2001) examined the educational experience of students in their high school years and how this experience shapes their ability to be successful after high school. The study consists of a review of research on high school students' educational experiences and leads to the conclusion that the skills and knowledge needed by high school graduates who enter the workforce are the same as those 
needed by graduates who go directly to college. The evidence suggests that virtually all students waste at least one year as they move from grades 11 through 13, leading to the need for better collaboration between high schools and colleges.

Based on the literature reviewed, England listed a set of policy issues needing to be addressed in order to create an better system of P-16 education. The following is a summary of key issues: (a) High schools and colleges must collaborate and produce clear statements about where high school ends and college begins. (b) Once high school graduation and college entrance standards are met, curricula should be aligned with these standards. (c) Middle school exit standards and curricula must also be created.

(d) Students should develop a school completion plan before entering ninth grade.

(e) To combat senioritis, students should be offered education options that are appropriate to their level of attainment as soon as they have demonstrated the skills necessary to graduate from high school. (f) Dual credit programs are a good interim way to meet the needs of a segment of high school students.

The research on the senior year of high school provides an affirmation of the need to reinvent the structure of secondary education. The senior year should serve as a launching pad rather than a weigh station for integration and increased student achievement by forging greater P-16 connections. Dual credit courses provide a viable method for an enhanced senior year with increased secondary and postsecondary integration. In the last two decades, increasing emphasis has been placed on the integration of career and technical education with a strong academic curriculum as a way of enhancing the high school experience. Studies of the senior 
year dilemma have emphasized the need for relevance in addition to rigor in the curriculum - career and technical education can provide an enhancement of curricular relevance for all students.

\section{Career and Technical Study for High School Students}

A major criticism of high school curriculum levied by reform advocates emphasize the large number of students taking a general curriculum that is not rigorous enough academically to prepare students for college. The general track is also not preparing those unprepared for college to enter a career by equipping students with technical skills or a trade. Subsequently a major strand of dual credit has been the utilization of dual credit in career, occupational, and technical coursework targeting students in the general track. In state sponsored dual credit programs such as Minnesota and Washington anywhere nearly a fourth of all students in the programs are taking courses in technical, trade, or occupational programs usually at comprehensive community colleges or technical colleges.

Since the mid-1980s, a series of reports and commissions pointed to the need of revamping the existing vocational and workforce preparation system to meet the needs of students that normally did not prepare to attend college. Reports such as Workforce 2000 (1987), The Forgotten Half(1988), the National Assessment of Vocational Education (1994), and Grubb (1996) stimulated a wave of thought regarding the goals and mission of public education, and the centrality of postsecondary education for workforce development. This accumulated attention lead to several public policy solutions, specifically Tech Prep of the Carl D. Perkins 
Vocational and Applied Technology Education Act, the School-to-Work

Opportunities Act, Goals 2000: Education America Act.

In a study of America's workforce needs by the year 2000, Johnson and Packer (1987) emphasized the shift in the U.S. economy from manufacturing to service industries, the pressures of the global economy, and the impact of technology on the workplace. They were among the first to articulate the need for more highly skilled workers and how the rapidity and uncertainty of change and its effects on the economy would necessitate "constant learning and constant adaptation by workers" (p. 37).

Among Johnson and Packer's recommendations for improved economic competitiveness, was to strengthen education and skills of all workers, stating that, "human capital—knowledge, skills, organization, and leadership —is the key to economic growth and competitiveness" (p. 106). They translated this recommendation into higher educational standards at the K-12 level and doing away with academically limited vocational educational programs.

While Johnson and Packer said little about postsecondary education, Grubb (1996) added to this analysis by identifying the sub-baccalaureate labor market as one that would be most affected by the influence of technology and up-skilling of work. This sector represents a wide variety of mid-skilled occupations including the largest portion of technicians, whose jobs are being upgraded through technology and require some college, including a two-year associate degree, but not necessarily a four-year degree. Grubb projected that this labor market would continue to grow, since it includes occupations with the highest growth rates. "Even 
if occupational forecasting is risky business, the educational level of the labor force is almost certain to continue increasing; much of the growth will take place at the sub-baccalaureate level" (p. 6).

This transformation has significant implications for the future of community colleges. Hamilton (1990) connected this transformation to the inadequate preparation many non-college-bound students receive in high school. Hamilton in particular identified roughly half of all high school students in this category. The post-high school consequences of which lead many students to wander between different educational and employment experiences - many of which are also equally unprepared for the workplace.

The public vocational education system has been widely criticized for its poor quality and significant weaknesses, especially in academic content and lack of challenging courses. The National Assessment of Vocational Education (1994) found a lack of coherence and sequential course concentrations in many vocational programs. In addition, public vocational educational programs became a dumping ground for problem students and students with special needs, stigmatizing it as an educational option for other students. In contrast, the study found that publiclyfunded postsecondary vocational programs, primarily provided through community colleges, were found to be more effective in providing students with a coherent training experience. These programs were far more likely to have an integrated curriculum. The economic outcomes were far better for postsecondary vocational education students, particularly if they attended community colleges. 
In recommending vocational education reform, the study proposed more advanced industry-based technical training and encouraged more integrated K-12 and postsecondary education experiences by preparing "participating students, as much as possible, for some form of postsecondary education, including both twoyear institutions and four-year colleges and universities" (p. 16).

In a literature review pertaining to occupational training in high school, Bishop (1989) addressed seven primary questions. (a) How large are the economic benefits of occupationally specific training? (b) To what extent are the occupationally specific skills being used? (c) Why are these skills not being used on a job? (d) Does vocational education generate non-economic benefits? (e) Does vocational education lower dropout rates? (f) Can basic skills substitute for occupational skills, and (g) Have high rates of skill obsolescence drastically lowered the payoff to occupationally specific training?

The research reviewed by Bishop clearly implies that occupationally specific education has a very positive impact on labor market success when training related jobs are obtained. If jobs are not related to training, high school graduates receive no economic or non-economic benefits from their vocational education. Unfortunately, less than half of the graduates of these programs get training related jobs. In many cases very little emphasis is put on placement of students in these jobs upon the completion of the program, and in most cases employers are not sufficiently involved in this training process. The research indicates no increase or decrease in the non-economic benefits of such training relative to a general curriculum. 
The research does point to a six percent decrease in dropout rates as a result of taking one vocational course per year. Studies reviewed by Bishop also do not point to an advantage of basic skills in substitution for occupational skills; jobs require a mix of both basic and occupational skills. There were no indications that skill obsolescence drastically lowered the payoff of occupational skill training. The research suggested that obsolescence is less important than the risk of not using and forgetting skills.

Bishop concludes his analysis with a discussion of the policy implications in the research for occupational studies at the high school level. Bishop favors a policy to increase the proportion of high school graduates who use occupational skills by evaluating such programs on the basis of the number of graduates who get a job or continue their education in the field. Employers should become more involved in delivering occupational training while teachers should no longer be the sole instructors for occupation specific skills. Funding for such systems should be performance based.

Recent strategies in vocational education have focused on making vocational courses more academic. An example, in a study by Bottoms and Mikos (1996) of 15 high schools that are part of the Southern Regional Education Board's (SREB) High Schools That Work (HSTW) model which emphasizes the integration of academic and vocational curricula, students' academic performance was tracked over three years. Test data from the HSTW NAEP-like assessment was administered to seniors in all 15 schools for each of the three years of the study. Data were analyzed using ANOVA and presented mainly using descriptive statistics. The test data was also 
triangulated using data from annual site-visits in which a team conducted interviews and surveys with students, teachers, and administrators.

The SREB researchers observed that skills in reading, mathematics, and science as measured by a NAEP-like assessment substantially improved in seven of the 15 schools. Using data from the HSTW assessment, site-visits, and student and teacher surveys, the researchers found that the seven schools where achievement improved most dramatically had expanded their efforts to integrate academic and vocational education, something more common place in college career and vocational education than in high school programs.

The brief review of research pertaining to career, occupational, and technical studies for high school students illustrates the important role a comprehensive community college through programs like dual credit can play in the connecting occupational and academic study. Such collaboration has been a major aspect of the Tech Prep program since its creation in the mid-1980s.

\section{High School and College Collaboration through Tech Prep}

Perhaps Parnell made the greatest strides toward an integrated secondary/ postsecondary curriculum in his landmark work The Neglected Majority (1985). Parnell originated the concept of the $2+2$ associate degree that connects the last two years of secondary education with the first two-year of postsecondary study. This model evolved out of the dilemma of imposing baccalaureate degree standards on all students while $75 \%$ of students do not complete a bachelor's degree. Parnell referred to this $75 \%$ of students as the "neglected majority." Far from advocating lower standards for this group, Parnell, and later co-author Hull (1991), believed the 
answer was in collaboration and partnership between the high school and the community college to improve the education and performance of ordinary students. Such collaboration according to Parnell was the only way to assure quality and equality in educating the masses.

Parnell criticized the "bifurcated view of high school" that created a sorting system of academic and non-academic students into tracks. Students that did not fit into either the academic or vocational track were forced into an unfocused general track that led to nowhere. The percentage of students seeking a diploma in the general track increased to nearly half of all graduates by 1980 , while the percentage of students in the academic and vocational tracks declined by about eight to ten percent. Parnell was an early advocate of the integration of the liberal, practical and fine arts due to the demands of the information age requiring a higher standard of education and increased emphasis on life-long learning.

Parnell and Hull (1991) launched the nationwide effort tech prep, overshadowed at the time by A Nation At Risk with its ascent on traditional academics, tech prep did not draw attention until the federal Carl D. Perkins Vocational and Applied Technology Act Amendments of 1990 (commonly called Perkins II) which authorized the Tech Prep Education Act, targeting federal funding toward the implementation of 2+2 programs. Soon after, in 1994, the School-toWork Opportunities Act was passed, reinforcing the tech-prep model and advancing the notion of secondary-to-postsecondary articulation as part of a more broadly reformed educational system for all students (Hull). 
Among a multitude of goals, Tech Prep was intended to establish formal articulation agreements identifying rigorous academic and technical programs of study having a logical progression from secondary to postsecondary. In many cases these articulation agreements lead to dual credit for high school students. Such a pathway was a key in Parnell's ideas to eliminate the general track in favor of two parallel and more equal pathways through high school. A traditional academic pathway for four-year college students and an equally rigorous Tech Prep pathway for career and community college bound students. Only recently have Tech Prep programs that started in the early 1990s reached a point where high school participants have graduated from high school and made the transition to college or work.

Bragg and Layton (1995) studied the implementation of Tech Prep initiatives and the goals, philosophies, policies, and practices associated with such implementation. A survey design was used for this research. It included the use of a telephone survey in the fall of 1991 and again in 1992. Survey findings were supplemented with analysis of print materials such as legislation, and policy guidelines. In some cases data were collected with a mailed version of the survey. The sample included the total population of state-level Tech Prep coordinators from all 50 states and the District of Columbia. Responses were received from all 50 states, including $70 \%$ from coordinators that held the position during the time of both surveys.

The survey instrument included both open- and closed-ended questions, with 1992 survey including more follow-up oriented closed-ended questions. In both 
years, a pilot test of the instrument was conducted prior to implementation. The telephone interviews were 30 to 60 minutes in length. Analysis of data involved using descriptive statistics and conducting a content analysis of qualitative survey responses and supporting documents. The researchers gave no further description of the content analysis.

The data collected from the surveys and from all available documents provided information on funding patterns, implementation activities, state and local administrative structures, Tech Prep policies and goals, and barriers to local implementation. The research suggests that the definition of Tech Prep is changing as practitioners build upon the skeletal federal program and make it their own. With regard to the benefit and value of the program, the findings indicate that with nearly 900 local consortia working to implement Tech Prep, it appears that roughly $75 \%$ of the country's public two-year colleges are involved. The data also show the need for states to play a more active role in Tech Prep implementation to insure its long-term effectiveness.

Findings suggest that the Tech Prep programs around the country are still evolving have not reached a final form, most practitioners indicate that the greatest impediment of the program is its lack of clear identity. With regard to the benefits and value of the program, it appears that roughly $75 \%$ of the country's public twoyear colleges are involved, many of which are providing leadership to their consortia. However, if Tech Prep is to succeed in the long run two-year colleges must do much more. 
Farmer and Honeycutt (1999) found similar results in a study that examined the status of Tech Prep in the North Carolina Community College System. The researchers addressed four questions in comparing attitudes of senior administrators, faculty, and staff toward Tech Prep programs and links to secondary schools.

Four research questions that are critical to the success of Tech Prep were addressed in the research. The questions were (a) to what extent are the 58 community colleges in North Carolina engaged in Tech Prep programs? (b) How many of the colleges have been actively involved in Tech Prep programs for four or more years? (c) To what extent do senior administrators, faculty, and administrative support staff differ in their opinions of Tech Prep, and (d) What are the differences in opinions of Tech Prep among community college presidents, faculty, and administrative staff on issues such as recruiting better-prepared students, retention, and graduation rates?

A two-way analysis of variance was utilized to examine the relationship among their opinions. A quasi-experimental design using survey research was employed using a Likert scale mailed to a sample of community college presidents and senior administrators, faculty, and administrative support staff $(n=274)$ in the North Carolina Community College System using a table of random numbers to choose the participants. Four subject matter experts for purposes of evaluating content validity examined the survey, revisions were made and a pilot survey was administered to two community colleges. Data analysis was conducted on the opinions of the three groups (presidents, $n=35$; faculty, $n=145$; and administrative 
support staff, $n=41$ ) and is presented in tabular form with means and standard deviations.

The findings are presented for each research question as follows: (a) As for the prevalence of Tech Prep, 94\% of presidents indicated that their colleges have been active in Tech Prep, (b) only 15\% indicated involvement or more than four years, (c) a statistically significant $(p<.05)$ difference was found among what the three groups think about the influence of Tech Prep at their college, and (d) data analysis was conducted on the opinions of the three groups. Results indicate that senior administrators, faculty, and administrative support staff had different opinions of the influence of Tech Prep at their colleges.

While many of the community colleges indicated that they were forming partnerships to collaborate with business and articulating with secondary schools, in most cases Tech Prep has not made a substantial change with the faculty or staff within community colleges. The researchers listed a limitation in that most Tech Prep programs did not start until 1992 and many community colleges, at the time of this research, had not graduated students from these programs.

Pucel and Sundre (1999) in a qualitative study of teachers and administrators in Minnesota Tech Prep consortia used ethnographic interviews to determine the extent to which articulated Tech Prep programs were being implemented and monitored to ensure that students receive benefits as they advance from high school to college. They addressed three research questions: (a) Whether those that develop and implement articulation agreements are knowledgeable about Tech Prep; (b) whether administrators and instructors who are responsible for implementing 
articulation agreements clearly understand the components and requirements of articulation agreements; and (c) whether and to what extent colleges actually implement their articulation agreements by modifying their curricula and providing the benefits to Tech Prep students.

A 33-item interview questionnaire was assembled, with questions developed with the aid of an advisory committee, which also reviewed Minnesota Tech Prep policies, and pertinent literature. This committee organized and provided expert validity analysis for each question and developed a sample process that included all major stakeholders in Minnesota Tech Prep. Interviews were conducted with a purposeful representative sample $(n=32)$ of members from eight consortia including Tech Prep coordinators and administrators from postsecondary and secondary institutions as well as those representing state agencies involved with Tech Prep. Interviews ranged from 60 to 90 minutes in length. Data were analyzed using inductive analysis. Transcripts were tabulated by group (administrator, instructor, and state coordinators). The responses for each group were compared using similarities and differences. Two different individuals reviewed each of the response summaries.

The findings indicate that (a) most administrators and instructors that develop articulation agreements understood the role of these agreements and linkages from secondary to postsecondary education. (b) Few administrators and instructors responsible for implementing these agreements understand the components and requirements of these agreements. (c) The data showed that few 
administrators and instructors involved with the program indicated modifications made to the curriculum as a result of their involvement with Tech Prep.

The results point to the fact that once Tech Prep programs had been established, little attention was paid to actual compliance and actually using the agreements for students to earn college credit through articulation. When asked if students more efficiently completed the postsecondary portions of Tech Prep programs because of having completed the postsecondary portion, only one of the 32 educators interviewed thought this to be the case. Consortia did not appear achieving the goals of Tech Prep articulation by ensuring that students were identified when entering postsecondary institutions and that adjustments were made in their college program of study based on what they did in high school.

In a case study of Virginia's statewide Tech Prep program, Cantor (1999) painted a different picture of Tech Prep outcomes. This case study approaches the Tech Prep movement from the community college perspective. This point of view is important, according to Cantor, in that much previous research on Tech Prep from the secondary school perspective has focused on the vocational aspects of the movement rather than the postsecondary associate degree initiatives that are possible through Tech Prep. The author provides few details of data collection and data analysis techniques. The lack of this descriptive detail is a limitation of the study.

The findings from Cantor's study of the Tech Prep emphasized the successful outcomes in programs across state community colleges, especially in creating associate degree technical programs across the state. The state Tech Prep charter and plan has fostered the following: (a) structured curriculum design and 
development; (b) closer liaisons with business and industry; (c) program development in high-demand, high-tech industries; (d) contextual learning opportunities for students; (e) closer positive relationships with secondary schools; and (f) an initiative that encourages workforce and economic development. Many of these mixed findings, as qualitative studies with small sample sizes, cannot be generalized to a larger population. They imply that Tech Prep alone is not providing the type of efficiency and productivity needed with the curriculum of secondary and postsecondary education. The success or failure of the Tech Prep movement has clear implications on the use of dual credit or concurrent enrollment as a rigorous secondary curriculum and closer partnerships between secondary and postsecondary institutions. Tech Prep has encouraged professional development and curricular articulation that has in some cases cleared a pathway to college that is more rigorous than the general education diploma. The research clearly shows, however, that the capacity of Tech Prep articulation and partnership to make secondary and postsecondary education more productive and efficient is only as good as the commitment from both secondary and postsecondary education in the local consortia and the state leadership. In many circumstances the successes of Tech Prep have created the $2+2$ structure to promote thriving dual credit programs. The failures of Tech Prep, on the other hand, necessitated that colleges and secondary schools go a step beyond articulation by dually enrolling students to ensure the goals of $2+2$ can be met.

The research reviewed here clearly shows the value of a P-16 approach to advocating a more rigorous high school experience for all students—not just the 
academically oriented. The next section will provide a detailed examination of the outcomes associated with dual credit programs in providing a challenging alternative to high school for a wide variety of students.

\section{Dual Credit Models and Outcomes}

Dual credit programs come in all shapes and sizes and research is just recently paying attention to student outcomes in various delivery formats. The Education Commission of the States (2001) analyzed the types of dual credit across the 50 states, and Puyear (2001) analyzed various delivery options for dual credit in Arizona. While diverse across all 50 states, the most common forms found in both studies were the following: programs taught as an enhancement of a regular high school course with students desiring college credit doing additional work; high school teachers, generally recognized as an adjunct faculty member, teaching a college course to high school students on the secondary school campus during the regular school day; a college course taught at the high school during the school day using a college instructor; a college course taught at another location, often a college campus, by a college instructor in a class of only high school students or in a class with a mix of high school and postsecondary students; and a college course linked via interactive television from a college instructor on either a college or high school campus to other high school students at other locations.

While these are the most common models of delivery of dual credit programs, many serve a multitude of purposes from accelerating students that are classified as gifted and talented to motivating students that are at-risk of graduating. 
Research from various models and student outcomes are discussed in subsequent parts of this section. We will first explore models that are intended to provide acceleration to typically to gifted students by replacing high school completely with an early college entrance model. The next programs reviewed are those utilizing high school teachers delivering college instruction on high school campuses. The final subsections review studies on the perceptions and outcomes of dual credit students and the outcomes of students in state sponsored programs.

\section{Early College Acceleration Models}

Perhaps the most common form of dual credit program is one intended to provide acceleration to students that are capable of doing college-level work while in high school. Kulik and Kulik (1984) completed a meta-analysis on the effects of accelerated instruction on elementary and secondary school students. Data for this study came from 26 controlled studies. Each of the studies reported results on student achievement, as measured by standardized examinations administered to students in accelerated and non-accelerated classes. For the purpose of the metaanalysis, acceleration is defined as grade skipping, curriculum compression for talented students, and extending the calendar to speed up progress of such students. Nonacademic outcomes of accelerated instruction were not measured as frequently as academic outcomes. Self-report questionnaires were used to measure subject matter attitudes as well as character rating completed by classroom teachers. To quantify outcomes in each of these areas, the researchers used effect sizes $(E S)$, defined as the difference between the means of the two groups divided by the standard deviation of the control group. 
The search of literature yielded 21 reports that met the criteria for metaanalysis. These 21 reports contained results from 26 different studies, 13 of which used same-age control groups to measure effects of acceleration, and 13 studies used older control students. Findings from the analysis of the same-age control groups showed greater student achievement in the accelerated class. In nine of the studies achievement level of the accelerated class was significantly higher than the achievement level of the control group. Overall, the clear message is that acceleration contributes to student achievement, based on the effect sizes in the 13 studies $(E S=.88, S D=.66)$. It is statistically unlikely that an $E S$ of this size would be found by chance $(t(12)=4.63, p>.001)$.

Results from the studies with older control groups were much different. Five of the 13 studies with older control groups reported a higher level of student achievement in the accelerated class and in two of these studies the achievement level of the accelerated class was significantly higher that the non-accelerated class. The remaining eight studies reported higher levels of achievement in the nonaccelerated classes, two studies show the level of non-accelerated classes to be significantly higher. The $E S$ in the 13 studies was $.05(S D=.30)$, indicating a trivial difference in examination performance of accelerated students compared to nonaccelerated students.

While this study does not include all influential studies related to student acceleration and it fails to address, as much of the literature in general, the nonacademic facets of student adjustment of acceleration, overall it presents 
evidence that supports academic benefits to students for early college entrance programs.

Focusing specifically on early college entrance at the University of Washington's Early Entrance Program (EEP), Noble and Drummond (1992) conducted a qualitative ethnographic study of EEP, which enables bright and highly motivated students to bypass high school completely and matriculate through a Transition School program directly to the university. The study addressed the following research question: how do EEP students fare at the university?

The data collection included a structured interview of 13 open-ended questions developed by the researchers based on questions most frequently asked about the program. The questions were submitted to the EEP Transition School faculty and program staff and several students for review before finalizing the instrument. A sample $(N=24)$ consisting of slightly more than half of those that has completed the Transition School and was currently enrolled in undergraduate coursework. Participants ranged in age from 14 to 21 and included members of every academic class as well as a broad spectrum of the academic disciplines. Data were collected and analyzed for content and frequency using inductive analysis. Frequencies represent the number of students who cited similar experiences within the framework of each question.

Findings revealed that all participants were unanimous in their satisfaction of the choice to forgo high school to participate in EEP. Several students decided to enter the program because they were bored and unhappy in junior high school, calling it an "academic dead end." 
A slim majority of students said their parents had been initially afraid that the program experience would harm their children academically or socially. Although a few of the students' parents were excited about the program, they were apprehensive - not wanting their children to regret the decision to attend the program just on their account. Slightly over half of the students enrolled in EEP because they wanted a challenge and the opportunity to accelerate their education. Four students used EEP to prove they were actually intelligent. One-quarter of the students were enticed by the opportunity to skip several years of school.

All students discussed how much they matured intellectually, emotionally, and socially during their year in the Transition School, "becoming less likely to conform without questioning, more individualistic, and more academically aggressive" (p. 108). Fourteen students said they learned time management skills and new way to organize, analyze, and express ideas so others could better understand them. One student "hated the experience because she could no longer procrastinate; she chose to stay in the program because it was 'better than high school' because of teacher encouragement" (p. 108). Ten students said they would not know how to work as hard and would have been less academically oriented, three said they would not have been as academically prepared for college, three others indicated that they would not be as mature or as aware of the world around them.

Noble and Drummond questioned why high school was widely perceived to be a necessary and normalizing experience. The results indicate that for EEP students it is not necessarily the best path. While there are limitations in making 
generalizations from qualitative studies with small sample sizes, the comments of these students illuminate several critical issues about the efficiency such a system created for them.

Janos, Robinson, and Lunneborg (1989) completed a multi-year comparative study of student academic performance and psychological adjustment in early college entrance programs, also using the EEP program. The study compared the academic transcripts and psychological questionnaire responses of a very young college group with data from three groups of students varying in age, ability, and academic placement (high school or college).

The study used a sample of 20 males and 23 females no older than 14-yearsold enrolled in the University of Washington EEP. The sample represented an $84 \%$ response rate of the students in EEP. The study developed three additional samples for comparison. The first comparison sample (QUAL) consisted of students around the same age that qualified for entrance to EEP, but chose to attend high school instead ( $n=44$, representing an $84 \%$ response rate). The second group (REG) consisted of regular-age University of Washington students and matched with the EEP students ( $n=43$, representing a 37\% response rate). The last group (NAT) consisted of regular-age college students that were National Merit Finalists and of a high academic caliber and matched to EEP students $(n=42$, representing a $60 \%$ response rate).

The study used high school/ college placement based on the samples listed above as the independent variables. Dependent variables included student intellectual ability, academic achievement, and psychological adjustment. Measures 
included a test battery of verbal and intellectual ability, Survey of Study Habits and Attitudes (SSHA), the California Personality Inventory (CPI), the Tennessee SelfConcept Scale (TSCS), the Inventory of Parent and Peer Attachment (IPPA), and the Defining Issues Test (DTI). Data were analyzed using analysis of variance (ANOVA), multiple analysis of co-variance (MANCOVA), multiple analysis of variance (MANOVA), and T-tests in the case of the EEP and REG comparisons with Dunn's procedure utilized for post-hoc comparisons.

The findings for intellectual and academic achievement variables indicate that the EEP group appeared to be better qualified than typical college-age students $(p<.001)$. The NAT group outscored both the EEP and QUAL samples $(p<.05)$. No significant differences among the groups were obtained on the SSHA scales, indicating that EEP students' attitudes toward study and knowledge about study were comparable those of the other students, including the academically oriented NAT group. EEP students earned a mean cumulative GPA comparable to the NAT group and higher than the REG students $(p<.001)$.

The findings for psycho-social variables included comparable scores on the TSCS, which characterizes normal and healthy adjustment. As observed with the cognitive measures, NAT, notably females, scored higher than all other groups on the CPI. IPPA scores also gave no evidence of EEP students being more alienated from parents or peers than any of the other groups. Attachment patterns such as these have been related positively to psychological well being, particularly in self esteem, overall satisfaction and the ability to cope with stress. The DIT scores rose after the second test administration (after the freshman year), but none of the groups 
changed more than the others. The EEP students scored comparably to NAT and REG students in that they were developmentally ready for college.

The Janos, et al study depicted patterns of success for youngsters that entered college markedly earlier that their counterparts in overall ability test scores, college grades. Janos, et al found no association between early entrance and psychological or social impairment. In every comparison, the early entrants were virtually indistinguishable from comparably bright peers that opted instead to attend high school.

One other such model of weaving together the high school and college curriculum for accelerated students can be found in Bard Early College High School and Simon's Rock Early College. These programs advocate a total rethinking of the concept of high school. Founded by Leon Botstein, the president of Bard College in New York and a staunch critic of high schools, both institutions allow students to enroll after the $10^{\text {th }}$ grade of high school. Students graduate in two years with an associate degree, not a high school diploma. Botstein, whose interest in school reform stemed from his involvement with the Paidiea Group in the 1980s, believed that high school curriculum should be changed to allow students to enter colleges after grade 10. The present institution holds students in captivity and delays their life unreasonably without fostering the intellect or advance student maturity (Botstein, 1999).

Goldberger (1980) studied the developmental needs of the early college students at Simon's Rock. Goldberger utilized much of the research done since the inception of Simon's Rock in 1972. The college has been engaged in a longitudinal 
study of incoming students to discover factors that underlie academic and social adjustment and successful performance at an early entry college. The study addressed six broad areas (a) intellectual characteristics, (b) academic performance, (c) attitudes, (d) self-concept, (e) ego, and (f) ethical development.

Goldberger analyzed data collected by the college in the form of interviews, and longitudinal assessments of student development using the GED test, CLEP exams, and Loevinger's measure of ego development. The findings were given ancetodally, without using data.

The findings indicate that early college students at Simon's Rock show: (a) Verbal and quantitative ability average for college freshmen, (b) well above average scores on tests of high school equivalency (GED), (c) critical thinking, the best predictor of college grade point average, was above that of average college freshman, (d) sophomores are above average compared with other college sophomores on academic achievement on liberal arts CLEP exams, and (e) on Loevinger's measure of ego development Simon's Rock students were less advanced than 18-year-old freshmen in terms of the proportion of students in the highest developmental stages. They were more advanced than the average 16-yearold and are comparable to students in selective prep schools.

These findings are consistent with other early college studies, affirming student academic and developmental success in well-organized early college programs. The early college concept is a rising trend in liberal arts college, community college and secondary school reforms around the country. Part of the interest in the early college has been precipitated by the attention paid to this model 
by the National Commission on the High School Senior Year and the monetary support provided by powerful education advocates such as the Carneige Foundation and the Bill and Melinda Gates Foundation. It is emerging as a prominent model of school-college collaboration. A major unresolved issue in this research is the potential these programs can factor these programs can play for minority, disadvantages, and academically average student populations.

In sum, research generally favors programs that allow student acceleration, including opportunities for early enrollment in postsecondary education. Such acceleration takes many forms. The next part of this review deals with one of the most popular and successful forms dual credit, courses delivered on the high school campus, the subject of the next part of this review.

\section{School-based Models}

The most successful model of such a program documented in the research on dual credit is the Syracuse University Project Advance (SUPA) program. This program, established in 1973 as one of the first high school-to-college cooperative programs in the country, enrolls more than 30,000 high school seniors in Syracuse University freshman-level courses (Mercurio, Lambert, \& Oesterle, 1983). The courses are all taught on high school campuses using high school teachers that have been accepted by the college faculty based on their credentials. Several research studies conducted by Mercurio and others $(1980,1982, \& 1983)$ document the success of the program as a mechanism of student acceleration.

Mercurio, Lambert, and Oesterle (1983) compared student performance in Project Advance (SUPA) courses to students taking traditional Advanced Placement 
(AP) courses posing two research questions. First, based on their SUPA experience, how well do SUPA students fare on the AP Examination when compared to AP candidates who have participated in the AP Program? Second, what is the relationship between the Syracuse grade and the AP Examination grade?

The causal comparative research design compared the grades of dual credit students to their performance on AP exams as a validation for dual credit programs delivered by high school teachers. The researchers chose two Syracuse University courses offered through SUPA for comparison with courses tested by the AP Program - Biology and Chemistry. Both are freshman level courses with comparable content to the companion AP courses.

The sample used for the study included volunteers $(N=60)$ of SUPA students in biology willing to take the AP Examination. This sample represents 25 $\%$ of the total enrollment of 252 students that earned a final grade of at least a $\mathrm{C}$ in the SUPA course and representing 16 of the 17 high schools offering biology. In chemistry the sample $(n=35)$ represented $32 \%$ of the total enrollment of students earning a final grade of $\mathrm{C}$ in the SUPA course and representing nine of the 10 high schools offering chemistry. An average of four students from each high school took the AP Examination in both biology and chemistry.

Data were analyzed using descriptive statistics from the SUPA sample that took the AP Examination and the total population of candidates across the country that took the AP Examination. Course grades from SUPA courses were also compared to AP Examination grades descriptively. Since such a small sample size of SUPA students taking AP Examination $(n=92)$ were being compared to the total 
population of AP candidates from around the country $(N=9,858)$, the researchers also provided SAT score ranges of the two groups. The SAT score ranges of each group, presented descriptively, were similar.

The findings indicate that Project Advance students perform as well as or better than AP candidates. Overall, $88.4 \%$ of SUPA biology students earned a grade of at least a three on a five-point AP Examination scale compared with $75.6 \%$ nationally. In chemistry $77.1 \%$ of SUPA students earned a three or better, while $67.9 \%$ of AP candidates nationally earned a three or better. The relationship between SUPA grade and AP Examination grade showed $96 \%$ of SUPA students earning a B or above in their SUPA classes received at least a three on the AP Examination. A significant limitation of this study is with the use of only descriptive data for analysis in comparing these two groups; this is the result of doing a non-experimental comparison using a small sample compared to a large national sample.

These results show that students who did well in SUPA biology and chemistry also did well on the AP Examination. While these results cannot be generalized to other subjects, it demonstrates that grades given in SUPA courses and the level of preparation of these students is comparable to the national standards set by the Advanced Placement Program. These results provide some evidence that dual credit/ enrollment is a viable alternative for acceleration and a rigorous high school curriculum.

One disadvantage of dual credit programs using the high school teacher model of delivery, as in Project Advance, is the question of the transferability of the 
credits earned to other colleges and universities. In many cases, such courses are not widely accepted for transfer. Herbert (2001) studied the issue of dual credit in courses taught by high school teachers compared to college faculty. Her study examined learning outcomes for students who enrolled in dual credit mathematics courses during a five-year period at a large multi-campus community college in Florida, addressing two research questions. First, is there a difference in learning outcomes for dual credit students taught by high school teachers and those taught by college faculty as measured by student grades in subsequent coursework for which the dual credit course should have prepared them? Second, is there a difference between the distribution of grades of dual credit students taught by high school teachers and those taught by college faculty in the grades earned in subsequent coursework for which the dual credit course should have prepared them?

Two groups were followed in a quasi-experimental design: one containing subjects who had high school teachers as instructors (qualified to teach at the college-level according the accreditation criteria) for college dual credit mathematics courses $(n=920)$ and other who had college faculty as instructors for college dual credit mathematics courses $(n=913)$. The sample included students that earned at least a $\mathrm{C}$ in a dual credit mathematics courses on a high school campus. Data on dual credit students were gathered from the state community college system database and subsequent course grades were gathered from the state university system database.

Data were analyzed for the first research question using a t-test to determine the difference between the mean course grades in subsequent subject area courses of 
those taught by a high school instructor compared to those taught by college faculty. The analysis used for the second question included a chi-square test to compare the distribution of subsequent subject area course grades for each group.

The findings indicate a significant difference $(t=2.71, p<.01)$ in student performance in subsequent subject area course grades of students taught by high school instructors compared to college faculty. Students taught by high school instructors made significantly higher grades than those taught by college faculty. Students taught by high school instructors earned significantly more A's and B's than those taught by college faculty. Students taught by college faculty earned significantly more D's and F's than those taught by high school instructors $\left(X^{2}=\right.$ $11.41, p<.05)$.

A major consideration in evaluating these results is significantly larger seat time factor for students taught by high school instructors compared to college faculty who spent half as much instructional time with the students. High school teachers have other advantages over their college counterparts, including familiarity with the school and techniques for dealing with high school students. The likelihood is also very strong that high school instructors assigned to these courses are among the best teachers in their subjects while these assignments for college faculty are often not the most desirable.

These limitations aside, Hebert's research provides some evidence that student outcomes are not affected negatively by utilizing a qualified high school instructor compared to a college faculty member. Students taught by high school teacher in dual credit courses are prepared to succeed in subsequent college courses. 
These outcomes, according to Hebert should be taken into consideration when making decisions about the transferability of dual credit courses.

Chatman and Smith (1998) provide arguably the most empirical evidence to support the dual credit courses offered using the school-based model. They studied student outcomes in subsequent coursework focusing on foreign language study only. Foreign language was used because it presented the researchers with the opportunity to make a direct comparison of dual credit and on-campus postsecondary coursework while controlling for the ability differences and measures of performance. Most comparative studies of academic performance for dual credit cannot control for the fact that most dual credit courses are restricted to high ability students and comparisons to the general population of college students in an oncampus program.

Chatman and Smith use a University of Missouri program in foreign language that meets the university general education requirement of 13 credits in a three-course sequence that are often meet partially through dual credit taught on a high school campus with a high school teacher. The quasi-experimental study used a random sample of students who earned credit in the prior course through oncampus postsecondary instruction; a parallel comparison was made for students earning credit in the prior course through the dual credit program. The random samples of on-campus postsecondary students mirrored the distribution of ACT Composite scores of the students in the dual credit sample. Transcripts of 8,000 students were analyzed for a five-year period from 1991 to 1995, the grades in the three course foreign language sequence of a sample $(n=92)$ of students taking the 
courses on-campus and via dual credit were selected and matched using the ACT criteria into two groups of 46 each. An additional comparison was made for a sample $(n=100)$ of students who had a combination of classes via dual credit and on-campus instruction. Data were analyzed using a chi-square test to determine the differences in grade comparisons.

The findings indicate that taking a course through dual credit has no negative impact on subsequent performance on the college campus as a postsecondary student. Comparisons of the first group $(n=92)$ found no significant differences $(p$ $=.46, p=.39)$ between the performance of the dual credit students and the oncampus students. An additional chi-square test made of the combination of these students also was not significant $(p=.78)$. The same comparisons were made with the second sample $(n=100), 39$ of the students had dual credits for the first course of the three-course sequence and on-campus instruction for the other two; 61 had dual credit for the first two courses and on-campus instruction in the third. Again, the distributions were not significantly different $(p=.85, p=.054)$. The fact that second comparison was very nearly significant is due to the differences in the distribution of A and B grades, according to the authors. Similar numbers of students from the dual credit courses and on-campus courses earned A's and B's in the third course. The difference was that more dual credit students earned A's and more on-campus students earned B's. The chi-square test of the combined groups was not significant $(p=.82)$.

The study provides strong evidence that dual credit courses taught by high school teachers prepare the students as well as those taught on campus with college 
faculty. This study surpasses others by controlling for the ability-level of the students, something absent in Windham (2001) and Hebert (2001). The primary limitation of this examination is that it cannot be generalized outside of the foreign language discipline. Chatman and Smith point out that other dual credit programs should not be judged as inferior due to the evidence suggesting that they are at least as good as on-campus postsecondary instruction.

\section{Perception of Dual Credit Programs}

Regardless of the model or type of program, much of the success of dual credit has been documented with research focusing on the perceptions of students, parents, and faculty. Marshall and Andrews (1991) examined student impressions of an experimental program between an Illinois high school and community college in 1986. The researchers used a combination of interviews and surveys to address the issue of student perceptions of the programs and of the college. A follow-up survey was conducted two-years later. The study focused on two primary questions: (a) Did dual credit improve performance in the courses the students are currently taking in college? (b) Did the courses transfer to other colleges or universities? The program was an acceleration program offered to junior and senior honors students. The courses were offered on the high school campus using college faculty. Students could earn up to 24 hours of college credit in the program. The sample included all students enrolled in the first three semesters of the program from the fall of 1986 to the fall of 1987 were used. Interviews were conducted with some students. 
Data were presented in the form of comments from students in the program, survey results, and a breakdown of the grades earned. The findings indicate positive perceptions of students involved in the program and improved perceptions about the college they attended. Student comments listed by the researchers indicate that the experience was a valuable one and a challenging academically. Student impressions of the college based on survey data increased from a mean of 2.9 to a mean of 4.2 on a five-point scale. The follow-up survey included questions about the level of preparation for postsecondary education. The survey was sent to 23 freshmen at colleges and universities in the Midwest. Of the 17 that responded, five indicated that the program gave them excellent preparation for college, 10 indicated the program gave them good preparation for college, two listed fair preparation, while no respondent felt the program provided less than adequate or poor preparation for college.

While this study does provide some useful information regarding student perceptions of the program, a major limitation of this research is the lack of adequate data analysis or procedures regarding data analysis cited by authors.

Marshall and Andrews (2002) completed a follow-up study based on the same Illinois high school and community college program previously reviewed. The researchers conducted a review of their 1991 study and compared those results to the results of the student responses to a survey sent to students from two previous high school graduating classes from the program.

The survey was mailed in the fall of 2000 to the graduates of the program. The students proved difficult to track because many were enrolled out of state. The 
surveys, sent to the students' home address, yielded a $43 \%$ response rate $(N=33)$.

The Likert-type survey was included in a table in this study, something absent in the previous research. Data were analyzed using percentages only.

The findings, similar to those reported in the 1991 study, indicated strong support for the program by student respondents. An overwhelming majority $(n=$ 24) identified the dual credit courses as "better than" or "as good as" the courses at the college or university they currently attend. All but three of the students $(n=30)$ reported that their credits transferred to other colleges or universities in and out of state. All but two $(n=31)$ students indicated that they would recommend the program to others. The 33 students reported an average of 1.18 semester saved as a result of their participation in the dual credit program.

This follow-up research provides a more solid base of research, despite the low response rate and sample size, for inferences about the success of the program. Marshall and Andrews estimate that over 500 students have now been served in the 16 -year history of the program, claiming a savings of $\$ 5,000$ to $\$ 24,000$ in tuition expenses for the transfer of one year of college credits.

Kiger and Johnson (1997) examined how students and parents perceived a suburban community college's postsecondary enrollment options program so that the college could base market strategies on these perceptions. The researchers used the entire population of 67 students that have participated in colleges dual credit program since its inception in 1990. Every student and parent were surveyed to assess his or her perceptions of the program. 
Kiger and Johnson in a quasi-experimental design used a 23-item survey instrument using a Likert-type scale to gage student perception of the program $(1=$ not a reason to participate in dual credit, $4=$ primary reason to participate in dual credit). Students and parents were mailed the survey with an incentive of a free transcript. The survey yielded a response-rate of $74 \%$ for both parents $(N=52)$ and students $(n=47)$. The data were analyzed using a Spearman Rho correlation coefficient to detect differences in the rank order between parent and student perceptions. A t-test was used to determine the significant mean differences between student and parent survey responses.

The findings revealed an overall positive relationship between parent and student perceptions of the community college's dual credit program. Significant differences $(r=.80, p=.00)$ between the rank order of student and parent perceptions of the program were found. The t-tests showed significant differences between the way parents and students perceive dual credit program of items five survey items, including understanding educational requirements for employment $(t=$ $1.90, p<.05)$, wanting to become accustomed to a college lifestyle $(t=-1.95, p<$ $.05)$, and developing a sense of independence $(t=-2.53, p<.01)$. Both parents and students had an overall favorable perception of the program, the research did not indicate whether the students or their parents had a more favorable perception.

The researchers suggest from the results that parents want students to use the dual credit program as a "hands on" career identification and planning tool. While students perceived the program as an opportunity to "try out" college and establish the independence that college students experience. Kiger and Johnson emphasize 
that these different perceptions be considered when marketing such programs to parents and students. A limitation of Kiger and Johnson's study is the strictly quantitative methods did not yield much detailed information.

In sum, while there are limitations on making sweeping generalizations of the research on student and parent perceptions of dual credit programs, the research clearly indicates a level of satisfaction among parents and students that are involved in such programs. This level of satisfaction is in many cases attributed to the benefits of these programs in saving them money and the students time in credits they need to earn at the baccalaureate level or decisions about career or major that such exploration in high school allows. In most cases, their perceptions of these programs are influences by the learning productivity they create. Perceptions are, however, far different from actual student outcomes, which is the subject of the next part of this review.

\section{Student Outcomes in Dual Credit Programs}

Evidence of student and parent satisfaction, while important for the longterm success of dual credit/ enrollment, is also critical to document successful student outcomes from their experiences in such programs. The transferability of credits in such programs have serious implications for both satisfaction and student outcomes in dual credit/ enrollment programs.

Lambert and Mercurio (1986) reviewed many transferability issues relating to college credits earned in high school specific to the Syracuse University Project Advance (SUPA) program. Each year SUPA conducts a transfer study of the program's most recent graduates $(N=856)$. The study objectives are to learn about 
graduates enrollment patterns, assess student perceptions of the program after a semester of full-time college study, and to determine the number of students attempting to transfer SUPA credits to other colleges and universities.

The data were analyzed and presented using descriptive statistics, primarily in the percentage of students transitioning from SUPA on to college and the rate of credit transfer. The findings indicate an overall favorable credit transfer record of SUPA graduates (65\%). Some students, however, report obtaining only partial recognition and others report receiving no recognition of credit (14\% partial credit, $35 \%$ no credit). Some of the reasons for variation (in some cases within institutions) includes: lack of university-wide policies for credit transfer; differences in transfer for majors and non-majors is specific subject areas such as biology; student's course grade in SUPA is a factor; in some cases students are asked to demonstrate subjectmatter competency via a proficiency examination; and many student actions cause difficulties in transfer, for example many students simply speak to the wrong college officials about credit transfer or may fail to request a transcript from Syracuse.

The increased number of high school students wishing to transfer credit from their high school experience to a college or university prompts colleges and universities to review their guidelines and set parameters for such transfer of credits earned in high school to postsecondary education. The authors claim these suggestions are only short-term solutions; the only long-term solution is the implementation of a new accreditation procedure to endorse such high school-tocollege cooperative programs such as SUPA. 
Using a questionnaire mailed to all 1,545 graduates that earned credit through the program in 1974-75, Mercurio (1980) conducted the first full-scale follow up study of the SUPA program tracking the class of 1975 . The study addressed five main questions: (a) What happens to graduates of high school-college cooperative programs? (b) What is their college-going rate? (c) How has the experience prepared them for more advanced courses in the same area in college? (d) How do students feel about the experience four years later? (e) And would you recommend this program to current high school students?

The questionnaires yielded a $52 \%$ response rate $(n=805)$. The questionnaire asked students basic demographic information about their education after SUPA, completion information, amount of time needed for degree, and an open-end section allowing students to express general comments about the SUPA program. Data were presented in a descriptive format.

The findings indicate that an overwhelming majority of program participants went on to college (98\%) and were generally satisfied with the level of preparation the program provided. Ninety-five percent of respondents that indicated that they went on to college after SUPA indicted that they had completed a degree, $90 \%$ of this group earned a four-year degree while $10 \%$ earned a two-year degree. Ninetyone percent of the respondents reported receiving an average letter grade of a B or above in college.

Despite these positive results, it seems the program did not significantly shorten the time-to-degree for most students, $84 \%$ of degree completers did so in the normal amount of time (two or four years). Eleven percent completed their 
degree one semester earlier, while five percent completed one year earlier than usual. The program did seem to have a positive impact on the level of student performance in more advance courses. According to questionnaire responses, $74 \%$ entered advance level courses in the areas for which they had taken a SUPA course and three quarters of the students indicate that the SUPA course they had served as "good" or "excellent" preparation for their advanced courses. Sixty-two percent of respondents indicated that they attend or plan to attend graduate school, while $95 \%$ of those responding would recommend the program to a current high school student. Around $60 \%$ of respondents submitted written comments. The statements were analyzed to be positive, negative, or neutral. Eighty-three percent of the written comments were judged to be positive, while seven percent were judged negative.

The study limitations include a lack of statistical analysis of survey responses and the researcher did not provide ample information about the field-test procedures, if any, used before the data were collected from the graduates. Despite these limitations, the results confirm many of the other research studies conducted on SUPA and dual credit/ enrollment programs as generally successful in their implementation, student perceptions, and postsecondary outcomes.

Windham (1998), in an exploratory study on student outcomes, examined issues of statewide rigor and transferability of dual credit courses in Florida. She addressed five research questions: Does the dual credit program serve high school students who have demonstrated capacity for doing college work? How many courses do individual students complete in the dual credit program? What proportion of students enroll in the state's postsecondary institutions after graduation? To what 
extent do students have to repeat courses taken at community colleges via dual credit at the university? How well do students fare in subsequent course work for which their dual credit classes are prerequisites?

This exploratory study utilized a sample drawn from the state databases for community colleges and universities to provide descriptive details of students in dual credit programs statewide. All students in the database were selected for the sample. Data were analyzed and presented using primarily descriptive statistics citing the percentage of students passing subsequent college courses after dual credit and the transferability of such credits.

The findings support the contention that dual credit provides a viable acceleration mechanism for qualified high school students. One indicator of this ability consists of the pass rates on the entry-level placement tests taken by entering college freshmen. The pass rates $(88 \%)$ for these tests were higher for dual credit students than entering community college freshmen, indicating that dual credit appears to be reaching those it is intended to serve—-students who are ready for college-level work while still in high school. As far as the number of dual credit courses taken, data indicates that while some students took as many as 10 dual credit courses, most students took three or fewer courses. Nearly $70 \%$ of the students taking dual credit were located in the state university or community college system databases, with about $35 \%$ of students ending up in the state university system. Data indicate a small percentage of courses (less than $1 \%$ ) repeated by students when they enter the university system. The rigor of the program, measured by student grades in subsequent courses $89 \%$ of English students and $67 \%$ of math 
students earning a least a $\mathrm{C}$ in their dual credit course that made the same grade or better in the subsequent college course in the same subject.

In an expansion of this exploratory research, Windham (2001) examined the level of preparation for subsequent courses after their dual credit experience. Her research was guided by three questions: Are students who have taken dual credit courses in Florida community colleges prepared for their next course? Does the affiliation of the instructor (high school teacher or college faculty) impact the grade in subsequent courses? Do students have to re-take dual credit courses once they enter the university system?

The sample for the quasi-experimental study included more than 26,300 students that had taken at least one dual credit course at a Florida Community College from 1994 to 1999 . Using the state community college and state university system database, the researcher identified the different courses taken via dual credit and the subsequent course grade based on Florida's Common Course Numbering System. The nine most popular dual credit courses were chosen for the sample to be studied $(n=11,857)$.

The data were analyzed using a chi-square test to compare the grade distributions of the two groups, the dual credit students compared to other students for the three research questions. Descriptive data of grade distributions are also included.

Findings indicate that dual credit students receive significantly more grades of A or B than would be expected if there were no difference between the groups $\left(X^{2}\right.$ $=349.04, p<.05)$. In comparison with of state university system students, dual 
credit students were statistically more successful in their subsequent course. The analysis also found no difference between the percentage of students earning a $\mathrm{C}$ or better in their dual credit a high school teacher versus a college faculty member taught course. Finally, of the total sample of students studied, only three percent repeated a dual credit course in the state university system. In general, dual credit students on a very large scale out performed other college students by earning more A's and B's and fewer failing grades regardless of the teacher. The sample size and statistical methods used in Windham's research provide strong evidence of positive outcomes of the subsequent success of dual credit students in postsecondary education.

Simmons (1994) studied the impact of various types of pre-college programs and their impact on student retention. He evaluated three pre-college programs at a large research university, a summer transition program (STP), a research apprenticeship program (RAP), and an introductory engineering program (IE) targeting at-risk students that often do not return to college after their first year.

The sample for this study consisted of students in each of the three programs (RAP, $n=23$; IE, $n=25$; STP, $n=87$ ). A content analysis was used to evaluate the responses to student questionnaires, interview transcripts, and measures of student performance in each program. The categories of content analysis included performance in each pre-college program compared with the students' first semester college record, changes in student interest as a result of their involvement in the precollege program, and the students' persistence in the first two years of college. No inter-rater reliability statistics were given. 
The findings indicate that hands-on experiences such as these can help students acquire the academic and social skills needed to be successful during their first year of college. The results also show increased student motivation for postsecondary education as well. The results have implications for involving at-risk students in collegiate programs as a mechanism for persistence and integration into college.

Delicath (1999) investigated the differences in integration and goal achievement of students entering college specific to dual credit programs. The primary problem investigated is to determine if credits earned in the St. Louis University Advanced College Credit 1818 Program (ACC) and the College Board Advanced Placement Program (AP) influence student's integration into college (first year persistency) and the influence on the students' goal attainment (graduation within six years). The primary research question was will ACC/AP programs impact a student's ability to persist and graduate. The study had three hypotheses: there is no significant difference in the likelihood of a student with ACC/AP credits and students without these credits to persist after one year of college; there is no significant difference in the likelihood of students with ACC/AP credits and students without these credits to graduate from college; and there is no significant difference in the time to graduation of students with ACC/AP credits and students without these credits.

The researcher used a cohort longitudinal study examining independent variables of gender, race, ACT Composite scores, ACC credits, AP credits, SES, and financial aid and family contribution. The dependent variables included measures of 
first-year persistence and six-year graduation rate. The population included firsttime bachelor's degree seeking students entering SLU in the fall of 1989 through the fall of $1991(n=2,760)$. The sample included 644 students with an average of 11.62 ACC credits and 6.11 AP credits. Data were analyzed using logistic regression models between each dependent variable and the independent variables.

The findings for the first hypothesis indicate that ACC credits significantly influenced the students' ability to persist after one year, yielding a log odds ratio of .0514 for each credit. This means that students with 20 ACC credits would be 2.7 times more likely to persist after one year than a student with a single ACC credit ( $p$ $<.01)$.

The results for the second hypothesis shows a statistically significant likelihood of students with ACC/AP credits to graduate within six years, yielding a $\log$ odds ratio of .0512 for each hour of ACC credit. This means that students with 20 ACC credits would be 2.6 times more likely to graduate within six years. Students without ACC/AP credit had a graduation rate of 49.20 compared to 68.78 for students with credit in ACC/AP.

The results for the last hypothesis dealing with time to graduation using backward stepwise linear regression also point to ACC/AP credits as significantly influencing a student's time to graduation $(p<.01)$. In fact ACC is the most powerful indicator of time to graduation of all of the stepwise variables analyzed. Students with ACC credits take about $5.1 \%$ less time to graduate than students without any credits. The researchers conducted a supplemental analysis to reduce the effect of a student's ACT score in the logistic regression model and see if certain 
variables might have been included in the original models due to their strong relationship with the ACT scores. The results show that of all of the persistency models, the only variable of significance at the .01 level was ACC credits. Therefore, the student's ACT scores do not affect ACC credits as much as the other variables in the study. These results agree with the logistic regression but contradict the linear regression. By controlling for the student's level of achievement using $\mathrm{ACT}$, the correlation between integration and goal attainment with the amount of ACC credits earned was supported and strengthened. The correlation between time to graduation was not supported.

This study illustrates the complexity of studying and analyzing retention and graduation characteristics, while being careful not to view the variables in isolation. All variables interact with each other in such designs. Future research should evaluate the interactions of these and other variables.

\section{Student Outcomes in State Sponsored Dual Credit Programs}

While many of the previous studies emphasized student outcomes in dual credit programs from the vantage point of various community colleges or universities that sponsor programs, it is important from the perspective of state policy and the learning productivity and efficiency perspective in analyzing key studies that examine the issue from the broad state policy context. This review has already highlighted the programs in Minnesota and Washington as catalyst for the dual credit movement nationally. Both are worthy of closer examination.

Crossland (1999) conducted a progress report of the Running Start program for the Washington Board of Community and Technical Colleges. The study was 
guided by the two following primary questions: Who participates in Running Start? Are students successful after the completion of the program?

The longitudinal study, collected data on student enrollment, transfer, and academic achievement from the state community and technical college system database $(N=12,548)$. Data are presented descriptively by percentage of student demographics, transfer, and achievement level.

The findings show that the academic performance of Running Start students and the support for the program among students and parents has been very positive. The data indicate that $59 \%$ of participants are female, more than $15 \%$ are students of color; $43 \%$ work part-time while attending college; and just over $50 \%$ take 10 or more credits per quarter. The average grade point average for a Running Start student is 3.12 , slightly above the average of regular community and technical college students (2.99). This study has implications to support a state sponsored dual credit program to impact student achievement, increase the college attendance rate, and assist with attracting under served population such as African Americans in dual credit programs.

Swiney (1999) conducted a study in conjunction with the Crossland (1999) study evaluating the transfer of Running Start students to state colleges and universities. His study followed the original Running Start students $(N=88)$ who entered in the fall 1993. The study focused on a single research question: are students successful after transferring to the universities? Swiney used data from the University of Washington system to trace student grade point averages and college graduation rates. The graduation follow-up study used a longitudinal design. 
The data were presented descriptively, with mean grade point averages and percentage of Running Start graduates. Findings showed that Running Start students graduated with a 3.42 GPA, significantly higher than the 3.14 for students who began their college education at UW. Running Start students also graduated at a higher rate in four years, $41 \%$ compared to $31 \%$.

Hanson (2001) conducted a progress report of the Running Start program similar to the Crossland (1999) study for the Washington Board of Community and Technical Colleges. The study was also guided by the questions of who participates in Running Start, and are students successful after the completion of the program?

The study using descriptive methods, collected data on student enrollment, transfer, and academic achievement from the state community and technical college system data warehouse $(N=13,699)$. Data are presented descriptively with the number and percentage of Running Start students, their demographics, and achievement levels.

Results of the study show demographics that are comparable to the previous studies. The findings show that 68 students graduated from high school and simultaneously form college with an associate degree. The average high school GPA of students in the program is 3.65 with a range of 2.70 to 4.0 . The average ACT score of students in the program is 25 , with a range of 16 to 34 (SAT average was 1180, with a range from 690 to 1570). Again, Running Start students are performing at the same level or better than traditional college students (3.12 Running Start, 3.09 all freshman, 3.18 community college). 
All of the studies from Washington provide very useful information on the type of students taking dual credit courses through the Running Start program. Data illustrates the wide spectrum of students touched by the program and successful outcomes of these students experience as college students. The major limitation of these studies is the lack of sophisticated statistical analysis in evaluating the beyond mere descriptive data.

In addition to Washington, Minnesota provides one of the more enduring state-wide models of dual credit. Urahn (1993) evaluated Minnesota’s Postsecondary Enrollment Options Program (PESO) for the Minnesota legislature. The program allows $11^{\text {th }}$ and $12^{\text {th }}$ grade students to attend postsecondary education institutions at state expense. This study analyzes the operating procedures, participation by students, funding, and policy considerations. The policy analysis study used data on PESO students $(N=7,540)$ from several state agencies, including the Minnesota Colleges and Universities Board and the Department for Families, Children, and Learning. Data are presented descriptively using means, medians, and percentages.

The results of the policy analysis show wide participation throughout the state for the program. Demographically, most students in PESO took courses through Minnesota community colleges or the University of Minnesota (41\% community colleges, $26 \% \mathrm{UM})$. The large percentage of participants hail from urban parts of the state, especially the Twin Cities Most PESO students took about 12 credits, with $9 \%$ of students taking a full-time college load. Communications, social science, and vocational credits were the most popular courses taken through 
PESO. About $15 \%$ of PESO students failed one or more courses, while only about seven percent of all PESO courses overall were failed.

Additional insight into the outcomes of students in the Minnesota program are provide in a study by the Minnesota Office of the Legislative Auditor (1996). The report examines the following student outcome-oriented questions: (a) what type of students have participated in the Postsecondary Enrollment Options (PESO) program and why? (b) To what extent have these students been satisfied with the program? (c) What types of courses have students taken, and have they completed them satisfactorily?

The study used an interpretive design with ethnographic interviews, surveys and already existing data available from the State Board of Colleges and Universities and the Department of Children, Families, and Learning. Data were analyzed using a variety of statistical methods. The researcher does not indicate many of the methods of analysis throughout the report. Findings are presented in a bulleted fashion throughout the text addressing all major research questions.

Major findings from the research included the following: most public, private, and technical postsecondary systems imposed tougher admission requirements on secondary students than on regularly admitted postsecondary students. A larger percentage of students failed technical college courses than other courses ( $9 \%$ compared to $6 \%$ overall). Although the program was intended to promote rigorous academic standards and a variety of education options, school administrators, parents, and students said that the most important reason why students participated in the program were to get a head start on college credits and to 
save money ( $94 \%$ of students, $87 \%$ of administrators, and $88 \%$ of parents surveyed listed this a "important" or "very important"). By comparison, 77\% of students, $30 \%$ of administrators, and $87 \%$ of parents said students participated because courses were more challenging. The data also indicated that a large majority of the students served by PESO were the "average" to "above average" students $(60 \%)$ with "B" or " $C$ " average grades rather than the academic elite.

In the surveys conducted through this study, stakeholders were asked about their overall attitudes toward the PESO program. Most students, parents, and administrators indicate an overall level of satisfaction with the program $(73 \%$ of students were "very satisfied" and 24\% were "somewhat satisfied"). Ninety-five percent of participant's parents said that they would "definitely" or "probably" encourage their children to participate again. If there is a disconnect in support, it is with the high school administrators faced with losing potential funding or staffing as a result of the program. While $82 \%$ of alternative school directors and $72 \%$ of college administrators "agree" or "strongly agree" that the program is performing in a satisfactory manner, only $42 \%$ of high school administrators answered the same way.

Despite the fact that advanced statistical methods and extensive data gathering and analysis are presented in this study, the organization of the study more from the policy rather than the scholarly perspective provided a limitation in that many statistical methods and forms of data analysis were not included in the study.

Broughton (1987) analyzed the demographics, attitudes, and opinions of both students and faculty who participated in the PESO program at two Minnesota 
community colleges. The study addressed the following questions: (a) Is PESO meeting the needs of the students enrolled? (b) Does the program provide options that are not available at the student's secondary school? (c) Is the student successful in completing college level work? (d) If the program is successful, it the concept portable to other states? (e) Is the student who participates in the program more likely to continue their education following high school, and (f) Are faculty who participated in the program supportive of the concept and the program?

The researcher used a survey design from a sample ( $N=24$ students, $N=9$ faculty) of students and faculty from two of the 18 community colleges in Minnesota. Surveys were sent to a total of 31 students and 11 faculty members, for an $81 \%$ response rate. The researcher used descriptive statistics to analyze the data gathered by the census-type questions. An F-test of variance was used for questions in the second part of the questionnaire regarding attitudes about the program. The survey instrument was included. The admissions office for content validity reviewed the instrument.

Findings indicate a general level of satisfaction by students and faculty for the program. The demographic data reveals that the greatest percentage of students at both community colleges were "B" average students (54\%). The average grade point average for students in PESO was 2.69, high school grades were similar to those earned in college.

The results from the attitude portion of the survey indicate that the program is meeting the needs of the students with quality instruction $(F=0.00)$ and high academic standards $(F=0.01)$. The courses offered seem to be meeting a need for 
students that is not available through their local high schools (21\%), however, a majority indicate that they choose to attend PESO because they were bored with high school (30\%). There is significant agreement among the students in the program indicating that they were successful in completing college level work with grades that were much better than their high school grades $(F=0.01)$. A majority of the students indicate that they wish to attend college after high school graduation ( $21 \%$ community college, $33 \%$ state university, $21 \%$ private college, $8 \%$ technical college). Some level of disagreement existed among the faculty at the two community colleges about whether the students did better than college students in the program $(F=0.91)$. Overall the faculty strongly disagreed that the high school students have not weakened the community college $(F=0.06)$. Both the students and faculty indicated they would recommend the program to friends $(F=0.01)$. Despite the limitation of the small sample size included in this study the results here paint an overall positive picture of the PESO program. This study also confirms, using more advanced statistical analysis, many of the findings of the statewide studies.

In sum, the research presented in the form of policy analysis or program evaluation from Washington and Minnesota are very useful in the impact of the programs on large numbers of participants. The overall positive outcomes shared, indicate a level of success for dual credit programs as a way of streamlining education productively and efficiently in a P-16-oriented package. A theme prevalent in each is wavering support from secondary schools, which view such programs as a robbery of their resources and a threat to their mission and autonomy. 
This attitude is most evident in the legal challenges the PESO program in Minnesota faced from the American Federation of Teachers, who sued the state claiming that the PESO was unconstitutional because it

The type of students served through the Minnesota program may prompt the conflict between the secondary schools and the state. Many PESO students come from the ranks of "B" and "C" students. Few dual credit studies previously reviewed emphasize the benefits of the program for the larger masses of high school students compared to the academically advanced. These results provide evidence of the need for more carefully constructed studies on the potential impact of dual credit programs for the masses of high school students rather than the elite.

\section{Factors of Dual Credit Student Success}

Statewide dual credit programs such as those previously reviewed from Minnesota and Washington bring to light a significant strand of research on dual credit programs - the utilization of dual credit as a means of aiding students with a different demographic background than found in most dual credit programs. Demographic factors, for the purpose of this study, are defined as follows: (a) race, ethnic, and socio-economic background, (b) urban or rural residence, (c) gender, (d) academic readiness for college, and (e) high school performance. Dual credit programs, as with many in previously reviewed studies, attract traditionally urban/suburban White or Asian students that are high achieving (in the top half to top third of their class) and academically prepared for college. In most cases, females out number males in these programs by about $20 \%$. This section reviews 
studies that emphasize issues related to access and participation in postsecondary education among various underrepresented populations. Dual credit experiences for students from diverse demographic backgrounds are also highlighted.

\section{Ethnicity and Socio-Economic Background}

In 1997, the College Board organized a National Task Force on Minority High Achievement to study recommendations for addressing the chronic shortage of Blacks, Hispanics, and Native American students who achieve at high levels academically. Because of this shortage, the vast majority of students who earn high grades in school, who score highly on standardized tests, and who earn a bachelor's degree or higher are still White and Asians.

The Task Force consisted of a group of 31 distinguished leaders from education and other sectors chosen by the College Board. The group met, conducted research, and deliberated for two years. The findings of the Task Force concluded that the limited presence of Blacks, Hispanics, and Native Americans among the top students is a product of several complex forces, including poverty, inadequate resources in schools, prejudice, limited educational resources in minority families, and cultural differences.

The dimensions of the problem are serious. Blacks, Hispanics, and Native Americans constitute only 13\% of bachelor's degrees, despite making up about $30 \%$ of the under-18 population. Many of the issues relate back to the achievement gaps originating in the disadvantaged circumstances that in which many minorities grow up. The Task Force recommended a series of strategies within the context of educational reform to improve minority achievement. While most of the 
suggestions focused on improved rigor in the secondary curriculum, exploring programs such as dual credit intended to encourage minority enrollment in postsecondary education.

Alexander, Holupka, and Pallas addressed the rigor of the high school curriculum in two studies of the determinants of access to college (1987a), and twoyear compared to four-year access to college among college-going youth (1987b). Both studies used data from the NLS Class of 1972 compared to the High School and Beyond (HSB) Class of 1980 cohort.

The earlier study by Alexander, Holupka, and Pallas (1987a) examined social background and academic determinants of which students go to college. The samples differed slightly in each study. The sample included $(N=33,041)$ data sets from NLS and HSB and employed a logistic regression design focusing on common independent variables, including SES, student assessment results (given as part of the NLS and HSB), gender, race, high school curriculum (college prep or non-college prep), high school GPA, and cohort group (NLS or HSB).

Postsecondary enrollment was the dependent variable.

The findings indicated little evidence of diminished opportunity to attend college. In general, social background had little bearing on attendance patterns. Hispanic youth were noticeably less likely than either Whites or Blacks to attend college $\left(R^{2}=.007, p<.001\right)$. Low SES students were modestly disadvantaged according to the results $\left(R^{2}=.020, p<.001\right)$.

The second study by Alexander et al (1987b) queried whether a student's social background and academic performance influenced whether they attended a 
two-year versus a four-year college. The sample $(N=33,041)$ eliminated cases of students that did not attend postsecondary education for a sample of just under 18,000 since the focus was on what type of college rather than college attendance overall. The data sets from NLS and HSB were merged. Data were analyzed using logistic regression with independent variables of SES, student assessment results (given as part of the NLS and HSB), gender, race, high school curriculum (college prep or non-college prep), high school GPA, and cohort group (NLS or HSB). The dependent variable was the type of postsecondary enrollment, either two-year or four-year.

The findings in the second study were similar to those of the earlier study. Little evidence of diminished opportunity to attend a four-year college was found. In general, social background in each case had little bearing on attendance patterns. Both showed Hispanic youth noticeably less likely than either Whites or Blacks to attend a four-year institution $\left(R^{2}=.009, p<.001\right)$. Low SES students were modestly disadvantaged to attend a four-year college, according to the results $\left(R^{2}=\right.$ $.025, p<.001)$. One limitation here is the fact that many minorities have much higher dropout rates than Whites. Academic resource measures, such as high school curriculum and GPA, differentiated attendance patterns more than student background factors.

Both studies offer wide-ranging implications. Access to higher education, at best, only moderately limited by a student's social background. Their background does not limit the type of higher education a student pursues. The postsecondary system is open enough that the type of entry into college is affected very little by 
student background. Access to four-year colleges is based on solid pre-college preparation. Students who tested well and made good grades in a solid academic track in high school had the edge over their less well-prepared peers in attending four-year colleges. Both studies make an effective case for offering students a rigorous academic curriculum regardless of race, gender, or socio-economic background and the role dual credit can play in providing a strong curriculum for students from diverse achievement levels and backgrounds.

Hugo (2001) reviewed a dual credit program that targeted minority and low socio-economic students in a California community college. The program enrolled 676 students from 17 Los Angeles area high schools in 1998. The program is now in its sixth semester and has served over 5,000 students. The end of affirmative action, brought about by the University of California regents, has challenged the university to continue expanding the pool of qualified minority applicants.

Students in the dual credit program have the chance to preview college-level classes in an environment less threatening than that offered by the Advanced Placement courses. The dual credit program appeals to students who are just below the level of $\mathrm{AP}$ - and often-neglected population, according to Hugo. The program provides a long-term strategy to improve the preparation of minority students so they will be competitive for college admission. Hugo sites the Adelman (1999) study on intensity of the high school curriculum for minority students as a strong predictor of postsecondary success.

Hugo reports positive student performance in the program, a $73 \%$ pass rate of students enrolled in dual credit, and an average GPA of 3.21. Hugo identifies 
Latinos and a critical population being served by the program. Many Latino students are attracted to the program because it allows them to earn advanced training toward an associate degree before their immigration status becomes an issue. The program treats all students as residents and does not charge fees or tuition. Hugo sums up the success of the program as an opportunity for minority and first generation students to learn about college and improve their study skills while giving them more information about the process of attending college.

Brigham (1989) documented the success of students in a program similar to one described by Hugo. The study evaluates the performance of minority and lowincome students in California that do not meet the University of California system admissions requirements and took dual credit courses at community colleges as a way to become eligible for college admission. The study addressed the following two research questions: (a) How can early academic outreach programs help increase the percentage of minority students that are meeting university admission requirements? (b) Can these programs help decrease the persistent gap that exists between the college eligibility rates of minority and non-minority students.

For the purpose of the study, Brigham defines a minority student as Black, Hispanic, and Native American. Whites and Asians are considered non-minority. He cites data from California Postsecondary Education Commission on the eligibility rates of California public high school graduates by race and ethnic group in 1983. Blacks (10.8\%) and Hispanics (13.3\%) lag far behind Whites (31.6\%) and Asians (50\%). Brigham characterizes dual credit as a viable option to help enable minorities to meet the college admissions requirements. 
Brigham evaluated the performance of 21 minority under-achievers that participated in the dual credit "Partnership" program at a community college from the Fall of 1987 to the Spring of 1989. An extensive review of student course performance with respect to University of California (UC) eligibility was undertaken. Brigham also evaluated the performance of 55 students that were involved in the dual credit Partnership program that qualified and attended UCLA, a primarily White university, between 1984 and 1988. Data were analyzed with descriptive statistics in the form of percentages and means. The second part of the analysis used a difference of proportions test.

The findings revealed that $11(51 \%)$ of the 21 students in the program met UC's eligibility requirements at the conclusion of the $12^{\text {th }}$ grade, the eligibility rate of this sample was considerably higher than expected. In the first two semesters (Fall 1987 \& Spring 1988) less than a fourth of the students in the study posted an average admissions GPA (A-GPA) of a 3.0 or greater. By the last two semester of the study (Fall $1988 \&$ Spring 1989) over $60 \%$ of the students posted a A-GPA of a 3.0 or above. The average A-GPA of students in the study climbed steadily from 2.71 in the fall of 1987 to 3.09 in the spring of 1989 .

The findings for the second part of the study that followed students from the dual credit Partnership to evaluate their performance at UCLA were also positive. The number of dual credit Partnership students at UCLA continued to increase from the fall of $1984(n=1)$ to the fall of $1988(n=26)$, while their aptitude for college as measured by the SAT fluctuated, their A-GPA continued to rise (Fall 1984 A-GPA = 2.5, Fall 1988 A-GPA = 3.15). Overall, the academic preparation of the dual credit 
students was good, but when compared to that of other UCLA freshman, it is among the lowest. Of the seven categories of freshman students those in the dual credit program had the second lowest admission GPA (non-minority regular admits A$\mathrm{GPA}=3.81$, Native American regular admits A-GPA $=3.5$, Hispanic regular admits $\mathrm{A}-\mathrm{GPA}=3.48$, Other minority regular admits $\mathrm{A}-\mathrm{GPA}=3.48$, Black regular admits $\mathrm{A}-\mathrm{GPA}=3.34$, Minority special admits A-GPA $=2.92$, and Dual Credit special admits A-GPA = 3.0).

The rank order of the seven groups changed significantly when the percentage of continuing students with a college GPA of 2.0 or above and the number of continuing students retained in college were analyzed. The analysis reveals that the percentage of dual credit continuing students with a college GPA of 2.0 or greater $(91 \%)$ was higher than that of all categories of students except for non-minority students. The difference between the dual credit students and all others was found to be statistically significant $(p<.05)$ when subject to the difference of proportions test. The same was true when retention rate were analyzed. Dual credit students retention rate $(80 \%)$ was found to be statistically significant $(p<.05)$ than that of all groups except non-minorities.

Despite the limitation of the small sample size, these results provide compelling evidence for the use of dual credit for underachieving minority students. The positive college student performance as a result of participation in the dual credit program targeting underachieving minorities has strong implications for the type of student populations that community college target for their dual credit programs. 
Dual credit programs can also impact positively student recruitment of minority students. Opp (2001) investigated institutional characteristics that assisted in the recruitment of Black students to two-year colleges. The data were drawn from a national survey of chief student affairs officers on recruitment barriers and strategies for students of color. These data were merged with 1995 NCES data on fall postsecondary enrollment.

The data were analyzed using stepwise regression models to identify significant predictors of the percentage of students of color at 562 two-year colleges. Findings indicated that demographic and institutional characteristics emerged as the strongest predictors of recruitment of students of color. College participation in dual credit programs with high school with large numbers of minority students was the fourth strongest predictor of successful recruitment of students of color $(F=25.7, p$ $=.042)$.

Two-year colleges with successful dual credit programs may help by involving high school students of color in the college experience and help "warm up" their educational aspirations to pursue postsecondary education. Increasing the pool of such students with postsecondary aspirations can help them in their decision to apply to college. While this study impacts the recruitment of students of color, it has implications for utilizing dual credit students to draw all types of students into college programs.

\section{Student Residence}

Much current educational research is examining rural and urban differences in student achievement and educational access, and attainment. Van Hook (1993) 
analyzed the educational aspirations of rural high school seniors in the U.S. using data obtained from the Monitoring the Future Project, a national study conducted by the University of Michigan to explore the experiences and expectations of students regarding many aspects of life. The sample includes about 16,000 high school seniors from 125 public and private high schools selected annually provide a cross section of U.S. seniors. The instrument was a lengthy anonymous questionnaire given to students by teachers. A core set of questions was given to all students and other questions were given to subgroups of 3,500 to 4,000 students each year.

The study addressed the following hypotheses: (a) Young people from rural areas will raise their educational aspirations during economic recession and community restructuring but will continue to lag behind young people in urban areas. (b) Educational level of parents will be positively associated with student educational aspirations. (c) Young people with higher self-concept regarding academic ability will indicate higher educational goals. (d) Rural youths will demonstrate lower academic self-concept than young people from more urban settings. (e) Educational aspirations will be positively linked with general sense of well-being. (f) Rural youths planning to graduate from college will have less of a commitment to remain in their community than will other rural young people. Although no hypotheses were generated for gender or race, these issues were analyzed in terms of these same dimensions.

Data for the analysis were chosen from three-year intervals from 1977, 1980, 1983, 1986, and 1989. The association between parental education, levels of academic self-concept, general sense of well-being, and aspirations regarding higher 
education was determined by chi-square analyses. The Kendall tau rank correlation was used to further examine the degree of association between the two variables. Aspirations for higher education among young people from different communities and gender and racial groups were analyzed by chi-square analysis of variance (ANOVA).

The findings support the hypothesis regarding a rise in educational aspirations, bt at rates that continue to fall behind youths from more urban areas, especially in terms of plans to graduate from a four-year college and attend graduate school $(F(2.5)=52.3, p<.01)$. Rural young people were as likely as urban young people to attend a two-year college or vocational school $(F(2)=3.2, p>.01)$. Plans to graduate from college more than doubled, but failed to catch up with the ongoing increase in more-urban areas. No gender or racial differences emerged in either the rural or small communities. Combining all types of education, students from rural areas had the lowest rates of plans for future education (58.2\%) compared to small towns $(69.8 \%)$, and larger communities $(77.3 \%)$.

While research on aspirations is not very positive for rural students, Edington and Koehler (1987) review research that suggests that students in small rural schools receive an inferior education than students from larger urban or suburban schools. Edington and Koehler contend this is an oversimplified point of view not supported by much of the research. They cite the rural deficit model of performance of rural students in higher education as one example. Considerable research cited by Edington and Koehler indicates that rural students who attend college perform as well as urban students. 
While research supports rural student performance in college, many other studies call attention to the inhibiting factors and access problems in providing postsecondary access to rural populations. Eller, Martinez, Pace, Pavel, Garza, and Barnett (1998) studied programs established at nine rural community colleges, two of which are from the eastern part of Kentucky, as part of the Rural Community College Initiative (RCCI) to improve access and foster economic development. The RCCI program is part of a national demonstration program, which began in 1995. A project documentation and assessment team conducted three years of field observations, site visits, interviews, focus groups, and other quantitative and qualitative data collected from the nine colleges. Conclusions were released through four reports published by the American Association of Community Colleges focusing on access, economic development, team building, and institutional capacity. The research briefs do not contain additional information on the collection or analysis of data.

The findings from the research brief on access found four general approaches as the most effective among the nine sites. For the purpose of this research, the most significant approach to improving access was through cooperation and partnerships with local schools. The two case studies for partnership in the transition from secondary to postsecondary were from the two eastern Kentucky community colleges part of the project. In Appalachian Kentucky as many as 50\% of ninth grade students do not complete high school and fewer than $50 \%$ of those who graduate go on to higher education. The RCCI team at Southeast Community College launched a partnership with three local school systems to establish a 
community college joint intervention program for eighth grade students. The program selects 16 students per year and provides them with scholarships to attend Southeast upon graduation.

Hazard Community College also formed a partnership with local schools through the school-to-work program, assisting in the development of entrepreneurship in local high schools. Results suggest that the college's presence in the schools has changes the attitudes, prevalent in many rural communities, toward higher education.

Southwest Texas Junior College created a partnership with 21 local school districts in 11 rural Texas counties and provided Internet access and videoconferencing capabilities. The system will provide access to academic offerings through dual credit for more than 20 courses per year to regional high school students.

While the research on rural participation and achievement in postsecondary education offers minimal evidence on outcomes of using dual credit as a means for encouraging rural student access and experiencing success in postsecondary education, much of the research on dual credit does focus on program located in urban communities. Many of the school-based models of dual credit delivery, such as the Syracuse Project Advance Program are concentrated in large urban areas. Most examples of the middle college model are also largely an urban phenomenon. As is often the case, many of the programs in urban communities target students in other demographic categories such as minorities or those academically at-risk. As a result, the interaction effects of all demographic variables are important to study. 
Chen, Konantz, Rosenfeld, and Frost (2000) identify a host of programs targeting urban minority students in Los Angeles. The Los Angeles Trade Technical College and the L.A. Unified School District have developed collaborative programs to help ethnically diverse urban students prepare to make the transition to college. The study identifies the following urban factors that present challenges to educators: lack of neighborhood safety, stereotyping and discrimination, poor study habits, student behavioral and psychological problems, and drugs and crime in student residential areas. To overcome many of these factors, the college and school district developed collaborative programs that include a middle college that allows students to earn dual credit, an afternoon and weekend program for students, and college courses offered at area high schools.

Student outcomes cited by Chen, Konantz, Rosenfeld, and Frost include the following: (a) the number of students attending the full-day or afternoon dual credit programs have doubled from 150 to 300 since the program began. (b) While $43 \%$ of Trade-Tech postsecondary students earned a C or better, $82 \%$ of high school students those taking dual credit earned a $\mathrm{C}$ or better. (c) The average semester retention rate was $90 \%, 14$ percentage points better than postsecondary students at Trade-Tech. (d) In comparison with a 59.6\% statewide college attendance rate, the college attendance rate of the dual credit graduates was $100 \%$.

The studies here do point to a need for examination of the variable of student residence for those taking community and technical college dual credit courses as well as the interaction of race, and high school performance with student residence. Many studies document the successes of students in urban communities 
in dual credit programs. No research has addressed the level of participation and student performance of rural students in dual credit programs.

\section{Gender}

As with the issue of rural students in dual credit courses, no studies of student participation or performance in dual credit programs focus exclusively on gender. No data exists to determine if more females than males take dual credit courses, although many studies previously reviewed, such as Windam (1997), Urahn (1993), and Crossland (1999) indicate that slightly more females take dual credit courses compared to males. This is consistent with the national trends in community colleges. Evelyn (2002) documented the increasing disparity between the number of male and female students currently enrolled in community colleges nationwide. Female students are outnumbering males by roughly $20 \%$, and female graduates significantly outnumber male graduates. Over 150 women receive associate degrees for every 100 men who do. The gender gap favoring females is also evident in high school performance. Males are more likely to need remedial courses in college than females and males are more likely to dropout of high school than females. The reasons for this disparity could lie in the experiences males have in their first years of education. Males tend to get frustrated early on in school and by the time of high school, many don't fit into the rules and rigidity of the secondary school environment. Dual credit programs for alternative, even at-risk students, such as the middle college model can be effective in providing an outlet or choice for many males to find some kind of engagement in school. 


\section{College Readiness}

Another student demographic used as a variable in this study is student readiness for college. Much of this variable is the result of the level of academic curriculum a student is exposed to in secondary school. Based on the research previously reviewed, the rigor of the curriculum in secondary school has a significant role on student preparation for postsecondary education. The increasing numbers of students needing remediation to be ready for college, however, is a further indication of the need for rigor during the last few years of high school and illustrates the disconnect between secondary and postsecondary education. The dramatic increase in remedial programs is a key factor in the declining productivity in higher education. Many colleges have sought programs to limit the amount the resources that are spent on remedial courses. The State University System of New York eliminated remedial courses at four-year campuses as a way to cut costs and increase productivity. All New York students needing remediation must first attend a community college (SUNY may limit remedial college courses, 1996). New Jersey and Montana considered forcing the costs of remedial education on the high school systems. Washington considered an outright ban of spending on remedial studies (Conklin, 1996). Remedial education, however, remains a significant part of the mission of the community college.

Sharon (1972) studied the effectiveness of remedial college courses. The researcher used an experimental design to assess the effect of courses on student satisfaction, persistence, and performance in subsequent courses. The study addressed the primary question of whether remedial courses compared to the regular 
college curriculum are a useful means to academically prepare those unprepared for college. The experimental design randomly selected three group $(N=448)$, the first took a remedial English course at a community college and proceeded to take the regular English course the following semester $(n=130)$, the second were placed in a regular English course in accordance with regular placement procedures $(n=245)$, and a third control group were placed in a regular English course regardless of placement recommendation $(n=73)$.

Predictor and criterion data were gathered on all three groups. The Comparative Guidance and Placement Verbal Test assessed ability. The criterion measures employed included grades, satisfaction, passing the course, and persistence in the course. A factor analytically constructed scale with cited specifications of the scale assessed satisfaction. Data was analyzed using a t-test to determine the mean difference in ability, performance, and satisfaction. The findings indicate that remedial courses had no effect on student satisfaction with college, and their persistence to graduation $(t=2.85, p>.05)$. Remedial courses had a modest effect of student performance in subsequent courses.

Abraham and Creech (2000) completed a policy analysis for the Southern Region Education Board (SREB) of the progress made by states to reduce remedial courses in higher education. They use descriptive data collected by SREB states to provide a profile of characteristics of students that need remediation and state policies for placement. Data were analyzed using descriptive statistics based on statewide reports of ACT, SAT, and the number of students taking remedial courses reported by state higher education officials. 
The findings include improvements in the way various SREB states monitor and identify students needing remediation. How states identify students for remediation via placement policies have a significant impact. While states that set consistent statewide standards for academic placement often see an initial increase, data indicates that as standards are established they decline over time.

This study has implications for using dual credit courses and even college remedial courses as a method to further align the secondary and postsecondary curriculum and increase the rigor of the high school curriculum. Courses students take in high school have a significant impact on their college readiness. Students who take the academic core are less likely to need remedial courses in college than other students.

A study by the an unnamed researcher at Kentucky Council on Postsecondary Education (1998) addressed student performance in remedial courses and their first college-level courses after remedial courses. The study examined the pass rates in remedial courses for students enrolled between the fall 1991 and fall 1996. The researchers analyzed the differences in the percentage of students who passed remedial courses in mathematics and English. The study also examined how students performed in entry-level mathematics and English.

Study findings indicate that the percentage of students who passes remedial courses in mathematics and English did not vary much from year to year and were consistently higher at universities than at community colleges. Nearly $60 \%$ of students in universities passed remedial mathematics compared with about half of the students taking remedial mathematics in community colleges. About $75 \%$ of 
students taking remedial English courses in universities passed, compared with over $60 \%$ of the students taking such courses at community colleges. The study also found that pass rates (grade $\mathrm{C}$ or higher) in entry-level courses in community colleges were even more successful in entry-level courses in universities.

Lieberman (1975) posits the middle college model as a method of reducing the need for remediation. She uses the proto-type model of the Middle College High School at LaGuardia Community College in New York. The program at LaGuardia covers three years of secondary school and the community college sequence with a program focus on remediation and career education. Lieberman argues that $30 \%$ of the senior year is repeated in the freshman year of college for most students. As a developmental psychologist, Lieberman advocates that students in the last years of high school as developmentally more akin to the 20 year-olds at the community colleges than the 14 and 15 year-olds at the traditional high school.

Lieberman claims that the philosophy of remedial programs rest on two propositions: increasing motivation and self-esteem, and more individualized teaching in a diagnostic prescriptive mode. The middle college format utilizes these premises in restructuring the teacher role into the teacher-counselor role. Every teacher in the middle college is a counselor, responsible for 15 students. The results have been positive. While Lieberman does not give data in this particular study to support the success of the LaGuardia program in dealing with student remediation needs, the next part of this review examines the middle college model at LaGuardia in more detail with data supporting to support positive student performance as a result of their participation in the middle college program. 
Collectively these findings point to the need for greater connections between secondary and postsecondary education to improve learning productivity. They also point to the overall high school curriculum, specifically the curriculum studied over the last year of high school. Successful integration as with dual credit programs can help reduce the need for remediation — the problem is many students that are on the path toward college remediation are automatically locked out of any dual credit program. Program integration between high schools and community colleges, such as with the LaGuardia model, can be an effective method to prepare students for college.

\section{High School Performance}

Research clearly documented the successes of high achieving students in dual credit (Andrews, \& Marshall, 1991; Janos, Robinson, \& Lunneborg, 1989; Kulik, \& Kulik, 1984; Marshall, \& Andrews, 2002; Mercurio, 1983, Mercurio, 1980; Windham, 2001). Mercurio, Lambert, and Osterle (1983), and Windham (1998) cite dual credit as rigorous as a rigorous curriculum for high school students, in many cases as rigorous as the Advanced Placement courses accepted universally at even the most elite colleges and universities. Most research conducted to date on dual credit courses has focused on programs that attract the highest performing high school students. Few studies have emphasized the utilization of dual credit courses for students that are not part of the academic elite and even academically at-risk of graduating from high school or attending postsecondary education. An examination of this variable to determine if a student's performance in high school is a predictor of their participation and performance in dual credit courses is critical if dual credit 
initiates a structural change in learning productivity between secondary and postsecondary education in the era of mass higher education. Policy changes in Kentucky with reforms in higher education lead to a relaxation in the level of high school achievement needed to enroll in dual credit courses. Research is needed to examine the significance of this change in the context of student success in dual credit programs based on their high school achievement and test scores.

Several studies reviewed in relation to the race and ethnic background variable support the use of dual credit courses for moderate to low performing students (Hugo, 2001; Brigham, 1989). Urhan (1993), Broughton (1987), Osborne and Gaebler (1992), and McCarthy (1999) cite survey data from the Minnesota Postsecondary Education Options Program (PESO) participants to indicate that many successful PESO participants are far from the academic elite: $60 \%$ were B, C, and D students in high school. More than half of those participating in PESO received a grade of A or B in their college courses.

The most aggressive approach to providing greater learning productivity among secondary and postsecondary education is with the middle college model. This mainly urban phenomenon involves placing students, most of who are classified as at-risk, on a college campus for a program that includes a combination of high school and college credit classes. Although models vary the program usually encompasses grades 10 or 11 through 14 .

The prototype example of the middle college high school is the program operated by LaGuardia Community College of the City University of New York. LaGuardia's program began in 1974 under the design of Janet Lieberman, a 
professor of psychology. LaGuardia's program appealed to students who were not being successful in a traditional comprehensive high school, but showed promise in their ability to complete high school and do college work. The curriculum is a fiveyear sequence including grades 10-12 and the first two years of postsecondary education. The curriculum focused a strong orientation toward eliminating remediation issues, and providing students during the end of their high school experience with an internship in a career interest. To insure student success, the curriculum also focused on small class sizes, peer and adult relationships in the program, and superior academic support. The pitfalls of the differentiated curriculum and the slump during the senior year do not factor into the equation at LaGuardia. Students take either courses for high school graduation, courses in an area of interest, or courses for college credit pointed toward their future (Lieberman, 1987). The expectations, both academic and social, are high and oriented toward treating the students as adults.

Moed and Greenberg (1982) provide an overview of the LaGuardia program emphasizing it as a key alternative education model to prevent dropouts. They cite data from the New York City Public Schools of a 54\% high school graduation rate overall, the graduate rate is much worse in the extreme urban sections of the city. The urban community college-- urban high school combination has resulted in a high school attrition rate of $14.5 \%$ compared to the $46 \%$ city-wide level. Attendance averages $84.5 \%$, which is significantly better than other city high schools. Approximately $85 \%$ of middle college graduates go on to postsecondary education. 
Cullen (1991) studied the collaborative structure of the LaGuardia Middle College High School in the context of Wehlage's (1989) study of the successful high school programs serving at-risk students in urban areas. Using a case study design, Cullen used Wehlage's framework of following three characteristics as applied to LaGuardia: students perception of a sense of belonging as members of a community of learners; programs and curricula engaged students and responded to their needs, interests, and strengths; and teachers accepted a proactive responsibility for educating at-risk students. Cullen did not provide additional details about the type of data collection and data analysis in the case study.

Findings indicate that the LaGuardia program contained elements of all three characteristics. The middle college high school is highly collaborative, cooperative, and student-centered. Faculty are actively involved in the development of a program based on the needs of at-risk adolescents to work with peers, motivate, and transform school to meet the interests of students.

Lieberman (1986) completed a 10-year study of the student outcomes from LaGuardia's middle college program. The study examined the following three questions: (a) Does the middle college program have a higher attendance rate, and a lower dropout rate than other New York City schools? (b) Does the middle college promote academic achievement compared to other New York City schools? (c) Does the middle college program have a positive impact of enhancing student college and career options?

Data for the first question were presented using descriptive statistics comparing the percentage of dropouts, attendance and graduation rates of students in 
the middle college compared with other New York City schools from the total sample of middle college graduates $(N=2,831)$. Data for the second question were drawn from city-wide assessment scores. Data for the third question were gathered through a survey sent in the spring of 1985 to 460 graduates of the middle college. Of that number, 137 responses were received for a $30 \%$ response rate. Nearly $20 \%$ of the students had moved and were not found. The surveys asked students to give their general feelings toward the middle college and identify the internships they participated in while enrolled at the middle college. The survey also asked students to identify what they had done since they graduated from the middle college.

The findings indicate that students in the middle college had a higher attendance rate than other New York City schools and New York City alternative schools over the past six years $(81 \%$ average attendance the past six years for the middle college; $69 \%$ average attendance the past six years city-wide alternative schools). Results on the percentage of students graduating from the middle college compared to other city high schools is also comparable, including the number of graduates receiving the regents endorsed diploma ( $87.8 \%$ middle college graduation rate in $1985,5.4 \%$ regents; $86.4 \%$ city-wide graduation rate, $5.4 \%$ regents). Similar results exist for dropout rate (5.8\% 1986 dropout rate for the middle college; $40 \%$ city-wide 1986 dropout rate). The academic achievement data also indicated a positive impact of the middle college program in both reading and mathematics ( $98.2 \%$ middle college students passed reading in $1984,49.5 \%$ passed math; $77 \%$ city-wide passed reading in 1984, 47\% passed math city-wide). 
Results of the survey indicate that $75 \%$ of graduates report going on to further education (105), business school (14), community college (47), or four-year college (44). The highest number (24) went to LaGuardia. Of the seven graduating classes, there have been five associate degrees, five bachelor's degrees, one master's degree, and 11 certifications. An average of $19 \%$ were employed in largely bluecollar jobs, clerical or secretarial positions or construction jobs. Half of those that found employment after graduation were in skilled jobs earning $\$ 10$ or more an hour. The same delayed education phenomena, exists with this population as with a traditional community college population. Students, after graduation, exit college, earn some money, and then reenter the educational pipeline over an interval of three to five years.

The researcher admits that the data collected fragmentary, and exploratory based on an evaluation of the impact of the LaGuardia program. A serious limitation of the study is the lack of data collection and analysis using rigorous research design and advanced statistical procedures. Never-the-less, the data does provide some compelling evidence to support the use of the middle college model as a method of high school -college collaboration and efficiency.

The dual credit component of the middle college program is open to students after $10^{\text {th }}$ grade with a satisfactory record at the middle college and completing the appropriate placement for the course they are about to enter. On average, 90 middle college students per year take courses ranging from three to 15 credits. In 11 years, 500 students, or $30 \%$ of the student body have successfully completed college courses. 
In sum, the review of demographic variables of student participation and performance in dual credit programs reveals the need for a close examination of each variable in this research. While many programs target the participation of many underrepresented groups such as minorities and at-risk students, little effort has been made by researchers to examine the impact of student participation and performance in dual credit courses in rural communities and or on gender differences of students involved in these programs. As is evident in the many of the studies reviewed, a close examination of the interactions among variables such as gender, race, and high school performance is need of this research as well.

\section{Summary}

This decade will be critical in the evolution of higher education in the U.S. Growing enrollment from large high school graduating classes and economic pressure for improved levels of education and training forces colleges and universities to find more productive and efficient ways of meeting the needs of students while facing significant financial challenges. One area identified by various researchers as a target of increased productivity is the transition between secondary and postsecondary education, particularly as more under prepared students enter the postsecondary system and as the high school senior year continues to be plagued by disengagement and a lack of productivity. Community colleges will play a significant role in creating such a continuum of learning from the high school to the college. 
Research on the need for rigorous, relevant, and challenging curriculum during high school is well documented. The "New Basics," advocated by A Nation At Risk and re-emphasized by numerous reports since, is a strong predictor for student success after high school. Once again, the senior year proves a critical gateway to college success and completion. The courses students take during the last year of high school correlate very strongly to their success after high school.

Programs such as Tech Prep intending to connect the last two years of high school with postsecondary education, while theoretically sound, have lacked the capacity and support at the postsecondary level to lead to true integration between grades 11 through 14 and beyond. Research has more definitively documented the use of various forms of college-level learning in high school, including AP, early college, middle college, and dual credit as a mechanism for building a stronger bridge with rigorous curriculum for students between secondary and postsecondary education. While wrought with problems of transfer and logistics, research studies continue to point to dual credit as a positive approach to increasing student achievement, second-year retention to college, degree completion, and overall student success. The following is a summary of the research supporting the use of dual credit as a successful approach to high school and college integration:

1. Dual credit courses invigorate the curriculum for high school students (Windham, 1998; Delicath, 1999; Mercurio, Lambert, \& Oesterle, 1983; Crossland, 1999; Hanson, 2001; Broughton, 1987; Chatman \& Smith, 1998). 
2. Dual credit courses are an effective strategy for acceleration for high performing students (Kulik \& Kulik, 1984; Noble \& Drummond, 1992; Janos, Robinson, \& Lunneborg, 1989).

3. Students are as successful in subsequent courses in school-based dual credit courses taught by high school teachers as they are in collegebased programs taught by college instructors (Hebert, 2001;

Mercurio, Lambert, \& Oesterle, 1983; Windham, 2001; Chatman \& Smith, 1998).

4. Dual credit courses are successful in encouraging students to enroll in postsecondary education (Crossland, 1999, Hanson, 2001;

Broughton, 1987; Delicath, 1999; Brigham, 1989; Lieberman, 1986).

5. Dual credit and other methods integrating the high school and college curriculum can be an effective alternative to remediation and motivating at-risk students to attend college (Brigham, 1989; Lieberman, 1986; Lieberman, 1975).

6. Dual credit encourages cooperation and integration of secondary and postsecondary education (Broughton, 1987; Clark, 2001; England, 2001; Johnstone \& Del Genio, 2000)

7. Dual credit and other forms of college-level learning in high school is a recommended approach to increasing the rigor and relevance of the senior year of high school (Johnstone \& Del Genio, 2000; Kirst, 2001a; National Commission on the Senior Year of High School, 2000; England, 2001). 
8. Statewide programs that offer students postsecondary options for dual credit courses while in high school have had positive students outcomes (Crossland, 1999; Swiney, 1999; Urahn, 1993; Minnesota Office of the Legislative Auditor, 1996).

Such success, influenced policy-makers from several states develop comprehensive programs to encourage dual credit. States such as Illinois, Minnesota, Utah, and Washington created funding mechanisms to enable students to attend postsecondary education in lieu of high school at the taxpayer expense creating an economic efficiency in addition to learning productivity and choice. Many of the studies previously reviewed support this concept. Elmore (1990) supports the practice of dual credit as a mechanism promoting effective school choice. Clark (2001) lists a number of benefits of such programs including savings in both costs and time, efficiency of learning through reduced repetition between grades 11-14, enhanced admission and retention rates in college, improved transition from high school to college, allowing students to "test the waters" of college learning, improving student access to college, and providing an additional P16 linkage of faculty in secondary and postsecondary institutions. The policy analysis, conducted by the Clark (2000), found that By creating alternatives to traditional high school-to-college transition, dual credit programs provide additional points of entry into postsecondary schooling for students whose options would otherwise be much more limited. (p. 2) 
Additional evidence exists on indicators that encourage students at-risk of attending postsecondary education to enter college. A National Center for Education Statistics (1997) study found that $81 \%$ of students not at-risk aspire to a bachelor's degree in $10^{\text {th }}$ grade compared to $56 \%$ of those characterized as at-risk. Additionally, only $44 \%$ of at-risk students progressed to the stage of academic preparation compared with $75 \%$ of those not at-risk. Even among students that completed an academic curriculum that prepared them for college, at-risk students were much more likely not to take an entrance exam, apply for college, and enroll than those not at-risk. Dual credit, especially for underrepresented minorities, rural populations, and those unprepared for college can effectively bridge the gap evident between college aspirations, preparation, and subsequent enrollment.

Kentucky, through its Council on Postsecondary Education (CPE), in the wake of higher education reform in the state needing to increase the number of students attending college, has encouraged colleges to implement dual credit through deregulation. Guidelines for admission of high school students transferred from stringent $\mathrm{CPE}$ admissions regulations to local college control. This deregulation gives colleges in the Commonwealth the option to extending dual credit programs to include aside from the traditionally served high performing elite. It allows for experimentation for the extension of dual credit to students not part of the academic elite, but wishing to find a more challenging alternative to high school during their junior and senior year.

This study evaluated impact of dual credit courses in the Kentucky community and technical colleges on the learning productivity in transition from 
secondary to postsecondary education for students according to their gender, race, residence, high school performance, and a student readiness for college. The evidence presented in this review of literature supports an investigation into the factors that predict student participation and performance in dual credit courses in Kentucky community and technical colleges. The levels of participation and performance of students in dual credit courses provides a pivotal measuring stick for the use of dual credit as a leveraging point for increased learning productivity and efficiency—and ultimately structural change of the existing transition between secondary and postsecondary education. 


\section{CHAPTER III METHODOLOGY}

The previous chapter reviewed advancements in the literature relating to factors that are reported to be significantly related to student performance in dual credit/dual enrollment courses. This chapter describes the methodology selected to gain information concerning the research questions posited in Chapter I of this study.

\section{Research Design}

The following research used a correlational design (Campbell \& Stanley, 1963 ) involving multivariate multiple regression analysis by which a set of predictor variables were used to predict a set of criterion variables. The predictor variables are student test performance, gender, residence, ethnicity, and socio-economic status. The criterion variables are credits earned in dual credit courses, deficient credits, and the cumulative college grade point average.

\section{Research Questions}

This research addressed the following research questions:

1. Is there a significant difference in the number of students enrolled in dual credit courses between Fall 2000 and Fall 2001 by gender, residence, ethnicity, and socio-economic status? 
2. Is there a multivariate significance in predicting the criterion variables (credits earned, deficient credits, and cumulative GPA) from the predictor variables (high school performance, gender, residence, ethnicity, and socioeconomic status)?

3. Is there a univariate significance in predicting credits earned from the predictor variables (high school performance, gender, residence, ethnicity, and socio-economic status)?

4. Is there a univariate significance in predicting deficient credits from the predictor variables (high school performance, gender, residence, ethnicity, and socio-economic status)?

5. Is there a univariate significance in predicting cumulative GPA from the predictor variables (high school performance, gender, residence, ethnicity, and socio-economic status)?

6. What is the relative contribution of each predictor variable (ACT English test score, ACT mathematics test score, student gender, student residence, student ethnicity, and student socio-economic status) as a predictor of the criterion variables (credits earned, deficient credits, college GPA)?

\section{Participants}

\section{Population}

The population in this study consists of all high school students enrolled in dual credit courses in the Kentucky Community and Technical College System (KCTCS) during Fall 2000, Spring 2001, Fall 2001, and Spring 2002. The rationale 
for using a population of high school students enrolled in Kentucky community and technical colleges is the growing trend of dual credit in the state community college system. This trend succeeds significant P-12 and higher education reforms in Kentucky during the last decade.

Sample

The sample $(N=3,821)$ extracted from existing data for this research are students enrolled using the "high school admit type" in KCTCS colleges during the Fall 2000, Spring 2001, Fall 2001, and Spring 2002 that have ACT scores in mathematics and English. The sample was extracted from the data KCTCS reported to the Kentucky Council on Postsecondary Education through the Reporting Data Mart (RDM) database used by KCTCS to track data from historical enrollment. 
Table 1

Sample Demographics

\begin{tabular}{|c|c|c|}
\hline Variable & $\begin{array}{c}\text { Demographic } \\
\text { Groups }\end{array}$ & $N$ \\
\hline \multirow[t]{2}{*}{ Student Gender } & Male & 1,652 \\
\hline & Female & 2,169 \\
\hline \multirow[t]{2}{*}{ Student Residence } & Urban & 1,105 \\
\hline & Rural & 2,716 \\
\hline \multirow{3}{*}{$\begin{array}{l}\text { Student Ethnic } \\
\text { Groups }\end{array}$} & White & 3,507 \\
\hline & Black & 140 \\
\hline & Other & 134 \\
\hline \multirow{4}{*}{$\begin{array}{l}\text { Median Household } \\
\text { Income Quartile }\end{array}$} & $\$ 7,000-\$ 23,466$ & 870 \\
\hline & $\$ 23,750-\$ 30,687$ & 919 \\
\hline & $\$ 30,728-\$ 36,379$ & 971 \\
\hline & $\$ 36,396-\$ 80,000$ & 1,005 \\
\hline
\end{tabular}

Table 1 shows the demographic composition of the sample according to gender, ethnicity, urban or rural residence, and median household income quartile. In addition, the average median household income, obtained by postal code residence according to U.S. Census data, was $\$ 31,255$ with the lowest average median income by residence of $\$ 7,353$ and the highest average median income of $\$ 80,634$. 


\section{Criterion Variables}

The criterion variables in this study are achievement variables. The three criterion variables include the total credits earned, the total deficient credits, and the cumulative GPA. Each one is defined as follows: Credits earned consists of the total college credits earned in dual credit courses. The total deficiencies are measured by subtracting the total hours passed from the total hours attempted by high school students enrolled. The cumulative grade point average is based on the grades earned in all dual credit courses.

\section{Predictor Variables}

The predictor variables include student performance in high school, and four demographic variables, including student gender, ethnicity, socio-economic status, and residence. The following is an operational and conceptual definition and rationale of each of the predictor variable in the study:

Student Test Performance: This is defined in the study as student performance on the American College Test (ACT) assessment used for placement or entrance into postsecondary education. The score on the English and mathematics ACT assessment is intended to provide an indication of a student's performance in high school.

Gender: This demographic variable is defined dichotomously as male or female students as reported on the KCTCS application used for admission $(0=$ male, $1=$ female $)$

Ethnicity: This demographic variable is defined in this study based on a student's race as reported by the student on the KCTCS application used for 
admission. Since the study focuses on dual credit in Kentucky, a state comprised of an overwhelming majority of White Caucasians, other ethnic groups that are not part of the majority group (White) were only specified in the analysis if the sub-sample was larger than 100 students. As a result, the following three ethnic group codes were classified: Whites, Blacks, and "other minorities." The data already contained numerical classifications based primary ethnic group $(1=$ White, $2=$ Black, $3=$ Hispanic, 4 = Asian/ Pacific Islander, $5=$ American Indian, and $6=$ not applicable). The dummy codes created for analysis included three groups $(1=$ White, $2=$ Black, and $3=$ other minorities). The "other minority" category consists of those classified as Hispanic, Asian/ Pacific Islander, and American Indian, and not applicable.

Socioeconomic status: This demographic variable is defined using the median household income of the students' home postal zip code from the Decennial 2000 U.S. Census. Socio-economic status was added to the file based on the students' home postal code. U.S. Census data from the 2000 Summary File of the Decennial Census of Median Household Income in 1999 Dollars for each zip code were matched manually to each postal code in the data file (U.S. Census Bureau, 2000). The median household income serves as a proxy measure of socio-economic status. The median household income levels were then ranked into quartiles and dummy codes were assigned for each quartile $(1=\$ 7,000$ to $\$ 23,466,2=\$ 23,750$ to $\$ 30,687,3=\$ 30,728$ to $\$ 36,379$, and $4=\$ 36,396$ to $\$ 80,000$ ).

Residence: This demographic variable is defined dichotomously in this study based on a student's residence in an urban or rural community based on the student home city listed on the KCTCS application used for admission. 
Home city was converted to an urban or a rural code as a way of qualifying a student residence as urban or rural $(1=$ urban, $0=$ rural $)$. According to the U.S. Census Bureau classification of urban and rural population areas (2002), the urban areas in Table 2 are classified as urbanized. Students residing in these cities will be given the urban classification in the study, all other cities were classified as rural. The U.S. Census Bureau classifies as "urban" all territory, population, and housing units which consist of core census block groups or blocks that have a population density of at least 1,000 people per square mile and surrounding census blocks that have a population density of at least 500 people per square mile. The Census Bureau's classification of "rural" consists of all territory, population, and housing units outside of urban areas. 
Table 2

Kentucky Urban Areas Classified according to U.S. Census Guidelines for Urban Population Area

\begin{tabular}{ll}
\hline Urban Area & $\begin{array}{l}\text { Home cities classified within the Urban } \\
\text { Area }\end{array}$ \\
\hline Bowling Green & \\
Cincinnati/ Northern Kentucky & $\begin{array}{l}\text { Alexandria, Bellevue, Burlington, } \\
\text { Covington, Independence, Highland } \\
\text { Heights, Erlanger, Florence, Ft. } \\
\text { Mitchell, Ft. Thomas, Ft. Wright, } \\
\text { Newport, Union }\end{array}$ \\
& \\
Clarksville/ Hopkinsville & Ft. Campbell, Hopkinsville \\
Elizabethtown/ Radcliff & Elizabethtown, Ft. Knox, Radcliff \\
Evansville/ Henderson & Henderson \\
Huntington/ Ashland & Ashland \\
Lexington/ Fayette County & Lexington \\
Metro Louisville & Anchorage, Buckner, Jeffersontown, \\
& New Albany \\
& \\
& \\
&
\end{tabular}

While the data file contained students taking dual credit courses without ACT scores in mathematics and English, a majority of the students in that category were in technical college courses where ACT scores are not required for high school 
student admission. The data file does contain, however, data from students at technical colleges with ACT data.

\section{Reliability of the Database}

The reliability and validity of the database were referred to in terms of the registration process and the accuracy of the data in the database as collected by the college system. The data in the KCTCS database were collected from the student application process employed on all 28 community and technical campuses of KCTCS. The application, completed by the student, contained demographic information such as race and ethnicity of the student, gender, and student residence based on their home city. The KCTCS utilizes a uniform procedure for the admission of high school students. Each high school student completes an application for admission each semester compared to postsecondary students that complete an application for admission upon initial admission to the college system. All high school students are also flagged using the "high school student" admit-type on the admission form. All data from admissions applications are entered in the KCTCS PeopleSoft database by admissions representatives under the supervision of the registrar of each college.

Based on the assessment results reported to the respective assessment center at each college via the high school transcript or by a counselor of the student's home high school, data from the American College Test (ACT) are entered into the PeopleSoft database by admissions representatives under the supervision of the registrar in each college. 


\section{Instruments}

ACT Assessment

The American College Test (ACT) was used to measure student achievement and performance in high school. The ACT yields four component scores (two of which will be used in this study): an English score based on 75 multiple choice questions, a Mathematics score based on 60 multiple choice questions, a Reading score based on 40 multiple choice questions, and a Science Reasoning score based on 40 multiple choice questions. The ACT also includes a Composite score. The content of the English test consists of Usage/ Mechanics, including punctuation, grammar, and usage; and Rhetorical Skills, including strategy, organization, and style. The content of the Mathematics test consists of items from pre-algebra, algebra, geometry, and trigonometry.

\section{Validity of the ACT}

The validity of using the ACT assessment as a measure of student performance in high school and as a predictor of performance in postsecondary education are well documented. The ACT tests of educational development are designed to measure students problem solving skills and knowledge in particular subject areas.

The usefulness of ACT assessment scores for this purpose provides the foundation for validity arguments for more specific uses. The ACT assessment includes scores on a scale from $0-36$, with 36 being the highest score and 0 the lowest. The 0-36 scale exists for each content area score on the test, including English and math scores. The total scores is a mean of all content area scores using 
a 0-36 scale. The norm study conducted in 1988 reported an English mean score of $17.18(S D=5.25)$ for all high school seniors and a mean of $18.01(S D=5.25)$ for college bound high school seniors. The Mathematics mean score is $17.44(S D=$ 4.44) for all high school seniors and a mean of $18.01(S D=4.54)$ for college bound high school seniors (ACT Technical Manual, 1997).

The ACT Technical Manual (1997) describes the following three indicators of content validity of the ACT: (1) detailed test specifications have been developed to ensure that the test content is representative of current high school and university curricula; (2) all test forms are reviewed to ensure that they match these specifications through an on-going process of content validity of the tests during the test development process; (3) after each operational administration of the test, differential item functioning (DIF) analysis results are reviewed for any anomalies such as substantial changes in item difficulty and discrimination indices between the administrations.

Dorans (1999) examined concurrent validity of ACT scores by correlating the ACT scores with another widely accepted test of pre-college aptitude, the Scholastic Aptitude Test (SAT). The concurrent validity coefficient reported by Doran was .89 , supporting its validity at a satisfactory level with other respected assessments.

The ACT Technical Manual (1997), Noble and Sawyer (2002), and Ang and Noble (1993) cite the predictive validity of the ACT. They report the statistical relationship between ACT assessment scores and first-year college grades and grade averages. ACT scores are valid predictors of overall first-year grade point averages. 
The results, based on 361 institutions participating in the Prediction Research Service during the 1993-94 academic year, yielded a median multiple $\mathrm{R}^{2}$ of .43 for the regression of college grade point average jointly on all four ACT assessment scores. This indicates that about 43 percent of the variance in college GPA is accounted for by the four ACT subtest scores.

For standard-level courses, the ACT assessment subject area score, the high school subject area average, and the overall high school average were all effective for making accurate placement decisions, but the ACT assessment score was the most effective predictor. Based on these coefficients, the ACT assessment has a satisfactory level of predictive validity.

\section{Reliability of the ACT}

Reliability and standard error of measurement (SEM) statistics on the ACT assessment were derived from five administrations of the ACT using systematic samples of 2,000 examinees per national administration that took the test in 199596. The ACT Assessment Technical Manual (1997) cites the scale score internal consistency reliability coefficient of the ACT assessments in mathematics as .91, and English as .91 for the five national ACT Assessment administrations in 1995-96. The average standard error of measurement of each assessment was 1.55 for English and 1.43 for mathematics. These internal consistency reliability coefficients indicate that the ACT assessments have a satisfactory level of reliability. In addition, the test-retest reliability coefficient of .80 was reported by Lanier (1994), indicating that scores from ACT subtests have a satisfactory level of stability. 
The ACT Assessment data used as a measure of student performance in high school and their readiness for postsecondary education are best data available in this study to gage high school performance as a predictor of student participation and success in dual credit programs. Overall, the studies reviewed here provide strong evidence supporting validity and reliability of the scores obtained from the ACT.

\section{Data Analysis}

Descriptive statistics, including frequency, mean, and standard deviation will be obtained. Data will be analyzed for each research question in the following manner:

For research question one, chi-square $\left(\chi_{2}\right)$ was conducted for each of the demographic variables to determine whether or not the observed frequencies differ systematically from the expected frequencies. The following two basic assumptions will be examined prior to conducting each chi-square test: (a) independence of observations, and (b) size of expected frequency as greater than five.

For research questions two through six, multivariate multiple regression was conducted. The following three basic assumptions were examined prior to conducting each multivariate multiple regression: (a) normality, (b) homoscedesticity, and (c) linearity. In addition, multicollinearity, outliers, and influential data points will be examined. For question two, multivariate significance was reported using Wilk's lambda, approximate $F$, to determine the significance of the relationship between the predictor variable set and the criterion variable set. For research questions three through five the univariate $F, R$, and $R^{2}$ for each regression 
of the criterion variable on the predictor set was reported. For research question six, the significance of the standardized regression coefficient of each predictor was reported.

Multivariate multiple regression was used to identify significant factors of student performance in dual credit/dual enrollment courses. Stevens (2002) advocates multivariate regression as a way of predicting several dependent variables from a set of predictors. The literature reviewed offers no compelling empirical evidence as to the strength of one predictor or demographic variable over the others; therefore, predictor variables were entered using a forced entry method for analysis. Data were analyzed using the Statistical Package for the Social Sciences (SPSS), Version 10.0. In addition to these statistical tests, observed power analysis will be reported.

The data in this study were accessed using the Reporting Data Mart (RDM) computer system used to create an ad hoc report using the Cognos Impromptu reporting tool software. The RDM system houses KCTCS historical enrollment data. The report generated for this research is a special non-recurring (ad hoc) report of data previously generated in the PeopleSoft, the data base that houses all "live" enrollment and academic data transactions processed by KCTCS.

The report was generated by creating a simple list with Cognos Impromptu accessed through the "K drive" from the CPE folder in the student records file. The file is created by filtering the following data fields: admit type recorded as "high school," student "emplid" (student id.) number, enrollment term from the Fall 2000, Spring 2001, Fall 2001, and Spring 2002, gender, ethnic group, home city, home 
postal code, home college, cumulative grade point average (GPA), career GPA, hours taken (term), hours passed (term), total hours taken, total hours passed, test scores from the ACT English and mathematics assessment, and the ACT test date. The report generated by Cognos Impromptu is downloaded to a Microsoft Excel spreadsheet for data analysis.

The Excel file was then prepared for data analysis by first eliminating all of the duplicate cases as sorted by "emplid," "enrollment term," and test score.

\section{Limitations}

While this study uses a design commonly found in other research conducted on dual credit programs, as with any social science research this study contains several limitations. Studies using existing data, drawn from a large database, offer the advantage of a large sample such as that found in statewide studies. The primary limitation of any study using existing data drawn from a database is that the researcher is captive to the data already collected. Since data from existing databases are static and unchanging, the researcher has very limited capabilities to enhance or clarify the data with additional information. An example from this study is the addition of socio-economic data drawn from the census to augment the data available in this database.

A second limitation to this study also deals with the lack of data to measure student high school performance for students who have not taken the ACT assessment. The ACT is the most widely used measure for placement of high school students in postsecondary education in Kentucky community colleges, however, not 
all high school students taking dual credit courses in Kentucky community and technical colleges have taken the ACT for placement. The KCTCS Assessment and Placement Policy (Kentucky Community and Technical College System, 2001) cites two alternatives for the admission of high school students. The first is to utilize the same enrollment standards established by the system for college students, which includes the use of an appropriate assessment for placement. The ACT is the preferred instrument for placement by KCTCS. The second alternative allows the local college district to develop its own placement policy for high school students. The KCTCS policy for admitting high school students to technical college programs indicates that no assessment is required for placement in technical colleges (Kentucky Community and Technical College System, 2002b).

The RDM database consists of 15,733 students, nearly 11,911 of which are without an ACT placement score. Of the nearly 12,000 high school students in the database without an ACT score, 9,215 are those in technical college programs where placement scores are not required, and 2,685 took courses in community colleges that use alternative placement policies and do not require ACT scores. The sample in this study $(N=3,822)$ consists of the entire population of dual enrollment/ dual credit students in the database with an ACT score, the majority of whom $(n=2,606)$ took courses in community colleges. The remaining 1,216 students with ACT scores took courses in technical colleges.

The lack of ACT data for the large majority $(9,215$ out of 10,431) of technical college students in dual credit courses was a potential limitation in making a reasonable conclusion about the participation and performance of students from 
technical colleges in dual credit programs. Conversely, the robustness of the sample $(3,822$ out of 6,507$)$ community college students with ACT scores provides ample data of student participation and performance in community colleges. Concerning the limitation regarding technical college student data, the 10,000 students being served by dual credit programs at technical colleges are being served in programs in lieu of vocational high schools or area technology centers in some communities. These programs are high school-oriented and do not conform to many of the characteristics of college dual credit programs previously reviewed in the literature. As a result, the 1,200 students taking dual credit courses in technical colleges with ACT scores will be analyzed and included in the study for the purpose of comparisons to the more traditional dual credit courses at community colleges.

A fourth limitation of this study is the emphasis on dual credit and dual enrollment programs in Kentucky only. While the results offer a large sample size and offer a better perspective than an analysis of dual credit and dual enrollment courses at just one college or focusing on just one program, the results still cannot be generalizable outside of Kentucky since the emphasis of the study is limited to the state.

A final limitation of this study is the use of grades as a measure of student success in dual credit programs. Using instructor assigned grades in a statewide study as a measure of student achievement offers some potential limitations concerning the consistency of the grading standard as applied by multiple instructors in all community and technical colleges around the state. Despite this, the use of instructor assigned grades is common as a measure of student success in dual credit 
programs is found throughout the literature previously reviewed. Broughton (1987), Crossland (1999), Delicath (1999), Hanson (2001), Mercurio (1983, \& 1990), Urahn (1993), Windham (1997), Windham and Perkins (2001), Herbert (2002), Chatman and Smith (1998), and Brigham (1989) all used instructor assigned grades to evaluate student success in dual credit programs. Additionally, this study will utilize the total credits earned and the deficient credits to provide additional measures that evaluate student performance. This standard is also widely used in the other research conducted of dual credit programs such as Broughton (1987), Crossland (1999), Delicath (1999), Hanson (2001), Mercurio (1983, \& 1990), Urahn (1993), Windham (1997), Windham and Perkins (2001), Herbert (2002), Chatman and Smith (1998), and Brigham (1989). 


\section{CHAPTER IV}

RESULTS

This study examined the factors that predict student performance in dual credit programs in Kentucky community and technical colleges. The predictor variables were high school performance, gender, residence, ethnicity, and socioeconomic status. The criterion variables were credits earned in dual credit courses, deficient credits, and the cumulative college grade point average. The population $(N$ $=3,821)$ consisted of high school students enrolled in dual credit courses in the Kentucky Community and Technical College System (KCTCS) from Fall 2000 to Spring 2002 semesters. Results of the analysis appear below.

\section{Analysis of Data}

\section{Descriptive Statistics}

The data in the sample were disaggregated according to student gender, residence by home city, student ethnic group, and the median household income quartile. A summary of demographics from the sample extracted from the Reporting Data Mart (RDM) database is provided in Table 1 on page 164. The median income quartile is the only demographic measure not extracted from RDM, it was derived by using the 2000 Census data for median household income according to the student zip code from RDM. The median income figures were ranked using SPSS into the income quartiles reported in Table 1. 
A summary of the descriptive statistics of the sample, including mean, standard deviation, and range for the criterion variables (total credits earned, deficient credits, and cumulative college grade point average) and the achievement predictor variables (ACT English and ACT mathematics scores) is provided in Table 3 below. An analysis using Kolmogorov-Smirnov Test of Normality found no violations for the interval scale predictor variables and the criterion variables.

\section{Table 3}

Mean, Standard Deviation, and Range of Achievement Predictor Variables and Criterion Variables

\begin{tabular}{lccc}
\hline Variables & M & SD & Range \\
\hline ACT English & 19.5 & 5.67 & $6-35$ \\
ACT Mathematics & 19.28 & 4.39 & $11-36$ \\
Total Credits & 5.5 & 6.4 & $0-76$ \\
Deficient Credits & 1.13 & 3.2 & $0-31$ \\
Cumulative GPA & 2.67 & 1.49 & $0-4.0$ \\
\hline
\end{tabular}

Because the sample $(N=3,821)$ consists of students enrolled in dual credit courses for the Fall 2000, Spring 2001, Fall 2001, and Spring 2002 semesters, a subsample $(n=1,914)$ was created to evaluate the changes in enrollment from Fall 2000 to Fall 2001 to determine if there was a significant difference in the number of students enrolled by gender, ethnicity, residence, and socio-economic status. A summary of descriptive statistics by Fall 2000 and Fall 2001 enrollment terms for 
the sub-sample is provided in Table 4 below. The table includes both frequency and percentage of students enrolled from each group.

Table 4

Frequency and Proportion according to Demographic Group for Fall 2000 and Fall 2001 Enrollment Terms

\begin{tabular}{|c|c|c|c|c|c|}
\hline \multirow[t]{2}{*}{ Variable } & \multirow[t]{2}{*}{$\begin{array}{l}\text { Demographic } \\
\text { Group }\end{array}$} & \multicolumn{2}{|c|}{$\begin{array}{c}\text { Fall } \\
2000 \text { Semester }\end{array}$} & \multicolumn{2}{|c|}{$\begin{array}{c}\text { Fall } \\
2001 \text { Semester }\end{array}$} \\
\hline & & $n$ & $\%$ & $n$ & $\%$ \\
\hline \multirow[t]{2}{*}{ Student Gender } & Male & 231 & 42.2 & 598 & 43.3 \\
\hline & Female & 317 & 57.8 & 768 & 56.2 \\
\hline \multirow{3}{*}{$\begin{array}{l}\text { Student Ethnic } \\
\text { Group }\end{array}$} & White & 498 & 92.2 & 1264 & 93.4 \\
\hline & Black & 23 & 4.3 & 51 & 3.8 \\
\hline & Other Ethnic & 19 & 3.5 & 38 & 2.8 \\
\hline \multirow{2}{*}{$\begin{array}{l}\text { Student } \\
\text { Residence }\end{array}$} & Urban & 177 & 32.3 & 392 & 28.7 \\
\hline & Rural & 371 & 67.7 & 974 & 71.3 \\
\hline \multirow{4}{*}{$\begin{array}{l}\text { Median } \\
\text { Household } \\
\text { Income } \\
\text { Quartile }\end{array}$} & $\$ 7,000-\$ 23,466$ & 141 & 26.4 & 342 & 25.4 \\
\hline & $\$ 23,750-\$ 30,687$ & 139 & 26 & 316 & 23.4 \\
\hline & $\$ 30,728-\$ 36,379$ & 147 & 27.5 & 359 & 26.6 \\
\hline & $\$ 36,396-\$ 80,000$ & 108 & 20.2 & 331 & 24.6 \\
\hline $\begin{array}{l}\text { Total } \\
\text { Enrollment }\end{array}$ & & 548 & 28.6 & 1366 & 71.4 \\
\hline
\end{tabular}


A comparison of descriptive statistics for the Fall 2000 and Fall 2001

enrollment terms sub-sample is provided below in Table 5. In addition, the group difference in ACT English and ACT mathematics was tested using ANOVA. The results show no significant difference between the mean ACT English and mathematics score from Fall 2000 to Fall 2001. The ANOVA also revealed significant increases in total credits earned by students, deficient credits, and cumulative college grade point average from Fall 2000 to Fall 2001.

Table 5

Descriptive Statistics and ANOVA Results for Fall 2000 and Fall 2001 Enrollment Terms

Fall $2000 \quad$ Fall 2001

\begin{tabular}{lccccc} 
& $\mathrm{M}$ & $\mathrm{SD}$ & $\mathrm{M}$ & $\mathrm{SD}$ & $\mathrm{F}$ \\
\hline ACT English & 19.85 & 5.6 & 19.39 & 5.7 & 5.99 \\
$\begin{array}{l}\text { ACT } \\
\text { mathematics }\end{array}$ & 19.48 & 4.6 & 19.20 & 4.3 & 3.46 \\
$\begin{array}{l}\text { Total Credits } \\
\text { Deficient }\end{array}$ & 3.3 & 4.9 & 5.4 & 6.0 & $42.85^{* *}$ \\
$\begin{array}{l}\text { Credits } \\
\text { Cumulative }\end{array}$ & .47 & 1.5 & 1.1 & 3.1 & $25.73^{* *}$ \\
GPA & 2.5 & 1.6 & 2.7 & 1.5 & $7.42^{* *}$ \\
\hline$* * p<.01$ & & & & &
\end{tabular}


The matrix of the correlations of the criterion variables, and predictor variables, provided in Table 6 on page 184, shows significant inter-correlations among the groups of variables. Phi correlations are reported for the nominal variables, including gender, ethnicity, residence, and income. Point biseral correlations are reported for those that include nominal and interval data. Pearson correlations are reported for total credits earned, deficient credits, and cumulative GPA.

Twenty-seven out of thirty-six correlation coefficients were statistically significant at the .05 alpha level. A significant correlation was observed between cumulative GPA and total credits earned, indicating the more total credits earned, the higher the GPA. The correlation between cumulative GPA and deficient credit was also significant, indicating that the higher the GPA the fewer the deficient credits a student will earn. Expectedly, the correlation between ACT English and math sub-scores was also significant. This shows that the higher the ACT English score, the higher the ACT math score. Overall, the majority of the correlation coefficients were low to moderate, thus indicating nonmulitcolinearity among the variables. Stevens (2002) considers multicollinearity a problem only if the coefficients are above .80 . None of the correlations in this study are at .80 or above. 
Table 6

Correlations Among Predictor and Criterion Variables

\begin{tabular}{|c|c|c|c|c|c|c|c|c|c|}
\hline & $\begin{array}{c}\text { Total } \\
\text { Credits }\end{array}$ & $\begin{array}{c}\text { Deficient } \\
\text { Credits }\end{array}$ & $\begin{array}{l}\text { Cum } \\
\text { GPA }\end{array}$ & $\begin{array}{l}\text { ACT } \\
\text { Eng. }\end{array}$ & $\begin{array}{l}\text { ACT } \\
\text { Math }\end{array}$ & Gender & Ethnic & Residence & Income \\
\hline $\begin{array}{l}\text { Total Credits } \\
\text { Earned }\end{array}$ & - & & & & & & & & \\
\hline $\begin{array}{l}\text { Deficient } \\
\text { Credits }\end{array}$ & $.06 * *$ & - & & & & & & & \\
\hline $\begin{array}{l}\text { Cum. } \\
\text { GPA }\end{array}$ & $.34 * *$ & $.29 * *$ & - & & & & & & \\
\hline ACT English & .01 & $.21 * *$ & $.32 * *$ & - & & & & & \\
\hline ACT Math & .01 & $.18^{* *}$ & $.29 * *$ & $.68 * *$ & - & & & & \\
\hline Gender & .01 & $.06^{* *}$ & $.07 * *$ & $.15^{* *}$ & $.04 * *$ & - & & & \\
\hline Ethnicity & .01 & .02 & .01 & .02 & .00 & $.06 * *$ & - & & \\
\hline Residence & $.05 * *$ & .01 & $.05^{* *}$ & $.05 * *$ & $.11 * *$ & $.04 *$ & $.21 * *$ & - & \\
\hline Income & $.03 * *$ & $.03 *$ & $.04 * *$ & $.11 * *$ & $.18 * *$ & $.09 * *$ & $.10 * *$ & $.55 * *$ & - \\
\hline
\end{tabular}


Research Question 1

Is there a significant difference in the number of students enrolled in dual credit courses between Fall 2000 and Fall 2001 by gender, residence, ethnicity, and socioeconomic status?

Four two-way Pearson independent samples chi square tests evaluating the independence of two variables were used to determine if the number of students enrolled in dual credit courses between the Fall 2000 semester and the Fall 2001 semester by gender, residence, ethnicity, and socio-economic status are independent of one another.

The first two-way chi square analysis was conducted to determine the relationship between enrollment term and gender. The proportion of females was 57.8\% in Fall 2000 and 56.2\% in Fall 2001, and males were 42.2\% in Fall 2000 and 43.8\% in Fall 2001. Enrollment growth of males and females were found to be not significantly independent of one another from Fall 2000 to Fall 2001 terms, $\chi^{2}$ (1, $N$ $=1,914)=.420, p=>.05$. This indicates that there is a greater than $95 \%$ probability that the two variables are not related to each other. Therefore, the enrollment of males was not significantly different from the enrollment of females from the Fall 2000 to the Fall 2001 terms.

The second two-way chi square analysis was conducted to determine the relationship between enrollment term and student residence classification. The proportion of rural residents was $67.7 \%$ in Fall 2000 and $71.3 \%$ in Fall 2001, and urban residents were 32.3\% in Fall 2000 and 28.7\% in Fall 2001. Enrollment 
growth of urban residents and rural residents were found to be not significantly independent of one another from Fall 2000 to Fall 2001, $\chi^{2}(1, N=1,914)=2.49, p=$ $>.05$. This indicates that there is a greater than $95 \%$ probability that the two variables are not related to each other. Therefore, the enrollment of rural residents was not significantly different from the enrollment of urban residents from the Fall 2000 to the Fall 2001 terms.

The third two-way chi square analysis was conducted to determine the relationship between enrollment term and student. Because the frequencies on Black and other ethnic groups were so small, the last two categories were collapsed into an "other ethnic minority" category for comparison with the White majority ethnic category. The proportion of White students was $92.2 \%$ in the Fall 2000 and $93.4 \%$ in the Fall 2001, minority students was $7.8 \%$ in Fall 2000 and $6.6 \%$ in Fall 2001. Enrollment growth of White, and other ethnic minorities were found to be not significantly independent of one another from Fall 2000 to Fall 2001, $\chi^{2}(1, N=$ $1,893)=.863, p=>.05$. This indicates that there is a greater than $95 \%$ probability that the two variables are not related to each other. Therefore, the enrollment of Whites was not significantly different from the enrollment of other ethnic minorities from the Fall 2000 to the Fall 2001 terms.

The last two-way chi square analysis was conducted to determine the relationship between enrollment term and student income. The proportion of students in the highest income quartile was $20.2 \%$ in the Fall 2000 and $24.6 \%$ in the Fall 2001, students in the second highest income quartile was 27.5\% in Fall 2000 and $26.6 \%$ in Fall 2001, students in the second lowest income quartile was $26 \%$ in 
Fall 2000 compared to $23.4 \%$ in Fall 2001, and students in the lowest income quartile was 26.4\% in Fall 2000 and 25.4\% in Fall 2001. Enrollment growth based on each median household income quartile was found to be not significantly independent of one another from Fall 2000 to Fall 2001, $\chi^{2}(3, N=1,883)=4.403, p$ $=>.05$. This indicates that there is a greater than $95 \%$ probability that the four variables are not related to each other. Therefore, the enrollment of students from each income quartile was not significantly different from the Fall 2000 to the Fall 2001 terms.

A one-way chi square test to determine if the observed frequencies differ significantly from the expected frequencies was conducted for students enrolled in Fall 2000 compared to Fall 2001. This test was conducted to determine if there was an overall increase in the number of students taking dual credit courses from the Fall 2000 to Fall 2001 terms. The results indicted that there was a statistically significant enrollment growth $\left(\chi^{2}(1, N=1,914)=349.595, p<.01\right)$.

\section{Research Question 2}

Is there a multivariate significance in predicting the criterion variables (credits earned, deficient credits, and cumulative GPA) from the predictor variables (high school performance, gender, residence, ethnicity, and socio-economic status)?

A multivariate multiple regression was used to analyze the data for this research question. Multivariate multiple regression is an extension of the multiple regression method. The major difference is that in multiple regression the predictive effect of two or more independent variables are examined in relation to a single 
dependent variable. In multivariate multiple regression the predictive effects of two or more independent variables are examined on multiple dependent variables simultaneously. Stevens (2002) cites the distinct advantage of multivariate multiple regression over separate multiple regression tests in that it considers the correlations between the variables rather than looking at each of them in isolation. The basic assumption of multivariate multiple regression requires that the dependent variables be theoretically, logically, and empirically related (Xu, 1993).

In this study, the three criterion variables each represent a dimension of student achievement in dual credit. An advantage of using multivariate multiple regression, as opposed to running separate multiple regression tests, is that the multivariate multiple regression looks at all three dimensions of student achievement in dual credit courses in one analysis. As a result, several tests were conducted to determine if the criterion variables collectively represent student achievement in dual credit courses. An examination of the correlation matrix in Table 6 indicated that empirically, the criterion variables together represent student achievement in dual credit courses. Bartlett's test of sphericity, which tests the null hypothesis that the residual covariance matrix is proportional to an identity matrix (Grimm \& Yarnold, 1995), also indicates that the correlation matrix of the criterion variables were significant in the population (Bartlett's test of sphericity $=8,148.262, d f=5$, $p<.000$ ). This indicates that multivariate multiple regression is an appropriate statistical test in examining the criterion variables as dimensions of student achievement in dual credit courses. 
To assess the appropriateness of the regression analysis, assumptions and requirements related to multiple regression were examined. Outliers were first examined to check whether or not they were influential. There were 68 points that were considered extreme from the criterion variable total credits earned, of which the standardized residual values ranged from 3.01 to 10.89 . There were 98 points that were considered extreme from the criterion variable deficient credits, of which the standardized residual values ranged from 3.03 to 9.45 . Cook's distance was used to see the combined influence of each point on the criterion and on the predictor sets. Cook's $D$ indicates the degree of influence measured as aggregate change in set of standardized regression coefficients if a case is omitted. A measure of 1.0 is considered a cutoff point (Cohen, Cohen, West, \& Aiken, 2002). The Cook's $D$ for both criterion variables with outliers ranged from .000 to .052 , well below the 1.0 cutoff. As a result, the outliers are not considered to be influential.

Linearity was assessed based on the partial regression plots of each predictor variable and each criterion variable, plotting standardized residuals versus predicted values. The plots must be approximately linear. A visual inspection of the plots indicated the appearance of linearity. Normality was evaluated using a normal probability plot and histograms of residuals. A visual inspection of the probability plots and histograms indicated the appearance of normality. The Durbin-Watson statistic was used to assess independence. Myers and Well (1995) and Draper and Smith (1981) indicate that a Durbin-Watson statistic within the 1.5 to 2.5 range is considered to be acceptable. An examination of the Durbin-Watson statistic for all criterion variables shows that all fall within the acceptable range, indicating 
independence. Homoscaedasticity was evaluated with a visual inspection of the standardized scatterplot of residuals. The visual inspection of the plot indicates homoscaedasticity.

Multicollinearity of high levels of correlation among the predictor variables was assessed using the correlation matrix (Table 6) and the Variance Inflation Factor (VIF), as the variance inflation factor increases, so does the variance of the regression coefficient, making it an unstable estimate. Large VIF values are an indicator of multicollinearity. Cohen et al. (2003) considers VIF of 10.0 to indicate high levels of multicollinearity. The highest VIF statistics for all of the predictors in predicting each criterion variable was a 2.08. Stevens (2002) indicates that multicollinearity is a concern only if the coefficients are above .80 . The highest correlation among the criterion variables was .68. Therefore, multicollinearity is not a problem. As a result, the diagnostic evaluations indicate that multivariate multiple regression is an appropriate test for the data set.

The multivariate multiple regression analyzing all of the criterion variables with the predictor variables was significant $(F(10,550.52,18.0)=34.09, p<.01)$. The Wilk's lambda is $.85, p<.01$. The strength of association (1- Wilk's) indicated that 15 percent of the variance in the student achievement in dual credit or dual enrollment courses was explained by the predictor set. This result exceeds the standard set by Stevens (2002), and Cohen and Cohen (1983) for medium level effect size and in practical terms is highly significant at the multivariate level in simultaneously predicting student performance in dual credit or dual enrollment courses, operationalized by credits earned, deficient credits, and cumulative college 
grade point average. Because the results of the multivariate test was significant, each criterion variable was separately examined at the univariate level.

\section{Research Question 3}

Is there a univariate significance in predicting credits earned from the predictor variables (high school performance, gender, residence, ethnicity, and socioeconomic status)?

The results of the first univariate test indicated that the first criterion variable, total credits earned by students in dual credit courses, was significantly predicted by the predictor set at the .05 level. The strength of association, indicated by the $R^{2}$, showed that less than one percent of the variance in total credits earned by students in dual credit courses was explained by the predictor set (Table 7 on page 194). The amount of total variance in total credits explained by the predictor set is extremely low. Statistical significance was likely due to the large sample size, not due to any practical significance.

\section{Research Question 4}

Is there a univariate significance in predicting deficient credits from the predictor variables (high school performance, gender, residence, ethnicity, and socioeconomic status)?

The results of the second univariate test indicated that the predictor set, significantly predicted the second criterion variable, deficient credits by students in dual credit courses at the .01 level. The strength of association, indicated by the $R^{2}$, 
showed that 5.1 percent of the variance in total credits earned by students in dual credit courses was explained by the predictor set (Table 7 below).

\section{Research Question 5}

Is there a univariate significance in predicting student cumulative college grade point average from the predictor variables (high school performance, gender, residence, ethnicity, and socio-economic status)?

The results of the third univariate test indicated that the third criterion variable, cumulative college grade point average earned by students in dual credit or dual enrollment courses, was significantly predicted by the predictor set at the .01 level. The strength of association, indicated by the $R^{2}$, showed that 12 percent of the variance in total credits earned by students in dual credit or dual enrollment courses was explained by the predictor set (Table 7 below).

Table 7

Summary of Univariate Tests

\begin{tabular}{lccl}
\hline $\begin{array}{l}\text { Criterion } \\
\text { Variables }\end{array}$ & $R$ & $\mathrm{R}^{2}$ & $\begin{array}{l}\text { Univariate } F, \\
d f=6\end{array}$ \\
\hline $\begin{array}{l}\text { Total Credits } \\
\text { Earned }\end{array}$ & .06 & .00 & $2.33 *$ \\
& & & \\
Deficient Credits & .23 & .05 & $33.43 * *$ \\
Cumulative GPA & .34 & .12 & $82.12 * *$ \\
$* * p<.01$ & & & \\
$* p<.05$ & & &
\end{tabular}

\section{Research Question 6}

What is the relative contribution of each predictor variable (ACT English test score, ACT mathematics test score, student gender, student residence, student ethnicity, 
and student socio-economic status) as a predictor of the criterion variables (credits earned, deficient credits, college GPA)?

The standardized regression coefficient in each individual univariate multiple regression analyses were examined to determine how much each predictive variable contributed to the prediction of student performance in dual credit or dual enrollment programs. The results, presented below in Table 8, indicated that ACT English as the most powerful and consistent predictor of student performance in dual credit or dual enrollment programs.

Table 8

Summary of Beta Weights for the Predictor Set

\begin{tabular}{|c|c|c|c|c|c|c|}
\hline & \multicolumn{6}{|c|}{ Criterion Variables } \\
\hline & \multicolumn{2}{|c|}{$\begin{array}{l}\text { Total Credits } \\
\text { Earned }\end{array}$} & \multicolumn{2}{|c|}{$\begin{array}{l}\text { Deficient } \\
\text { Credits }\end{array}$} & \multicolumn{2}{|c|}{$\begin{array}{c}\text { Cumulative } \\
\text { GPA }\end{array}$} \\
\hline & $\begin{array}{c}\text { Stan. } \\
\text { B }\end{array}$ & $\begin{array}{c}\text { (Unstan.) } \\
\text { B }\end{array}$ & $\begin{array}{c}\text { Stan. } \\
\text { B }\end{array}$ & $\begin{array}{c}\text { (Unstan.) } \\
\text { B }\end{array}$ & $\begin{array}{c}\text { Stan. } \\
\text { B }\end{array}$ & $\begin{array}{c}\text { (Unstan.) } \\
\text { B }\end{array}$ \\
\hline ACT English & .02 & $(.02)$ & $.14 * *$ & $(.08)$ & $.21 * *$ & $(.05)$ \\
\hline $\begin{array}{c}\text { ACT } \\
\text { Mathematics }\end{array}$ & .00 & $(.00)$ & .09 ** & $(.06)$ & $.15^{* *}$ & $(.05)$ \\
\hline Gender & $.04^{*}$ & $(.54)$ & $.05^{* *}$ & $(.30)$ & $.05^{* *}$ & $(.15)$ \\
\hline Ethnic Group & .03 & (.47) & .02 & (.13) & .01 & $(.03)$ \\
\hline Residence & $.04^{*}$ & $(.57)$ & $.04 *$ & $(.28)$ & $.07 * *$ & $(.22)$ \\
\hline Income & .03 & $(.18)$ & $.04^{*}$ & (.12) & $.04 *$ & $(.06)$ \\
\hline
\end{tabular}

Student gender and residence were the only two predictors with significant Beta weights on all three criterion variables. The student's previous high school 
performance as measured by the ACT assessment in English and mathematics contributed significantly to the student's ability to pass and their overall grade point average in dual credit or dual enrollment courses. Both scores were insignificant in predicting the total credits earned by students in dual credit or dual enrollment courses. Student ethnic group is the only predictor that did not significantly predict student performance on any of the three criterion variables. These results suggest that while student performance in high school is significantly related to their success in dual credit or dual enrollment programs, the demographic background of students also play a role in the level of student participation and subsequent performance in college courses that high school students take.

\section{Summary of the Results}

A chi square test indicated a significant increase in students taking dual credit and dual enrollment courses at Kentucky community and technical colleges from the Fall 2000 to Fall 2001. Research question one explored the demographic backgrounds of the students that participated in dual credit courses in Fall 2000 compared to Fall 2001. Two-way contingency table analyses of proportions of student gender, ethnicity, residence, and socio-economic background from Fall 2000 to Fall 2001 revealed no significant changes in the proportion of students from each demographic background taking dual credit courses despite the significant increase in the overall numbers of students taking these courses.

Research question two utilized multivariate multiple regression to evaluate the multivariate significance in predicting the criterion variables (credits earned, 
deficient credits, and cumulative GPA) from the predictor variables (high school performance, gender, residence, ethnicity, and socio-economic status). The results indicated that the predictor set significantly predicted student performance in dual credit courses, operationalized by credits earned, deficient credits, and cumulative college grade point average.

Research questions three through five addressed the univariate level of significance among each criterion variable to the predictor set. In each case the criterion variable, that represented each element of student performance in dual credit courses, was significantly predicted from the predictor set.

The last research question examined the relative contribution of each predictor variable in the predictor set in its contribution to the prediction of the student performance in dual credit or dual enrollment programs. The demographic variables of gender and residence are the most consistent predictors of the criterion variables, however, student high school performance as measured by the ACT English subtest is the strongest predictor of student performance in dual credit and dual enrollment courses.

These results, therefore, illustrate that the typical student in Kentucky community and technical colleges taking dual credit courses are above average White middle class females mainly from rural areas. Based on these data, females from rural areas with high ACT English scores are the most likely to succeed in dual credit courses.

Chapter V provides a discussion and conclusions, including implications of the findings analyzed in Chapter IV. 


\section{CHAPTER V \\ DISCUSSION}

The previous chapter examined results from chi square tests and multivariate multiple regression analyses of the factors that predict student participation and performance in dual credit programs in Kentucky community and technical colleges.

The chi square tests found that enrollment in dual credit courses differed significantly from the Fall 2000 to Fall 2001 semesters $\left(\chi^{2}(1, N=1,914)=349.595\right.$, $p<.05)$. Despite this increase, the proportion of students in demographic representations by gender $\left(\operatorname{Pearson} \chi^{2}(1, N=1,914)=.420, p>.05\right)$, ethnicity $\left(\right.$ Pearson $\left.\chi^{2}(2, N=1,893)=.94, p>.05\right)$, residence $\left(\right.$ Pearson $\chi^{2}(1, N=1,914)=$ $2.49, p>.05)$, and median income (Pearson $\left.\chi^{2}(3, N=1,883)=4.40, p>.05\right)$ were not found to be significantly independent of enrollment term during Fall 2000 to Fall 2001. This indicates that the overall increase in the number of students taking dual credit courses from the Fall 2000 to Fall 2001 terms is statistically significant.

The regression analysis found that student high school achievement, as measured by student ACT scores in English and mathematics, as well as student demographic representations was significant at the multivariate level in predicting student performance $(F(10,550.52,18.0)=34.09, p<.01)$ in the three criterion variables (total credits earned, deficient credits, and cumulative college grade point average). Univariate levels of significance were discovered for each of the three criterion variables. Of the predictor variables, ACT English was the strongest 
predictor of the grades a student makes in dual credit courses, while student gender and residence was the most consistent predictor across the three criterion variables.

\section{Discussion of the Findings}

The analysis of the descriptive statistics and the chi square tests evaluating enrollment growth demonstrated that despite significant increases in the number of students in Kentucky taking dual credit courses in community and technical colleges since 2000 , traditionally underrepresented groups in higher education were still not enrolling in these courses.

As is the case with community college enrollments nationally and in Kentucky, males are significantly underrepresented in dual credit courses. Kentucky Community and Technical College System (2003) enrollment data for Fall 2000 and Fall 2001 indicate that 58 percent of all students enrolled were females in 2000 compared to 54 percent in 2001. The dual credit enrollments mirror the overall numbers, 58 percent were female in Fall 2000; the number fell to 56 percent in Fall 2001. The data analyzed in this study provides further evidence that males are not only underrepresented in community colleges in general, they are also a significant minority in dual credit courses in Kentucky community and technical colleges.

The data also provide a clear picture of access to dual credit courses based on student ethnic background and urban or rural residence by home city. These data clearly show that the Council on Postsecondary Education's (CPE) deregulation of dual credit guidelines in 2000 has not lead to a significant increase in the proportion of students from ethnic minority groups taking dual credit courses. Based on the 
sample in this study, the proportion of Black students taking dual credit courses declined from Fall 2000 to Fall 2001 (4.3 percent in 2000 to 3.8 percent in 2001), while other minority groups fell slightly as well during the same period (3.5 percent in 2000 to 2.8 percent in 2001). As a state with a largely homogeneous population, Kentucky clearly faces significant obstacles to enrolling more Black and other minority students in postsecondary education. Overall enrollment in the Kentucky Community and Technical College System (2003) bears this out. Blacks constituted 8.4 percent of KCTCS enrollment in Fall 2000 compared to 7.7 percent in Fall 2001. These numbers do not differ greatly from the overall demographics of state population. U.S. Census Data (2000) indicates that Blacks constitute 7.3 percent of Kentuckians; other ethnic groups constitute 2.6 percent. Despite this, access to college for Blacks and other ethnic groups through dual credit courses does not appear to have changed significantly since 2000 .

As a primarily rural state, it is not surprising that a larger proportion of students enrolled in dual credit courses come from rural areas compared to urban communities. Results from the 2000 U.S. Census, however, indicate that a majority of Kentuckians (55.7 percent) now live in urban areas. An examination of the demographic data in the sample from Fall 2000 to Fall 2001 based on student residence by home city is difficult to interpret. From Fall 2000 to Fall 2001 the proportion of students that hail from rural areas increased from 68 percent to 71 percent, while naturally the proportion of students from urban areas declined. Overall, an increase in access to dual credit courses by students in rural communities is a positive trend; colleges in rural areas of the state seem to be utilizing dual credit 
courses as a mechanism to increase the college attendance rate among students in rural high schools. The fact that urban enrollments have not grown as much as rural enrollments does demonstrate that barriers may exist to inhibit student access to dual credit courses in urban areas. However, the issue of access to dual credit among students in urban communities warrants further exploration.

A careful analysis of the descriptive data show high school performance as measured by the ACT English and mathematics assessments remaining constant from the Fall 2000 to Fall 2001 (Table 6). This implies that the level of high school achievement among the students taking dual credit courses is relatively unchanged. The mean ACT score both semesters is around 19 on a scale of 36 (Kentucky Department of Education, 2002). This score is slightly below the 2000 state mean score of 20.1 for the ACT. This provides an indication that, despite the deregulation, few colleges were willing to lower their academic standards in admitting students with lower levels of academic preparation.

Results of the multivariate multiple regression analysis confirm the predictive capability of the ACT, particularly the ACT English sub-score, as a predictor of student performance in college — in dual credit courses or otherwise. While ACT math is a strong predictor of a student's cumulative grade point average, it serves as a poor predictor of the credits a student earns in dual credit courses. Demographic groups, especially gender and student residence, were the only variables to significantly predict student performance on all three criterion variables. Overall, the regression analysis identifies that there are factors other than student 
academic achievement in high school that influence student participation and performance in dual credit courses.

\section{Implications for Practice}

The results of this analysis provide significant implications for current practice in Kentucky with the reform of postsecondary education. These data indicate the possible emergence of a significant trend for high school students taking dual credit courses since the CPE deregulated the practice in 2000. Of the four semesters evaluated in this analysis, a significant increase in the enrollment of high school students occurred each semester. This trend seems to be affecting all community and technical colleges in Kentucky. As a result, a serious implication for practice in each college is to prepare to accommodate the growing demand of high school students for dual credit classes.

Another overarching emphasis of postsecondary reform in Kentucky advocated an increased articulation among the education providers from preschool through grade 16 (P-16). Dual credit is clearly a by-product of this emphasis. Since 2000, the CPE has funded the creation of local P-16 Councils in various communities around the state. These councils have emphasized greater articulation among secondary and postsecondary schools.

These findings show little change in the type of student taking dual credit courses. At this point, the deregulation of dual credit has not lead to significant changes in access to these courses. This could signal that the critical players in attracting students from underrepresented populations to dual credit courses are 
those at the local level. The changes initiated at the state level either have not filtered down to local colleges and high schools, or local colleges and high schools still have significant barriers that impede the creation of a new type of dual credit program in Kentucky. Because this study focused on data from only four semesters, spanning two academic years, the results of this analysis may provide a limited view of the issue. In light of this result, the CPE and state policy-makers would be well served to evaluate more closely the benefits of deregulation compared to the virtues of a state sponsored and state-funded dual credit program as found in states like Illinois, Washington, Minnesota, or Utah.

A useful aspect of future study would be to evaluate the local aspect of dual credit programming to evaluate the importance of practices used by colleges with strong and focused programs in dual credit to determine how successful such colleges are in targeting underrepresented populations of students to dual credit courses. It would also be beneficial to study the relationship these colleges have with local high schools.

Another implication for practice includes guidelines for colleges in the placement of students in dual credit programs. Despite deregulation, it is unclear whether many colleges actually changed their policies with regard to the enrollment of high school students for dual credit courses. The results from this study indicate that many have not changed their guidelines, because the increased enrollment of high school students has not lead to an increase in those not traditionally served by dual credit courses. While the overall emphasis of this study is exploratory in nature rather than focused on a specific practice in dual credit, the results here do not 
provide a strong indicator of the success of at-risk students and those from lower academic ability levels in being successful in dual credit courses.

The data analyzed demonstrate that a student's ACT English score is the best indicator of the grade they will make in a dual credit course, however, ACT scores in English and mathematics do not have a significant bearing on the credits a student will earn. As a result, colleges in Kentucky should be open to experimenting with enrolling students that are not the traditionally targeted academic elite. Certainly these results could lead colleges to experiment with methods of selection and placement that are not tied to traditional methods more closely connected with the model of dual credit that preceded the CPE deregulation. This model was based solely on a student's ACT score, class rank, and high school grade point average.

Overall, the results of the study seem to support practices by community and technical colleges in accommodating increasing numbers of students taking college courses while in high school and the role of the college in working with high schools on the types of students best suited for these classes and the placement parameters for students to be successful.

\section{Implications for Reform}

The theoretical implications of this study are also numerous. The significant growth in interest of dual credit during a period of intense K-12 and postsecondary reform in Kentucky gives further credence to dual credit as a link between both reform ideologies and the integration of secondary and postsecondary education. 
Many aspects of theory and practice have come together in the national reform efforts centered on adding rigor to the senior year of high school.

The increase in the number of students enrolled and the success of students in earning college credits while in high school, well documented by this analysis, is a further indication that the high school senior year needs to be restructured and more closely aligned with postsecondary education. Previously reviewed research makes a strong connection between the importance of a rigorous experience for students, especially during the senior year of high school. The increased number of students, particularly those taking transfer courses in core academic areas at community colleges, gives an indication of how more and more students are seeking rigorous courses by leaving the high school for courses taught at local community colleges. This analysis suggests that students in high school are capable of the increased expectations that dual credit courses offer to them. These results could provide information for policy-makers at state and local levels to explore many theoretical approaches that blend the senior year of high school with more intensive community college experiences in lieu of the traditional approach taken to the senior year by many high schools. Because the scope of this study explores data from an entire state system, it could spur interest in experiments using the middle college, and early college approach to dual credit delivery as well.

In many ways, the successes of students documented in this work questions the long-term role of both the comprehensive high school and the comprehensive community college. It is only logical that the more college credits a student earns by grade 12 , the lower the value of the traditional high school diploma. It is also 
plausible that this and future studies documenting consistent high school student success in community colleges will challenge the time-honored approach to the sequence from the middle grades to secondary and to the community college-level based on competencies rather than the traditional model of education revolving around time. Increases in the credentialing of high school students becoming eligible for postsecondary certificates and degrees while still in high school may lead to a careful re-examination of exactly what a high school diploma should mean. Discussions advanced through the work of the American Diploma Project (2002) are already advancing the approach that a high school degree should be more competency- driven and tied to the expectations of postsecondary education and the workforce.

Much of the landscape dominating education reform literature at the K-12 level revolves around increasing parental and student choice. While much of the emphasis advocates choice among schools, dual credit programs offer another dimension of parental and student choice. Secondary schools have shown lackluster responses to efforts encouraging reform and restructuring. An increase in the trend toward more students choosing to leave the secondary school by the junior and senior year in favor of more rigorous and relevant courses at a local college, could make a significant contribution to the impetus for high school reform based on the theoretical imperative that increasing choice eventually creates better schools. This market-driven approach has serious policy implications for the basic 100 year structure of the high school, leading potentially to downsizing the public sector function of the secondary school. 
Additional theoretical reform implications can be found by examining dual credit as a tool to increase the learning productivity of students in the transition from secondary to postsecondary education. Challenges to the overall structure of the secondary to postsecondary transition, and the evidence presented here that supports dual credit as a successful model of secondary and postsecondary integration have theoretical implications for what general education, associate, and baccalaureate degree competencies represent. The theoretical approaches to grade 11-14 integration, presented in chapter II of this study, advanced by Adler, Hutchins, and Proctor advocating the associate degree as credential representing general educational competencies and connecting the end of high school with postsecondary education are gaining momentum with the increase in popularity of dual credit and the increased financial support of foundations like the Gates Foundation in support of the early college concept (Williams, 2002).

\section{Implications for Future Research}

Because there is no current published research on dual credit programs in Kentucky community and technical colleges, this study provides an exploratory look at a vast set of possibilities for further research.

In aligning more closely with theories of learning productivity and the integration of secondary and postsecondary education, the most pressing need for future research is in connecting the practice of dual credit with these theoretical frameworks. Quasi-experimental studies that track groups of students that were participants and non-participants in dual credit programs to evaluate the impact dual 
credit has on measures such as postsecondary attendance, retention, and completion would provide the most compelling argument for dual credit as a mechanism for increasing the productivity of learning in the P-16 education continuum. Such studies would also provide empirical evidence of the influence that dual credit has on time to degree, degree attainment, and the value of these courses in allowing high school students to select majors, and career exploration. This study provides a framework of the growing trend toward dual credit programs in the first generation after the postsecondary reform in Kentucky. Yet, the study is too exploratory and proximate to the beginning of the reform to assert any long-term trends. It rather, provides a framework from which long-term trends can begin to be framed.

Another area where future research is needed pertains to the differences between dual credit experiences for students in academic courses intended for transfer to four-year colleges and universities compared to dual credit courses in technical and occupational programs. This study offered a broad view of both programs, but the clear bias was toward students that were taking courses in community colleges intended for transfer $(n=2,606$ from community college transfer programs; $n=1,216$ students from technical programs). The students in the sample extracted from the state database for analysis in this study consisted of only those with ACT scores. Students that completed the ACT were typically those interested in pursuing transfer courses. This was done out of necessity to try and provide an indicator of the influence of high school achievement on their performance in dual credit courses. Nearly 75 percent of the high school students in the database did not take the ACT. These students were primarily enrolled in dual 
credit courses in occupational or technical programs, where an ACT score is not needed for placement or where students often did not take the ACT because they had no plans to attend a four-year college or university. Research is needed to evaluate the overall enrollment picture of students with and without ACT scores. Such an evaluation could shed additional light on the access issue of students from underrepresented populations. Additionally, students that are taking occupational and technical courses should be tracked after high school graduation in the same way that transfer students should be tracked to evaluate the impact of these courses on postsecondary attendance, retention, completion, degree attainment, and employment opportunities.

Adelman (2003) has noticed a significant trend in comprehensive community colleges in providing technical education services for high school students. In the spring 2002, KCTCS developed a dual credit agreement with the Department of Technical Education to offer dual credit to every student in the state taking courses in local area technology centers. The numbers analyzed in this study did not reflect any potential growth in dual credit enrollment that resulted from this agreement because it did not take effect until the Fall 2002 semester. Research on the impact of this agreement in providing dual credit opportunities to every high school student enrolled in occupational or technical programs is also needed.

More research is also needed to evaluate adequately the role dual credit courses play in the scope of high school reform. A careful comparison of the rigor of dual credit courses compared to the rigor and expectations of students in courses in the regular high school curriculum would give an indication of the role dual credit 
plays as an alternative to the traditional high school curriculum and how it provides added rigor and relevance to the senior year of high school.

Due to the use of existing data in this study, the model of dual credit delivery was unable to be the focus of this research. Future research, particularly pertaining to dual credit programs in Kentucky, is needed to evaluate the success of students that take dual credit courses on college campuses compared to those that take such courses using alternative delivery methods such as located on a high school campus, using high school instructors, or varieties of distance learning.

A final strand of future research needed in dual credit programs as a result of this study is to connect the results of this statewide analysis to many results already conducted emphasizing focused dual credit programs at various colleges and universities across the country. In this way, the research could reveal some of the mitigating factors that make these programs successful compared to sporadic dual credit experiences offered at colleges with little or no emphasis on serving high school students. Evaluation of the importance of strong relationships with area high schools, development of high school faculty as instructors of these courses, delivery options, and programs that emphasize serving the gifted or students at-risk or those not normally targeted for dual credit. This study does little to contribute to these questions, however, the database accessed for this analysis could easily yield some results that combined with some follow up research could provide a good comparison of the success of those colleges that provide a focused program for high school students compared to those that offer few parameters for the enrollment of 
high school students. Further comparisons could be made to the performance and relationship with high schools located within each college's service area.

As the trend toward student enrollment in dual credit courses begins to increase, so will the volume of research on the success of the various types of programs. A significant contribution of this study is that it is the first to evaluate the issue of student participation and performance in dual credit programs in Kentucky, thereby exposing a need for future research in the public policy approach the state is taking to dual credit compared to that of other states.

\section{Conclusions}

The most significant contribution of this research is in documenting the emerging trend toward dual credit courses on the heels of both K-12 and postsecondary reform in Kentucky. While the results consider data from only two academic years, these data show consistent growth in the number of high school students taking courses in the Kentucky Community and Technical College System since the deregulation of dual credit programs in 2000. Indeed, KCTCS enrollment data (2003) indicate that the percentage of high school students enrolled in dual credit courses increased from 701 students (1.34 percent) in Fall 2000 to 4,842 (7.67 percent) in Fall 2001 to 8,978 (13.24 percent) in Fall 2002.

Furthermore, it gives an indication that the Council on Postsecondary Education wisely realized that if dual credit would be an effective tool to increase access to postsecondary education then a new approach should be taken in considering which students should be eligible to take such courses. With the 
creation of a new system governing community and technical colleges with KCTCS, the Council's willingness to let each local college or university determine student eligibility for dual credit courses empowered colleges to begin to explore options in serving high school students that they had not before considered. The question remains as to whether a decentralized, deregulated approach is more effective than a more centralized state-sponsored approach to dual credit programs.

Despite this growth, these data also demonstrate that since deregulation little impact has been made in making dual credit courses accessible to populations often underrepresented in postsecondary education. Dual credit programs since 2000 have attracted the same type of students-- just in larger numbers. Colleges have perhaps been reluctant to experiment with new and different service delivery options for dual credit that could attract students from not just the academic elite and other underrepresented demographic groups.

The results indicate that student success in dual credit courses is tied to their academic achievement in high school, but not entirely. Demographic factors such as gender and residence are contributing factors that predict student performance in dual credit courses.

This analysis clearly demonstrates that an increase in the number of students taking dual credit courses in Kentucky community and technical colleges did not have a detrimental impact on overall student performance in these classes. The mean number of credits earned by high school student rose significantly between Fall 2000 and Fall 2001. The mean cumulative college grade point average also rose significantly during the same period. Such results could spur more growth in the 
programs offered by colleges and could lead to better integration between the high school and the community college for an even larger number of students.

The research reviewed for this study showed positive outcomes for high school students taking college courses, particularly at community and technical colleges. The results from this study generally support the existing body of research reviewed on student performance in dual credit programs. The study results demonstrate that dual credit is a successful educational model serving an increasingly larger body of students in Kentucky high schools—a model that should be carefully analyzed by policy-makers at the state level.

The statewide scope of the results from this evaluation of student participation and performance in dual credit courses provide an avenue for state policy-makers to begin to evaluate the overall role that dual credit should play in the scope of P-16 educational reform in Kentucky. States like Minnesota, Washington, Utah, and Illinois played a more activist role than Kentucky in choosing to fund comprehensive statewide dual credit programs in creating a more formal approach to secondary and postsecondary integration by allowing high school students to take any type of dual credit course free of tuition. Policy-makers in Kentucky, with the deregulation of dual credit in 2000 , have chosen a less centrist approach in trying to emphasize dual credit as an effective tool for secondary and postsecondary integration. The onus is completely on the local colleges and boards of education to make this integration successful. Leaders in Kentucky have chosen rather to spend money on the Kentucky Educational Excellence Scholarships (KEES) given to students based on grades and ACT scores to encourage postsecondary attendance in 
the state. Studies reviewed in Chapter II of this study found that statewide dual credit programs improved secondary to postsecondary transitions and greater productivity of learning P-16. This study is an early look at ways dual credit is evolving out of the strands of K-12 and postsecondary education reform in Kentucky. An important unresolved issue is whether the policy choices Kentucky made for dual credit courses are sufficient to fully optimize the gains in learning productivity for P-16 education offered by this important curricular innovation. 


\section{REFERENCES}

Abraham, C. \& Creech, S. (2000). Reducing remediation: What progress are states making? Atlanta, GA: Southern Regional Education Board.

ACT technical manual (1997). Iowa City, IA: ACT, Inc.

Adelman, C. E. (2003). A growing plurality: The "traditional-age community college dominant" student. Community College Journal, 73(5), 26-33.

Adelman, C. E (1999). Answers in the toolbox: Academic intensity, attendance patterns, and bachelor's degree attainment. Washington, DC: U.S. Department of Education, Government Printing Office.

Adelman, C. E. (1983). Devaluation, diffusion, and the college connection: A study of high school transcripts, 1964-81. Report prepared for the National Commission for Excellence in Education. Washington, DC: U.S. Department of Education (ERIC Document Reproduction Service No. ED228244).

Adler, M. (1977). Philosopher at large: An intellectual autobiography. New York: Macmillan.

Adler, M. (1982). The Padiea proposal. New York: Macmillan.

Agnus, D. L. \& Mirel, J. E. (1999). The failed promise of the American high school 1890-1995. New York: Teachers' College Press.

Alexander, K. L., Holupka, S, \& Pallas, A. M. (1987a). Social background academic determinants of two-year versus four-year college attendance: Evidence from two cohorts a decade apart. American Journal of Education, 96, 56-80.

Alexander, K. L., Holupka, S, \& Pallas, A. M. (1987b). Social background academic determinants of college attendance: Evidence from two cohorts a decade apart. American Journal of Education, 94, 76-85.

Alexander, K. L. \& Pallas, A. M. (1984). Curriculum reform and school performance: An evaluation of the "New Basics." American Journal of Education, 92, 391-420. 
Alexander, K. L., Riordian, C., Fennessey, J., \& Pallas, A. M. (1982). Social background, academic resources, and college graduation: Recent evidence from the National Longitudinal Survey. American Journal of Education ,90, $315-333$.

Allen, M. P. (1997). Understanding regression analysis. New York: Plenum Press.

American Diploma Project (2002). Overview of year one research. Washington, D.C: Author.

Andrews, H.A. (2001b). The dual credit explosion. Community College Journal, 71 (3), 12-16.

Andrews, H. A. (2001a). The dual-credit phenomenon: Challenging secondary students across fifty states. Stillwater, OK: New Forum Press.

Andrews, H. A., \& Marshall, R. P. (1991). Challenging high school honors students with community college courses. Community College Review, 19(1), 47-51.

Andrews, H. A. (2000). The dual-credit movement in community colleges. Journal of Staff, Program, and Organizational Development, 17, 201-206.

Ang, C. H., \& Noble, J. P. (1993). Incremental validity of ACT assessment scores and high school course information for freshman course placement (ACT Research Report No. 93-5). Iowa City, IA: ACT, Inc.

Armstrong, Bryan (2002, April 29). KCTCS News Release: KCTCS colleges producing more graduates. Lexington, KY: The Kentucky Community and Technical College System.

Bishop, J. (1989). Occupational training in high school: Does it pay off? Economics of Education Review 8, 1-15.

Bird, R. E. (2002). Demographics of the $21^{\text {st }}$ Century Workforce. Keynote address at the Annual Meeting of the Southern Growth Policies Board: Human Capital Strategies for the Next Economy, Atlanta, GA, June 9-11.

Boesel, D. (2001). The college movement and its critics. Phi Delta Kappan, 83, 537-541.

Boswell, K. (2001). State policy and postsecondary enrollment options: Creating seamless systems. In P. F. Robertsons, B. C. Chapman, \& F. Gaskin (Eds.), New Directions for Community Colleges: Vol. 113 (pp. 7-14) San Francisco: Jossey-Bass. 
Botstein, L. (1997). Jefferson's children: Education and the promise of American culture. New York: Doubleday.

Bottoms, G., \& Mikos, P. (1996). Seven most-improved High Schools That Work sites raise achievement in reading, mathematics, and science. Atlanta, GA: Southern Regional Education Board.

Bragg, D. H., \& Layton, J. D. (1995). Tech Prep implementation in the United States: The once and future role of community colleges. Community College Review, 22, 3-16.

Brigham, F. (1989). Concurrent enrollment: Its effects on under-achieving minority high school students and their retention rate at a predominately white university. Paper presented at the annual convention of the California Association of Community Colleges, Santa Clara, CA: 18 November 18. (ERIC Document Reproduction Service No. ED327102)

Broughton, R. W. (1987). The Minnesota $11^{\text {th }}$ and $12^{\text {th }}$ grade Postsecondary Enrollment Options Program: Is it changing the traditional structure of secondary and Postsecondary schools? Rochester, MN: Council of North Central Community and Junior Colleges. (ERIC Document Reproduction Service No. ED28600)

Camara, W., Dorans, N. J., Morgan, R. , Myford, C. (2000). Advanced Placement: Access not exclusion. Education Policy Analysis, 8 (40). Retrieved February 12, 2002, from http://journals.epaa.asu.edu/epaa/v8n40.html

Cambra, R. E. (2000). A survey of dual enrollment practices in higher education in the United States. Seattle, WA: Institute for Educational Inquiry.

Cantor, J. A. (1999). Tech Prep as a catalyst for community college instructional program development. Community College Journal of Research and Practice, 23, 357- 369.

Carnegie Commission on Higher Education (1973). Continuity and discontinuity: Higher education and the schools. New York: McGraw-Hill.

Carnegie Commission on Higher Education (1973). Less time, more options: Education beyond the high school. New York: McGraw-Hill.

Carnevale, A. P. \& Desrochers, D. M. (1999). Help wanted...credentials required: Community colleges in the knowledge economy. Annapolis Junction, MD: Community College Press.

Chatman, S. \& Smith, K (1998). Dual-credit preparation for further study in foreign languages. NASSP Bulletin, 82 (597), 99-107. 
Chen, M. K., Konantz, J. L., Rosenfeld, M. L., \& Frost, C. (2000). Working with urban schools that serve predominately minority students. In James C. Palmer(Ed.), New Directions for Community Colleges: Vol. 27 (pp. 73-82). San Francisco: Jossey-Bass.

Clark, R. (2001). Dual credit: A scan of programs and policies related to high school student acquisition of college credits. New York: The Pew Charitable Trust.

Clune, W., \& White, P. (1992). Education reform in the trenches: Increased academic course taking in high schools with lower achieving students in states with higher graduation requirements. Educational Evaluation and Policy Analysis, 14, 2-20.

Cohen, J., \& Cohen, P. (1983). Applied multiple regression/ correlation analysis for behavioral sciences $\left(2^{\text {nd }}\right.$ ed.). Hillsdale, NJ: Lawrence Erlbaum.

Cohen, P., Cohen, J., West, S. G., \& Aiken, L. S. (2002). Applied multiple regression: Correlation analysis for the behavioral sciences. Hillsdale, NJ: Lawrence Erlbaum.

College Entrance Examination Board (1970). 16-20: The liberal education of an age group: Four school study report. New York: Author.

Conklin, K. A. (1996). Career and educational interests of high school students: A high school-college collaboration. Journal of Applied Research in the Community College (4), 76-85.

Conley, D.T. (2001). Rethinking the senior year. NASSP Bulletin, 85 (625), 26-41.

Cremin, L. A. (1961). The transformation of the school: Progressivism in American education, 1876-1957. New York: Vintage Books.

Crossland, R. (1999). Running start, 1998-99 progress report. Olympia, WA: Washington State Board for Community and Technical Colleges. Retrieved March 16, 2002, from http://www.sbctc.ctc.edu/Pub/runstart_989.pdf

Cullen, C. (1991). Membership and engagement at middle college high school. Urban Education, 26(1), 83-105.

Delicath, T. A. (1999). The influence of dual-credit programs on college students' integration and goal attainment. Journal of College Student Retention, 1, 377-398. 
Dorans, N. J. (1999). Correspondence between ACT and SAT I scores. New York: College Entrance Examination Board.

Draper, N. R., \& Smith, H. (1981). Applied regression analysis, $2^{\text {nd }}$ ed. New York: Wiley and Sons.

Edington, E. D., \& Koehler, L. (1987). Rural students achievement: Elements for consideration: ERIC Digest. ERIC Clearinghouse for Rural Education and Small Schools. (ERIC Document Reproduction Service No. EDD 00036)

Education Commission of the States (2001). Postsecondary options:

Concurrent/dual enrollment. Denver, CO: Center for Community College Policy.

Education Trust. Thinking K-16, 3(2), Washington, DC, 30.

Eller, R., Martinez, R., Pace, C., Pavel, M., Garza, H., \& Barnett, L. (1998). Rural community college initiative project brief: Access, removing barriers to participation. Washington, D.C.: American Association of Community Colleges.

Elmore, R. F. (1990). Working models of choice in public education. CPRE Report Series. Boston: Center for Policy Research in Education.

England, J. (2001). Bringing secondary education into the information age: Universal college preparation-preschool through postsecondary. (ERIC Document Reproduction Service No. ED 453752)

Evelyn, J. (2002, June 28). Community colleges start to ask, where are the men? The Chronicle of Higher Education, pp. A32-A33.

Farmer, E. I., \& Honeycutt, D. F. (1999, September). Community college administrators and faculty opinions of tech prep. Community College Journal of Research and Practice, 23, 717-725.

Florida Postsecondary Education Planning Commission (1988). Funding acceleration mechanisms, Report 1. Tallahassee, FL: Author.

Galloway, J. R. (1994, April). Dual enrollment gets students where they want to go only faster: Program at Sante Fe Community College, Gainesville. Vocational Education Journal, 69, 13-25.

Goldberger, N. (1980). Simon's Rock: Meeting the developmental needs of the early college student. New Directions for Higher Education, 29, 37-46. 
Gravetter, F. J. \& Wallnau, L. B. (2000). Statistics for behavioral sciences $\left(5^{\text {th }}\right.$ ed.). Belmont, CA: Wadsworth Thomason Learning.

Grimm, L. G. \& Yarnold, P. R. (1995). Reading and understanding multivariate statistics. Washington, DC: American Psychological Association.

Grubb, D. N. (1996). Working in the middle. San Francisco: Jossey-Bass.

Hage, J. (1972). Techniques and problems of theory construction in sociology. New York: John Wiley and Sons.

Hamilton, S. F. (1990). Apprenticeship for adulthood: Preparing youth for the future. New York: Free Press.

Hanson, S. Z. (2001). Running start, 2000-01 progress report. Olympia, WA: Washington State Board for Community and Technical Colleges. Retrieved March 16, 2002, from http://www.sbctc.ctc.edu/Pub/runstart 001.pdf

Haycock, K., \& Huang, S. (2001). Are today's high school graduates ready? Thinking P-16, 5(1), 3-17.

Hebert, L. (2001). A comparison of learning outcomes for dual enrollment mathematics students taught by high school teachers. Community College Review, 29 (3), 22-39.

Henry, T. C. (1997). ...[W]hile focusing on career preparation. Community College Week $10(11), 4-5$.

Hershey, A.M., Silverberg, M.K., Owens, T., \& Hulsey, L.K. (1998). Focus on the future: The final report of the national tech prep evaluation. Princeton, NJ: Mathematica Policy Research.

Hoffman, N. (2003). College credit in high school: Increasing college attainment rates for underrepresented students. Change, 35 (4), 42-48.

Hofstadler, R. (1963). Anti-intellectualism in American life. New York: Alfred A. Knopf.

Horn, L., Kojaku, L. J., \& Carroll, C. D. (2001). High school academic curriculum and persistence path through college: Persistence, transfer, behavior of undergraduates three years after entering four-year institutions. Washington, DC: U. S. Department of Education, NCES.

House, E. R. (1996). A framework for appraising educational reforms. Educational Researcher, 27(7), 6-14. 
House, E. R. (1994). Policy and productivity in higher education. Educational Researcher, 23(5), 27-32.

Huck, S. W. (2000). Reading statistics and research (3 ${ }^{\text {rd }}$ ed.). New York: Longman.

Hugo, E. B. (2001). Dual enrollment for underrepresented student populations. In P. F. Robertsons, B. C. Chapman, \& F. Gaskin (Eds.), New Directions for Community Colleges: Vol. 113 (pp. 67-72) San Francisco: Jossey-Bass.

Hull, D., \& Grevelle, J. (1998) Tech Prep: The next generation. Waco, TX: CORD.

Illinois Community College Board (1999). Administrative rules of the Illinois community college board. Springfield, IL: Author.

Janos, P. M., Robinson, N. M., \& Lunneborg, C. E. (1989). Markedly early entrance to college: A multi-year comparative study of academic performance and psychological adjustment. Journal of Higher Education, 60, 495-518.

Johnston, W. P., \& Packer, A. E. (1987). Workforce 2000. Indianapolis, IN: Hudson Institute.

Johnstone, D. B. (1993). Learning productivity: A new imperative for American higher education. Albany, NY: State University of New York, Office of the Chancellor.

Johnstone, D. B., \& Del Genio, B. (2000). College-level learning in high school: Purposes, policies, and practical implications. Washington, D.C.: American Association of Colleges and Universities.

Johnstone, D. B., \& Maloney, P. A. (1998). Enhancing the productivity of learning: Curricular implications. New Directions for Higher Education: Vol. 103. San Francisco, CA: Jossey-Bass.

Jones, S. W. (2000, November). Is it dual enrollment - or double vision? Should community colleges be in the business of blending with high schools? Yes: Combining Resources makes more sense than ever. Community College Times.

Kentucky Community and Technical College System (2002b). Administrative policies and procedures. Lexington, KY: Author.

Kentucky Community and Technical College System (2001). Kentucky Community and Technical College System student assessment and placement policy (KCTCS) Administrative Policies and Procedures, 4.13). Lexington, KY: Author. 
Kentucky Community and Technical College System (2000). Community college rules of the senate. Lexington, KY: Author.

Kentucky Community and Technical College System (2002c). Dual credit agreement with Cabinet for Workforce Development and Kentucky Department of Technical Education. Lexington, KY: Author.

Kentucky Community and Technical College System (2003a). KCTCS Fall 2000 enrollment reports. Lexington, KY: Author, from http:// unity.kctcs.edu/dscgi/ds.py/View/Collection

Kentucky Community and Technical College System (2003b). KCTCS Fall 2001 enrollment reports. Lexington, KY: Author, from http:// unity.kctcs.edu/dscgi/ds.py/View/Collection

Kentucky Community and Technical College System (2003c). KCTCS Fall 2002 enrollment reports. Lexington, KY: Author, from http:// unity.kctcs.edu/dscgi/ds.py/View/Collection

Kentucky Community and Technical College System (2002a). KCTCS strategic plan. Lexington, KY: Author.

Kentucky Council of Higher Education (1990). Guidelines for dual credit. Frankfort, KY: Author.

Kentucky Council of Postsecondary Education (2001). Action agenda: Vision 2020. Frankfort, KY: Author.

Kentucky Council of Postsecondary Education (2000). Guidelines for admission to state-supported postsecondary institutions in Kentucky. Frankfort, KY: Author.

Kentucky Council of Postsecondary Education (1998). Status of Kentucky postsecondary education: Progress toward reform. Frankfort, KY: Author.

Kentucky Department of Education (2002). Progress in ACT and SAT scores. Frankfort, KY: Author, from http://www.kentuckyschools.net/cgi

Kentucky Department of Education (2001). Commonwealth Accountability Testing System Interim Accountability Report, 1996-2000. Frankfort, KY: Author, from http://www.kde.state.ky.us/oaa/implement/KCCT_score release_2000/kcct $\underline{2000}$

Kentucky General Assembly (1997). House bill 1. Frankfort, KY: Author. 
Kentucky General Assembly (2002). Senate bill 74. Frankfort, KY: Author.

Kern, S., P., \& Kern, R. P. (1993). Evolution of secondary and two-year college Tech Prep programs from the articulation movement. Community College Journal of Research and Practice, 17, 533-542.

Kiger, D. M., \& Johnson, J. A. (1997). Marketing the perceptions of a community college's postsecondary enrollment options program. Community College Journal of Research and Practice 21, 687-693.

Kirst, M.L. (2001b). Bridging the great divide between secondary schools and postsecondary education. Phi Beta Kappan 83, 92-97.

Kirst, M.L. (1998) Improving and aligning K-16 standards, admissions, and freshman placement policies. Palo Alto, CA: The National Center for Postsecondary Improvement.

Kirst, M.L. (2001a) Overcoming the senior slump. Washington, DC: Institute for Educational Leadership.

Kruger, L. A. (2000). An analysis of the costs and savings of the concurrent enrollment program and at Salt Lake Community College. Digital Dissertations (UMI No. 9998836).

Kuhn, T. (1996). The Structure of Scientific Revolutions ( $3^{\text {rd }}$ ed.). Chicago: University of Chicago Press.

Kulik, J. A., \& Kulik, C. L. (1984). Effects of accelerated instruction on students. Review of Educational Research, 54, 409-425.

Kummerer, L. (2000, November). Is it dual enrollment—or double vision? Should community colleges be in the business of blending with high schools? No: High standards have been an unfortunate casualty. Community College Times.

Kummerer, L. (2000). Dual enrollment: Paying double for low standards. Phoenix, AZ: Goldwater Institute.

Lambert, L. M. \& Mercurio, J. A. (1986, Spring). Making decisions: College credits earned in high school. Journal of College Admissions, 28-32.

Lanier, C. (1994). ACT composite scores on retested students. (ACT Research Report No. 94-3). Iowa City, IA: ACT, Inc.

Legislative Joint Subcommittee on Advanced Placement (2001). Summary of proceedings. Frankfort, KY: Kentucky General Assembly. 
Lichten, W. (2000). Whiter Advanced Placement. Education Policy Analysis 8 (29). Retrieved February 12, 2002, from http://journals.epaa.asu.edu/epaa/v8n29.html

Lieberman, J. A. (1975). The Middle College High School: A new model for remediation. Paper presented at the Annual Meeting of the International Reading Association, New York: May 13-16. (ERIC Document Reproduction Service No. 105419)

Lieberman, J.A. (1985). Combining high school and college: LaGuardia middle college high school. New Directions in Teaching and Learning, 24, 47-51.

Lieberman, J. A. (1986). Middle college high school: Ten year study. New York: CUNY. (ERIC Document Reproduction Service No. ED271153)

Massachusetts Department of Education (1999). The Massachusetts dual enrollment program. Malden, MA: Author. Retrieved March 15, 2002, from http://www.doe.mass.edu/doedocs/news/cm497bro.html

Marshall, R. P., \& Andrews, H. A. (2002). Dual credit outcomes: A second visit. Community College Journal of Research and Practice, 26, 237-242.

Marby, T. (1988). The high school community college connection: An ERIC Review. Community College Review, 16 (3), 48-55.

McCarthy, C. R. (1999). Dual enrollment programs: Legislation helps high school Students enroll in college courses. Journal of Secondary Gifted Education, 11, 24-33.

McNeil, W. H. (1991). Hutchin's university: A memoir of the University of Chicago, 1929-1950. Chicago: University of Chicago Press.

Mercurio, J. A. (1983). College credit earned in high school: A four Year follow-up of the Syracuse University Project Advance class of 1977. College and University, 60, 83-89.

Mercurio, J. A. (1980). College courses in the high school: A follow-up study. College and University, 52, 89-111.

Mercurio, J. A., Lambert, L., \& Oesterle, F. (1983). College credit earned in high school: Comparing student performance in Project Advance and Advanced Placement. College and University, 59, 74-86.

Myers, J. L., \& Well, A. D. (1995). Research design and statistical analysis. Hillsdale, N.J.: Lawrence Erlbaun Associates. 
Michigan Department of Education (1999). Postsecondary enrollment options act update for fall of 1999. Lansing, MI: Author. Retrieved March 15, 2002, from http://cdp.mdc.state.mi.us/TalentDevelopment/PSEO/Update99.html

Minnesota Office of the Legislative Auditor (1996). Postsecondary enrollment ptions program. St. Paul, MN: Author. Retrieved March 15, 2002, from http://auditor.leg.state.mn.us/ped/pedrep/9605ful.pdf

Moed, M. G., \& Greenwell, A. (1982). College with its own high school. Community and Junior College Journal, 52 (5), 33-35.

Murphy, K. R. \& Myors, B. (1998). Statistical power analysis: A simple and general model for traditional and modern hypothesis tests. Mahwah, NJ: Lawrence Erlbaum Associates.

National Assessment of Vocational Education (1994). Final report to Congress. Washington, DC: Office of Educational Research and Improvement, U.S. Department of Education.

National Center for Education Statistics (1997). Confronting the odds: Students at risk and the pipeline to higher education. Washington, DC: Author.

National Center for Education Statistics (1997). Digest of education statistics. Washington, DC: Author.

National Center for Education Statistics (1999). Digest of education statistics. Washington, DC: Author.

National Center for Education Statistics (2000b). Digest of education statistics. Washington, DC: Author.

National Center for Education Statistics (2000a). The nation's report card: NAEP long-term trend summary data. Washington, DC: Author.

National Commission on Excellence in Education (1983). A nation at risk: The imperative for educational reform. Washington DC: Government Printing Office.

National Commission on the Senior Year in High School (2001). Lost opportunity of senior year: Finding a better way. Washington, DC: Author.

National Commission on the Senior Year in High School (2001). Raising our sights: No high school senior left behind. Washington, DC: Author. 
National Task Force on Minority High Achievement (1999). Reaching the Top: A report of the National Task Force on Minority High Achievement. New York: College Board.

New Mexico Association of Community Colleges (1990). New Mexico policies governing concurrent enrollment of secondary students at postsecondary institutions. Santa Fe, NM: Author.

Noble, K. D., \& Drummond, J. E. (1992). But what about prom? Student perceptions of early college entrance. Gifted Child Quarterly, 36, 106-111.

Noble, J., \& Sawyer, R. (2002). Predicting different levels of academic success in college using high school GPA and ACT composite scores (ACT Research Report No. 2002-4). Iowa City, IA: ACT, Inc.

Opp, R. D. (2001). Enhancing recruitment success for two-year college students of color. Community College Journal of Research and Practice, 25 (2), 71-86.

Oregon University System (1999). Oregon early options study. Eugene, OR: Author.

Orrill, R. (2001). Grades 11-14: The heartland or wasteland of American education. In M. Johanek (Ed). A Faithful Mirror: Reflections on the College Board and Education in America. New York: College Entrance Examination Board.

Orr, M. T. (1998). Integrating secondary schools and community colleges through school-to-work transition and educational reform. Journal of Vocational Education Research, 23 (2), 93-113.

Osborne, D., \& Gaebler, T. Reinventing government: How the entrepreneurial spirit is transforming the public sector, from the schoolhouse to the statehouse, city hall to the Pentagon. New York: Addison Wesley Publishers.

Parnell, D. (1985). The neglected majority. Washington D.C.: Community College Press.

Parnell, D., \& Hull, D. (1991). Tech prep associate degree: A win/win experience. Waco, TX: Center for Occupational Development.

Perna, L. W. (2000). Promoting college enrollment through early intervention. The ERIC Review, 8 (1), 4-9.

Powell, A.G., Farrar, E., \& Cohen, D.K. (1985) The shopping mall high school: winners and losers in the educational marketplace. Boston: Houghton and Mifflin. 
Pucel, D. J, \& Sundre, S.K. (1999, Fall). Tech prep articulation: Is it working? Journal of Industrial Teacher Education, 37 (1), 26-37.

Puyear, D. E., Thor, L. M., \& Mills, K. L. (2001, Spring). Concurrent enrollment in Arizona: encouraging success in high school. New Directions for Community Colleges, 113, 33-41.

Ravitch, D. (2000). Left back: A century of failed school reform. New York: Teachers College Press.

Reisberg, L. (1998, June 26). Some professors question programs that allow high school students to earn college credits. The Chronicle of Higher Education, pp. A39-40.

Ryan, T. P. (1997). Modern regression analysis. New York: John Wiley and Sons.

SPSS advanced models 10.0 manual. Chicago: SPSS, Inc.

Sharon, A. T. (1972). Assessing the effectiveness of remedial college courses Journal of Experimental Eduation 41(2), 60-62.

Simmons, R. (1994). Pre-college programs: A contributing factor to university student retention. Journal of Developmental Education, 17(3), 42-45.

Smart, J. M., \& Evans, C. (1977). State policymakers and time-shortened degree program. Journal of Higher Education, 48, 202-215.

State Higher Education Officers (1998). Statewide college admissions, student preparation, and remediation policies and programs. Boulder: $\mathrm{CO}$ : Author.

Stevens, J. P. (2002). Applied multivariate statistics for social sciences $\left(4^{\text {th }}\right.$ Ed.). Hillsdale, NJ: Lawrence Erlbaum.

SUNY may limit remedial college courses (1996). Journal of Developmental Education, 19 (3), 36.

Swiney, J. F. (1999). Running Start transfer performance at the University of Washington. Seattle, WA: University of Washington.

Urahn, S. (1993). Postsecondary enrollment options program: A research report. St. Paul, MN: Minnesota Legislature.

U.S. Census Bureau (2000). Census 2000: Table DP-1 profile of general demographic characteristics: 2000 from geographic area: Kentucky. Retrieved May 29, 2003 from http:// cpba.louisville.edu/ksdc/ 
U.S. Census Bureau (2000). Census 2000: Summary file3 for Kentucky 2000. Retrieved May 29, 2003 from http:// cpba.louisville.edu/ksdc/

U.S. Census Bureau (2002). Census 2000: Urban/ rural classification. Retrieved October 25, 2002, from http:// www.census.gov/geo/www/ua/ua 2k.html

U.S. Census Bureau (2000). Census 2000: Survey file 3 (SF 3) sample data. Retrieved October 28, 2002, from http:// www.factfinder.census.gov/servlet/GCTtable

Valentine, J. A. (1987). The College Board and school curriculum: A history of the College Board's influence on the substance and standards of American education, 1900-1980. New York: College Entrance Examination Board.

Van Gelder, E. (1972). The three-year BA: A wavering idea. Gainesville, FL: University of Florida.

Van Hook, M. P. (1993). Educational aspirations of rural youths and community economic development: Implications for school social workers. Social Work in Education, 15, 215-225.

Wattenbarger, J. L. \& Witt, A. A. (1995). Origins of the comprehensive community college. Community College Journal of Research and Practice, 19, 565-570.

Whitlock, B. (1978). Don't hold them back. New York: College Entrance Examination Board.

Who takes Advanced Placement (1999). Education Statistics Quarterly, 1 (4), 39 40.

Williams, A. Y. (2002, March 19). Gates Foundation to bankroll creation of 70 'early college high schools.' Chronicle of Higher Education.

Willingham, W. W., \& Morris, M. (1986). Four years later: A longitudinal study of Advanced Placement students in college. New York: College Board Report No. 86-2.

Windham, P. (1998). High school and community college dual enrollment: Issues of rigor and transferability. Journal of Applied Research in the Community College, 5, 111-115.

Windham, P. (1997). Dual enrollment is alive and well in Florida's community College system. Tallahassee, FL: State Board of Community Colleges. 
Retrieved March 21, 2002, from

http://www.dec.firn.edu/decrepts/oeer/ff02.htm

Windham. P., \& Perkins, G. (2001). Dual enrollment as an acceleration mechanism: Are students prepared for subsequent courses? Paper presented to the Association for Institutional Research Forum, Long Beach, CA: June 3-6.

Winter, G. (2002, December 15). Junior colleges try niche as cheap path to the top. New York Times. pp. A1.

Xu, M. (1991). The impact of English-language proficiency on international graduate students' perceived academic difficulty. Research in Higher Education, 32, 557-570. 
NICHOLAS L. BRAKE

nick.brake@kctcs.edu

\section{CURRICULUM VITAE}

\section{ACADEMIC BACKGROUND}

University of Louisville, Louisville, KY (1998- 2003)

Doctor of Philosophy in education administration.

Dissertation title: Factors that Predict Student Success in Dual Credit Courses in

Kentucky Community and Technical Colleges, August 26, 2003.

Western Kentucky University, Bowling Green, KY (1992-1997)

Master of Arts in History; completed 39 graduate hours in history with an emphasis of study on modern European history (12 hours). Thesis-type project focused on the political impact of German immigration to the northern Kentucky region.

Northern Kentucky University, Highland Heights, KY (1985-1991)

Bachelor of Arts in History

Bachelor of Arts in Social Studies

\section{ADMINISTRATIVE EXPERIENCE}

\section{Owensboro Community and Technical College, Owensboro, KY}

Dean, Institutional Effectiveness and Academic Programs, 2003- present

Serve as dean and chief officer for all institutional research and effectiveness for the college. Represent and oversee all accreditation activities, supervise director of institutional research. Supervise faculty in two divisions and work closely with faculty in five other divisions. Serve as "principal" of dual credit and early college programs offered for high school students by the college. Report directly to the college president.

Dean, Technical Programs, 2002-2003

Serve as dean for technical and occupational programs for the college district. Chief Administrative Office for the district's two branch campuses. Report directly to the college president. Supervise faculty in two divisions and work closely with faculty in three other divisions. Oversee the dual enrollment and early college programs offered for high school students by the college.

\section{Daviess County Public Schools, Owensboro, KY.}

Director of Curriculum, Research, and Assessment, 1998-present

Serve as District Assessment Coordinator, consultant to instructional directors, conduct educational research relating to increasing student achievement, and serve as the district curriculum development director. Accomplishments include the following: 
- Implementation of the Paideia program in all three middle schools focusing on school leadership, transformation, active learning, and the use of the Socratic Seminar.

- Introduction of the International Baccalaureate Diploma at Apollo High School, which emphasizes a rigorous curriculum to further challenge high school students.

- Created a student leadership development program for high school seniors similar to Leadership Owensboro called Leadership 2000.

- Served as an integral force in the development of the Regional Alliance for Education, recognized by the Council of Postsecondary Education as a P-16 council committed to providing connections between secondary, postsecondary education and the workforce.

- Created the Discover College program to help increase the on-to-college rate in the community by allowing high school students the opportunity to attend postsecondary education during their junior and senior year.

\section{Daviess County High School, Owensboro, KY.}

Dean of Liberal Arts, 1997-98

Head of the Social Studies, English and Foreign Language departments, directed 37 faculty, responsible for the budget, curriculum development, and student advisement.

\section{ACADEMIC EXPERIENCE}

\section{Owensboro Community and Technical College}

Associate Professor of History, 2003

\section{Daviess County High School, Owensboro, KY.}

History and Humanities Instructor, 1991-1998

Brescia University, Owensboro, KY.

Adjunct Professor, 1996-98

\section{RESEARCH AND SCHOLARLY ACTIVITY}

\section{REFEREED PRESENTATIONS PUBLISHED IN CONFERENCE PROCEEDINGS:}

Brake, Nicholas (2000, November). Student course-taking delivered through a high school block schedule: The relationship between the academic core and student achievement. Annual Meeting of the Mid-South Educational Research Association, Bowling Green, Kentucky.

Brake, Nicholas, Davis, Mimi, \& Ashley, Pat (2000, November). Fostering reading and language skills in young children: A statistical analysis. Annual Meeting of the Mid-South Educational Research Association, Bowling Green, Kentucky. 


\section{PUBLISHED MANUSCRIPTS:}

Welsh, John F., \& Brake, Nicholas (2003). Factors that Predict Student Success in Kentucky Community and Technical Colleges. Manuscript published as a dissertation in partial fulfillment of Ph.D. at the University of Louisville.

\section{MANUSCRIPTS IN PROGRESS:}

Welsh, John F.; Brake, Nicholas; Choi, Namok (2004). Student Participation and Performance in Dual Credit in a Reform Environment. Manuscript submitted to three research and scholarly journals for peer review and publication.

\section{HONORS, AWARDS, AND RECOGNITION:}

Selected, 25 Under 40: Faces of Leadership, Owensboro Messenger-Inquirer, 2004 Nominee, Kentucky Outstanding Leaders of the New Century, 2000.

Who's Who Among American Teachers, 1994-2000. Member, Phi Alpha Theta History Honor Society, 1990-1997. Outstanding Faculty Advisor Kentucky/ Tennessee Region, Key Club, 1998 Outstanding Teacher Selected by Daviess County HS Class of 1997.

Northern Kentucky Soccer Hall of Fame, 2002

\section{SERVICE}

\section{STATEWIDE SERVICE:}

External Leader, Kentucky Department of Education Refocusing Secondary Education Task Force, 2003- present.

Member, Chief Academic Officers Peer Group, Kentucky Community and Technical College System, 2002-present.

\section{INSTITUTIONAL SERVICE}

Founding Member and Board Chair, Regional Alliance for Education P-16 Council, 1999-present

Chair, Owensboro Community and Technical College Assessment and Accountability Action Team, 2002-present

Creator and Chair, Discover College Steering Committee, 2000-present

Member, Hancock County Industrial Training Consortium, 2002

Member, President's Leadership Team, Owensboro Community \& Technical College, 2002- present.

Member, Academic Council, Owensboro Community \& Technical College, 2002-present.

Member, Search Committee for Adult Education Trainers, Owensboro Community \& Technical College, 2002 
Member, Search Committee for Discover College Mentor, Owensboro Community \& Technical College, 2002.

Member, Search Committee for Family Literacy Coordinator, Owensboro Community \& Technical College, 2002.

\section{COMMUNITY SERVICE:}

Chair and Member, Leadership Owensboro Curriculum Committee, 2000, 2004

Past Chair and Member, Community Conversations, Inc., 2000- present

Member, Wendell H. Ford Government Education Center Task Force, 1997-2002

Member, Owensboro Museum of Science and History Board of Directors, 1999

Member, Leadership Owensboro, Class of 2000, 1999-2000.

Member, Owensboro Kiwanis Club, 1998-2000.

Member, Owensboro Kiwanis Club Board of Directors, 1999-2000 